\title{
Dos tradiciones en la medición del ciclo: historia general y desarrollos en Colombia*
}

\section{Two traditions in the measurement of the economic cycle: General history and developments in Colombia}

\author{
Enrique López Enciso
}

Economista de la Universidad Nacional de Colombia Investigador principal de la Gerencia Técnica del Banco de la República, Colombia ealopezen@gmail.com

Fecha de recepción: 5 de abril del 2018 Fecha de aceptación: 15 de junio del 2018 Disponible en línea: 15 de diciembre del 2018

Sugerencia de citación: López E., E. (2019). Dos tradiciones en la medición del ciclo: historia general y desarrollos en Colombia. tiempo\&economía, 6(1), 77-142, doi: http://dx.doi.org/10.21789/24222704.1432

\section{RESUMEN}

Este trabajo analiza dos grandes tradiciones en la medición del ciclo económico: los indicadores cíclicos y el cálculo de variables agregadas no observadas (producto potencial, tasa de interés natural, tasa de desempleo natural y tasa de cambio de equilibrio) y de sus brechas asociadas. La primera tradición, también conocida como la visión empírica del ciclo, debe mucho al esfuerzo del NBER y tuvo un gran desarrollo sobre todo en las economías avanzadas. En Colombia, se han hecho muchos trabajos en esa dirección. Sin embargo, pocos de estos sobreviven, con lo cual el país ha perdido un instrumento valioso en el análisis de la coyuntura

* Una versión anterior fue publicada en la serie Borradores de Economía del Banco de la República, N. 9 986, Bogotá, Colombia, disponible en http://www.banrep.gov.co/es/borrador-986 
económica. El presente documento es la primera parte del trabajo completo y narra la historia de la primera tradición.

Palabras clave: ciclo económico, sistemas de indicadores, medición del ciclo, historia económica.

\section{Código JEL: E32}

\section{ABSTRACT}

This paper analyzes two great traditions in the measurement of the economic cycle: the cyclical indicators and the calculation of aggregate non-observed variables such as potential product, natural interest rate, natural unemployment rate and equilibrium exchange rate, and their associated gaps. The first tradition, also known as the empirical vision of the cycle, owes much to the effort of the NBER and developed considerably, especially in the advanced economies. In Colombia, a lot of work has been done in that direction. However, few of these survive, resulting in the country losing a valuable instrument in the analysis of the economic conjuncture. This document is the first part of the complete work and tells the story of the first tradition.

Keywords: economic cycle, systems of indicators, cycle measurement, economic history.

\section{JEL Code: E32}




\section{Introducción}

Desde tiempos lejanos la presencia de fluctuaciones en la actividad económica ha sido una preocupación para la humanidad. Las épocas de penuria y de abundancia se suceden en diferentes relatos antiguos como lo ilustra la alternancia bíblica de las vacas gordas y las vacas flacas (Sigogne y Riches, 1993). Si bien en las sociedades patriarcales las malas cosechas eran un presagio de tiempos difíciles, fue solamente con la presencia de la manufactura y el trabajo asalariado que aparecieron los datos que permiten medir cuantitativamente el fenómeno de una mala situación. Esto sucede a finales del siglo XVIII en Inglaterra y hacia mediados del siglo XIX en Europa continental y E.E.U.U., cuando las revoluciones en la producción agrícola, el transporte y la industria hacen emerger las estructuras de las sociedades desarrolladas, con una creciente sensibilidad de los resultados económicos ante eventos inesperados, como resultado de la interdependencia entre la actividad económica, los ingresos y los flujos financieros.

En un primer momento la información económica era de frecuencia anual, lo cual hacía difícil el seguimiento de la actividad; fue solo a mediados del siglo XIX que se empiezan a recolectar y organizar los datos de frecuencia mensual y trimestral. De esa forma, se tomó conciencia de la necesidad de mejorar las estadísticas que permiten observar el dinamismo de la economía. En diferentes frentes fue ganando momentum el trabajo de los llamados estudiosos prácticos del ciclo. Rötheli (2007) argumenta que ese desarrollo se adelantó a la investigación teórica sobre el ciclo y fue impulsado por las necesidades concretas de los empresarios. El problema no se encontraba en que los estudiosos prácticos fueran los mejores teóricos del ciclo de negocios, sino en que la teoría no estaba preparada para incorporar lo que esos analistas ofrecían a los empresarios: una visión de la economía e incluso pronósticos sobre el comportamiento a futuro.

En el avance del enfoque práctico de los ciclos coincidieron varios factores. Un primer cambio de importancia fue la idea de tomar el pulso de la actividad económica con algunas medidas estadísticas representativas que habían surgido en Europa en el siglo XIX. Esos esfuerzos (Juglar, 1862; entre otros), participaban de un movimiento positivista que buscaba medir y capturar los rasgos y las evoluciones características de las sociedades a partir de una serie de indicadores, representativos de su nivel de desarrollo sobre el eje del progreso económico y social. Con una aproximación más empresarial, en E.E.U.U. comenzaron a ofrecerse varios servicios de examen y pronóstico. A esta industria se sumaron prestigiosos centros académicos (v. gr., Harvard y Yale) que fueron juzgados con mucha severidad cuando fallaron en la anticipación de la crisis de 1929. Sin embargo, su presencia cualificó el análisis y dejó para la posteridad un avance esencial en el desarrollo de las técnicas de manejo de los indicadores económicos. Por el nombre que se dio a algunos de esos productos, a esta etapa se la denominó la era de los barómetros económicos. Otro elemento de gran importancia que aportó a este proceso fue el desarrollo de los gráficos estadísticos modernos y de los mapas, que comienza a principios del siglo XIX y tiene su apogeo en la segunda mitad de ese siglo (Friendly, 2008). En efecto, en ese periodo los adelantos en la estadística, la recolección de datos y en la tecnología produjeron una "tormenta perfecta" en los gráficos de datos que fue aprovechada por los creadores de los primeros barómetros. 
De otro lado, en la controversia de principios del siglo XX sobre los ciclos, participó Wesley Mitchell quien, en su trabajo de 1913, ya enunciaba lo que sería la guía de su fecundo trabajo académico: la necesidad de apoyar el análisis con una amplia y sólida base de datos. En su libro de 1943, Mitchell enunciaba la necesidad de hacer más y mejores barómetros. Posteriormente, el punto de vista de Mitchell va a impregnar la filosofía del influyente National Bureau of Economic Research (NBER) fundado en la década de 1920 por iniciativa de varios inversionistas privados, entre ellos, el propio Mitchell. Sin embargo, el NBER no creó un nuevo barómetro, el trabajo de Mitchell en coautoría con Burns haría que esa entidad tomara otra dirección: los indicadores cíclicos. En la década de 1930 la entidad inició una importante línea de investigación que, de la mano de Kuztnes, participó en el desarrollo de las cuentas nacionales.

La metodología de construcción de los indicadores se difundió por todo el mundo y hoy en día la mayoría de los países posee alguna versión de estos instrumentos. En las economías en desarrollo, incluida Colombia, su asimilación fue lenta; en parte, porque para que esto fuera posible era necesario el insumo de un sistema estadístico y, también, porque no existía el capital humano ni los recursos necesarios para ponerlo en marcha. Aunque esas dos limitantes se superaron, y hoy se cuenta con un sistema estadístico bastante avanzado y con un recurso humano competente, en Colombia no ha sido posible instaurar esa visión de los ciclos, a pesar de los esfuerzos privados y públicos.

De otro lado, Wicksell, el importante economista de la escuela sueca quien escribió sus principales trabajos a finales del siglo XIX y principios del XX, fue el pionero de dos importantes vertientes para el estudio teórico de los ciclos. Posteriormente, con la experiencia de la Gran Depresión y la influencia de la contribución de Keynes y de otros autores, la teoría de los ciclos se transformó en un campo de la macroeconomía. En primer lugar, el ejemplo de Wicksell acerca de los movimientos de un caballito de madera que se producen después de un golpe, sirvió de base a Slutzky para plantear su conjetura del origen de los ciclos económicos a partir de los choques exógenos que afectan a las economías, un enfoque que se encuentra en la base de las teorías macroeconómicas modernas. El otro aporte -que trataré en detalle más adelante- fue la elaboración de una teoría de la inflación basada en la brecha entre la tasa monetaria de interés y la "tasa natural de interés", con la cual respondió a la preocupación por las presiones inflacionarias como parte del análisis de las condiciones económicas corrientes. A partir de entonces se han desarrollado muchos trabajos teóricos y empíricos para el análisis y el cálculo de diferentes tasas naturales como, por ejemplo, la de desempleo, en algunos casos asociada a una tasa no inflacionaria (NAIRU). Pertenece a la misma tradición el concepto de producto potencial y la brecha de producto; así como también la tasa de cambio de equilibrio y la noción de desalineamiento de la tasa corriente, en relación con esta última.

De todos esos conceptos, el más utilizado es el de producto potencial, por su capacidad como medida resumen de la capacidad productiva de una economía. Aunque existen varias acepciones posibles, el producto potencial se define generalmente como un producto agregado de pleno empleo alcanzable si la economía tiene una alta utilización de sus recursos. No representa en realidad un límite técnico que no pueda ser excedido, sino una medida de un producto sostenible en la medida en que la intensidad de uso de los recursos puede contribuir a generar o reducir las presiones inflacionarias. Si, por ejemplo, el producto actual excede el nivel del potencial, las restricciones en la capacidad comienzan a hacerse manifiestas, de forma que el crecimiento se ve afectado y se podrían presentar presiones inflacionarias. Si, por el 
contrario, el producto corriente se encuentra por debajo del potencial los recursos productivos permanecen ociosos y podría ocurrir una reducción en los precios.

Esta vertiente de pensamiento tiene una relación mucho más estrecha con la teoría económica y también un pujante desarrollo empírico. Las mediciones de las tasas naturales y las brechas son muy utilizadas en las políticas monetaria y fiscal en los países desarrollados y en desarrollo. En Colombia, desde hace un cuarto de siglo se han realizado numerosos trabajos en esa dirección; por supuesto, con todas las virtudes y defectos sobre la utilización y contenido de esos conceptos que hoy se debaten en el nivel internacional.

\section{Los pioneros}

\section{De la crisis al ciclo: los trabajos de Clément Juglar}

Tanto el estudio pionero de Juglar de 1862, como su revisión de 1889, dejaron varios legados de gran importancia. En primer lugar, como lo ha señalado Besomi (2009), hay que destacar que su obra canalizó la discusión en una dirección que posteriormente permitió el avance de la teoría sobre bases más sólidas. En su estudio estableció que un requisito epistemológico esencial para una buena teoría estaba en que el principio de explicación de la recurrencia de las crisis debería estar basado en el encadenamiento de las diferentes fases de los ciclos, una aproximación que más adelante sería cuestionada por Slutzky y sus sucesores. Otro aporte importante fue el trabajo estadístico en el cual se apoyó y que buscaba aislar el ciclo de otros movimientos económicos y, así mismo, identificar los elementos endógenos que posibilitan reconocer las crisis periódicas como un fenómeno autogenerado (Besomi, 2005).

Un mérito adicional de Juglar fue haber compilado en un solo libro una gran cantidad de argumentos que estaban dispersos. No se trataba en realidad de ideas totalmente novedosas $y$, en un primer momento, sus explicaciones no se destacaron y no fueron muy influyentes fuera de Francia, pero la coherencia de su trabajo llamó la atención de autores importantes que lo hicieron conocer mundialmente.

La obra de Juglar influenció la de Jevons quien a su vez la refinó técnicamente; pero sin duda fue Schumpeter el más entusiasta seguidor de Juglar. Para él, la obra de Juglar representaba la ruptura con la tradición de las crisis del capitalismo que había arraigado en algunos autores clásicos como Malthus, Sismondi y el mismo Marx. En su Historia del Análisis Económico, Schumpeter (1954) glorificó a Juglar adjudicándole un papel fundamental en el pensamiento económico en la medida en que este autor tenía claro cómo la teoría, la estadística y la historia debían cooperar en el análisis. En sus palabras, Juglar no solo había escrito un gran libro de hechos, sino que había establecido, a partir de la observación fáctica su más famosa aseveración: "la única causa de la depresión es la prosperidad" o, en otras palabras, la depresión es una reacción a lo acaecido en la fase de prosperidad. Era la primera vez que se expresaba de forma nítida que cada fase del proceso económico engendra la siguiente y que, en particular, las tensiones que se acumulan en la fase de prosperidad conducen a la recesión, la cual a su vez llevará posteriormente a una nueva prosperidad. 
Hay que recordar que el estudio de Juglar se construyó sobre la base de una gran cantidad de hechos estadísticos: los reportes del parlamento inglés y las publicaciones de la Banca de Francia fueron las fuentes esenciales que serían ensambladas posteriormente en su libro. Este último, se construyó minuciosamente país por país, periodo por periodo, en una historiografía detallada y repetitiva. Pero, sobre todo, mostró la recurrencia y la periodicidad de las crisis y con ello una aproximación que se empezó a imponer gradualmente en la literatura: la noción de ciclo económico.

Para dar un ejemplo, Juglar analizó series largas de estadísticas bancarias entre 1860 y 1862 (descuentos, reservas metálicas, circulación de billetes, depósitos) para Francia, Inglaterra y Estados Unidos, y con menor extensión también para Prusia y Hamburgo. Estas series fueron comparadas con las variaciones de la población, el precio del maíz, importaciones y exportaciones, rentas e ingreso público. Juglar notó una estricta correlación, especialmente entre los descuentos y las reservas, y, también, que los cambios se daban en fases específicas en los países donde la industria y el comercio estuviesen más desarrollados. ${ }^{1}$ Esta regularidad llevo a que Juglar asegurara que:

Sea cual sea la época a la cual uno se remonte en este estudio, se encuentra la misma sucesión de eventos. Las crisis se renuevan con una constancia y una regularidad tales, que es necesario entender bien su aparición y verlas como el resultado de la diferencia entre la especulación y un desarrollo inferior de la industria y de las grandes empresas comerciales, al tiempo con frecuencia se da también el empleo y la inmovilización de un capital superior a aquel que podrían proveer los recursos ordinarios de un país, en otras palabras, el ahorro. (Juglar, 1862, p. 164, trad. propia)

Schumpeter (1954) también popularizó los ciclos Juglar que tenían una duración de entre 7 y 11 años y hacían parte de un sistema que, según él, comprendía ciclos de corto, mediano y largo plazo. Los movimientos de Juglar podrían caracterizarse como de mediano plazo y correspondían al ciclo de vida de los bienes de capital y precedían a las fluctuaciones del producto, la tasa de inflación y el empleo.

\section{La época de los barómetros}

Desde 1887 el estadístico austriaco Neumann-Spallart proponía una especie de cuadro general de los síntomas que permitían determinar el estado de una economía nacional y que también sirviera de base para hacer comparaciones internacionales. Se trataba de tres baterías de indicadores que seguían el estado de la economía (producción de carbón, hierro, vidrio, armas, tráfico de viajeros, de mercancías, navegación y comercio exterior), el estado de la sociedad (consumo de tabaco, cerveza, café en cada caso de acuerdo al país; depósitos en las cajas de ahorro, emigración, quiebras) y el estado moral de la sociedad (frecuencia de los matrimonios, natalidad, nacimientos ilegítimos, suicidios, criminalidad) (Glasner, 2013).

1 Juglar afirmaba que las crisis están asociadas al desarrollo de una economía. En economías menos desarrolladas (según los conceptos modernos), éstas no se presentan. Textualmente, afirma que "en países donde no hay división del trabajo, no hay comercio exterior, el comercio interior es más seguro, el crédito es pequeño y entre más pequeño sea, es más confiable" (Juglar, 1862, p. 5, traducción propia). 
Ese trabajo fue la base de los llamados barómetros. La denominación respondía a una visión que tomaba prestada de la meteorología y de la medicina la idea de resumir en un grupo pequeño de indicadores los movimientos económicos. En todo caso se buscaba calificar el estado de la economía e incluso de la sociedad y no solamente mostrar las cifras. En el trabajo de De Foville (1888), por ejemplo, se construían gráficos que se coloreaban de acuerdo con sí el año era considerado bueno, regular o malo (Armatte, 1992).

Cuando el año es bueno el cuadrado que corresponde es rojo. El cuadrado es rosado si el año no es tan bueno. Es gris, semi-duelo, si el año es mediocre, más malo que bueno. Y, finalmente, el cuadrado es negro cuando el año es definitivamente malo (De Foville, 1888, p. 245, trad. propia)

Los colores permitían observar la sucesión de fases del ciclo, así como los rezagos de los indicadores entre sí. Infortunadamente, el gráfico del que se dispone no conserva los colores originales. Ver gráfica 1.

De esos trabajos pioneros, la mayoría de ellos olvidados, se pueden tomar tres enseñanzas que perduraron: primero, a pesar de no entenderse las causas últimas de las crisis comerciales, era posible anticiparlas con el estudio empírico de los hechos. En segundo lugar, era viable construir índices sintéticos o "barómetros económicos" que con una sola mirada permitían establecer el estado del ciclo económico y, así mismo, aislarlo de otros movimientos; y, por último, si se establecía el perfil de un ciclo, se podían prever sus evoluciones más probables.

En Europa, y especialmente en Francia, se dieron las primeras tentativas de construcción de barómetros con los trabajos de Cahen y March, pero fue en Estados Unidos donde se llevaron a cabo los esfuerzos más conocidos asociados a los nombres de Babson y Brookmire. ${ }^{2}$ En ambos casos, se trata de empresarios privados que empiezan a recolectar y dar un tratamiento básico a las series, así como a introducir un concepto de equilibrio en su análisis estadístico (Sigogne y Riches, 1993). La idea de estos autores era proveer servicios de pronóstico a sus clientes para que llevaran a cabo sus negocios.

Babson creó en 1904 la Babson Statistical Organization como plataforma para dar a conocer sus trabajos. En estos Babson tomó 25 series y las reunió en 12 grupos: construcción y patrimonio, compensaciones bancarias, dinero, comercio exterior, transacciones en oro, precios al detalle, mercado de colocaciones, cosechas, ingresos del ferrocarril y condiciones sociales. Las series abarcan varios campos de la economía, y el indicador que resulta, llamado la Babsonchart semanal, representa su evolución efectiva; con el tiempo en la abscisa y el valor del índice en la ordenada (ver gráfica 2). Apoyándose en ese indicador, Babson estimó una línea de desarrollo "normal" de los negocios que atraviesa la curva efectiva. Con este procedimiento logró construir valles y picos cuyas áreas bajo la curva se compensan. A partir de ahí es posible definir las fases de la coyuntura definidas en relación con un nivel normal. Con el apoyo explícito de una ley, que Babson llamo de igualdad entre la acción y la reacción, se puede predecir el comportamiento del barómetro: la brecha negativa acumulada entre la curva efectiva y la normal será de gran magnitud si ha estado precedida por una brecha positiva acumulada de gran tamaño.

2 John Moody también es un nombre importante en esta historia de acuerdo con Friedman (2013). Cabe señalar que las empresas creadas por estos personajes dieron nacimiento a diferentes instituciones que todavía son importantes en mundo de los negocios y en la academia de Estados Unidos. 
Gráfica 1. Elementos característicos de la estadística nacional francesa según De Foville

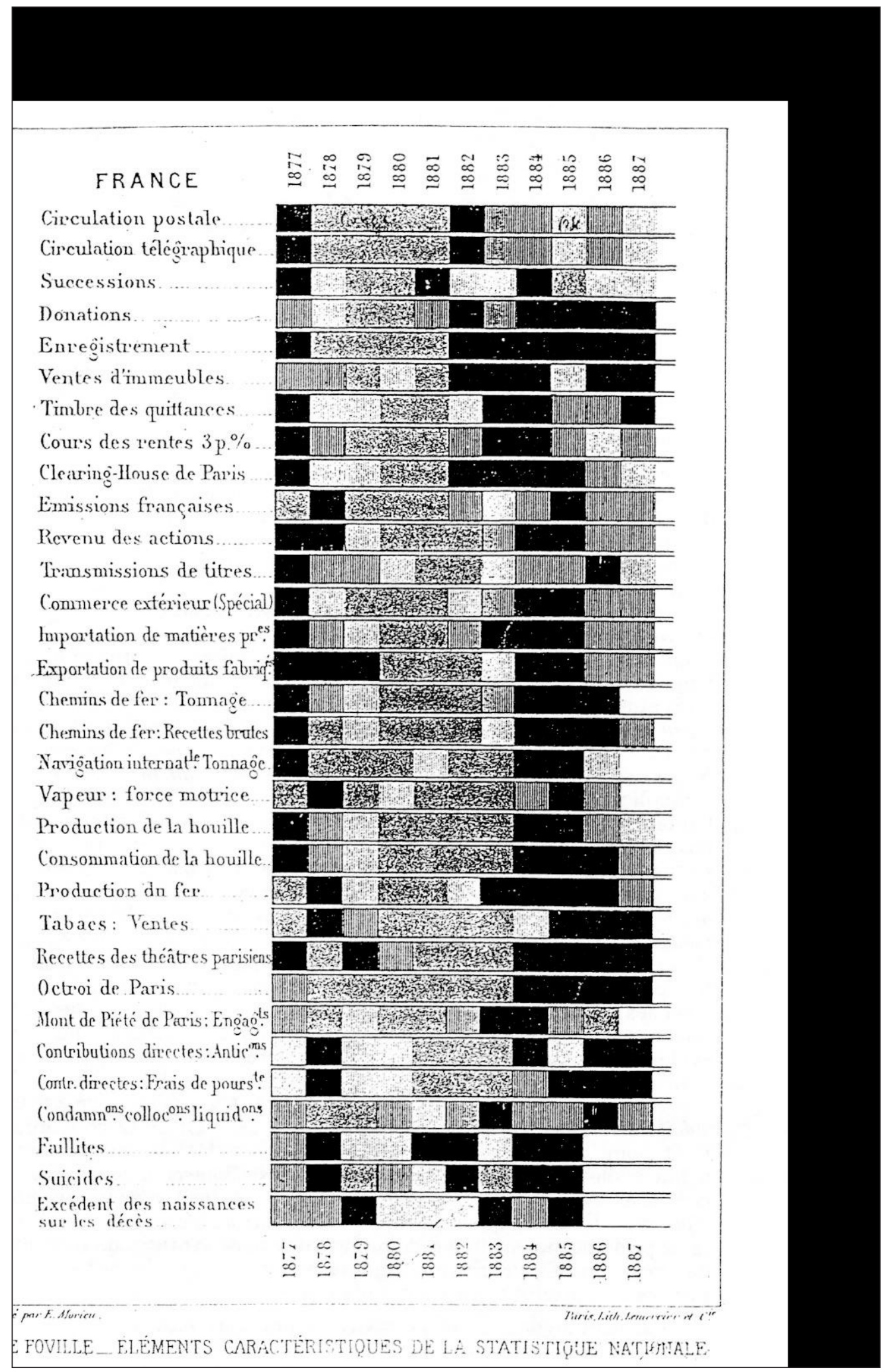

Fuente: documento provisto por Friedman W., mimeo sin fecha, titulado 
La ley de acción y reacción era la versión Babson del principio de equilibrio de Newton y que, en este caso, simplemente compensaba las áreas bajo y sobre la curva efectiva. Babson mismo reconoce que no hay una base científica en su método, diferente de esa utilización bastante arbitraria del principio de equilibrio de Newton (Babson, 1950).

\section{Gráfica 2. El barómetro de Babson en 1921}

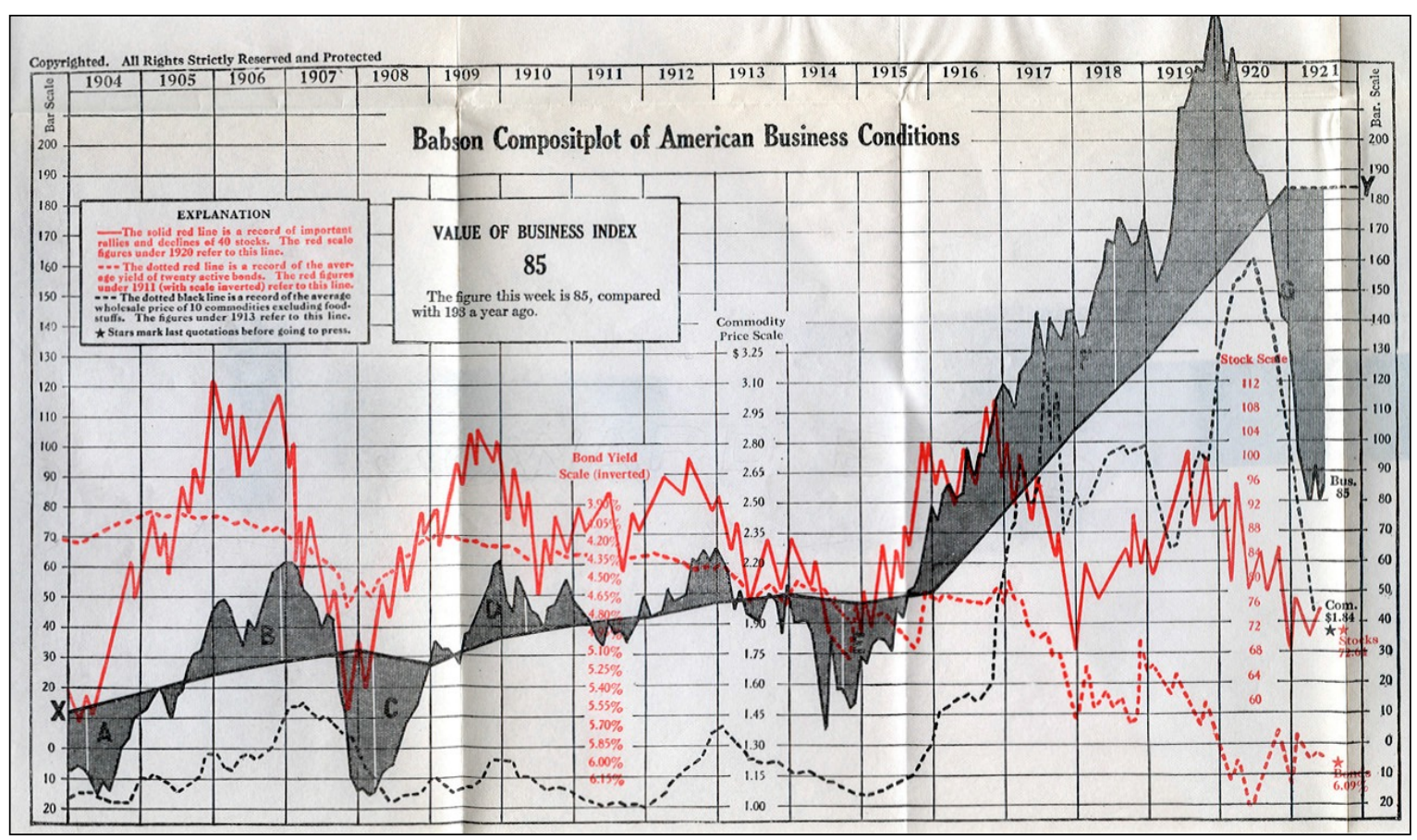

Nota: las áreas sombreadas A, B, C, D, E, F, y G son depresiones cuando están debajo de la línea "normal", y son expansiones si están por encima. Babson creía que las áreas de expansión (por ejemplo, B), deben ser iguales a las áreas de recesión que les seguían (por ejemplo, C).

Fuente: Babson (1921).

Brookmire, por su parte, fundó en 1910 en la ciudad de San Louis en E.E.U.U. la Brookmire Economic Chart Company, la cual publicaba un folleto a todo color con gráficos, y una gran cantidad de información que incluía ciclos de precios del acero y el hierro; así como también un "barómetro de negocios" de todas las condiciones de la economía. Brookmire (1913a, p. 44) plantea que el trabajo sobre ciclos de Jevons se queda corto porque solamente se refiere a las cosechas. En su opinión, un indicador del ciclo debe incluir también elementos políticos y las condiciones de crédito de los bancos. Finalmente, Brookmire construye un gráfico de "fundamentales". Se presentan tres gráficos: uno para los negocios, uno para los bancos y otro para la "especulación" que incorpora treinta y dos acciones líderes (ver gráfica 3). 
Gráfica 3. La economía estadounidense en 1907, de acuerdo con el barómetro de Brookmire

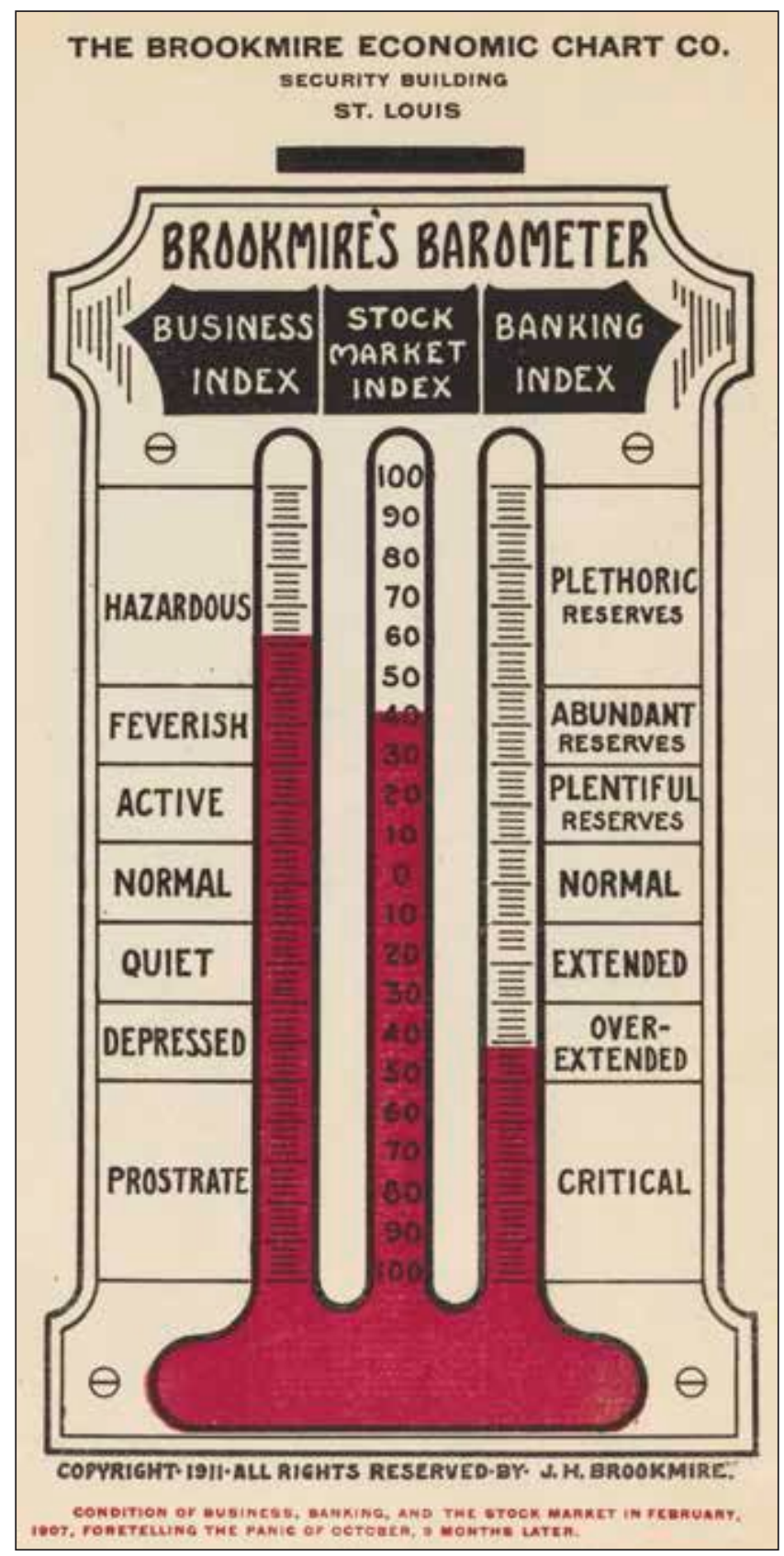

Nota: el barómetro de Brookmire's incluye tres índices: actividad económica, mercado accionario y recursos bancarios.

Fuente: Brookmire (1913b).

El informe de Brookmire también hacía pronósticos basados en la observación según la cual "cuando los bancos comienzan un cambio importante (aumento o descenso), los precios de las acciones siguen meses más tarde y más adelante seguirán los indicadores del comportamiento general de los negocios" (Vance, 1925, p. 79 citado por Favero, 2007, trad. propia). La 
importancia dada al crédito y al dinero se basaba en la ecuación cuantitativa de Fisher, para quien esa variable era independiente en el ciclo de negocios.

Para Brookmire (1913a, p. 56) el ciclo estaba compuesto de cuatro fases: (1) Mejoramiento, (2) Prosperidad, (3) Liquidación y (4) Reajuste. Brookmire, con el examen sistemático de las secuencias dentro del ciclo siguiendo la tendencia de diferentes índices, puede considerarse el precursor de los barómetros más sofisticados que vinieron después.

La academia se inspiró en muchas de las ideas de estos primeros barómetros, pero fue muy crítica frente a sus debilidades técnicas. En 1916 Persons, profesor de la Universidad de Harvard, publicó en la American Economic Review un artículo examinando los barómetros de Babson y Brookmire. En ese trabajo, Persons consideraba que los barómetros eran una estadística indispensable para las decisiones de los empresarios y los gobiernos. En los trabajos estudiados existían algunas series que precedían las variaciones de los barómetros de negocios y que para Persons eran especialmente útiles para pronosticar, una de sus principales preocupaciones. Para Babson, los mercados de inversión preceden a todos los negocios, pero existen otras estadísticas mucho más reveladoras como la producción de arrabio ${ }^{3}$ que antecede en seis meses el desempeño futuro de la industria de la construcción. Los cambios en esta última anticipan en dos años la llegada de una crisis generalizada. Para Brookmire es un aumento en el mercado bursátil el que anticipa en tres o cuatro meses un mejoramiento de las condiciones generales de los negocios (Persons, 1916, p. 741).

Sin embargo, para Persons los barómetros adolecen de diferentes problemas. En primer lugar, fueron construidos con un conjunto heterogéneo de estadísticas cuyo agrupamiento no estaba basado en un análisis científico; en segundo lugar, el método utilizado para eliminar la tendencia no era satisfactorio y, en tercer lugar, la utilización de la llamada ley de acción y reacción tomada de la física no era sino una analogía que no estaba basada en una investigación estadística, con lo cual los ciclos descritos en la Babsonchart eran construidos a dedo. En su artículo, Persons propone un nuevo barómetro con correcciones a los diferentes problemas señalados; el resultado fue un barómetro con nueve series anuales que fluctúan con los índices de precios. Se encontraron otras series que precedían las del barómetro. Esa pesquisa sería la base del conocido barómetro de Harvard.

\section{El barómetro de Harvard}

La Universidad de Harvard comenzó a involucrarse firmemente en la construcción de un barómetro para Estados Unidos. La creación de un Committee on Economic Research en 1917 fue un primer paso en esa dirección y una de sus primeras decisiones fue elaborar estadísticas económicas y, específicamente, un barómetro. Persons fue contratado para esa tarea y sus resultados fueron divulgados en los primeros números de The Review of Economic Statistics and Statistical Service, publicados en 1919 (Persons, 1919). ${ }^{4}$ En 1922 comenzó la publicación del Weekly Letter que divulgó al público los resultados de esa investigación sobre el estado presente y futuro de la economía.

3 El arrabio es un producto intermedio del proceso de fundición del hierro. Se utiliza como materia prima en la obtención del acero en los hornos siderúrgicos. 
Persons quiso corregir los problemas que él mismo había detectado en los barómetros existentes, pero su nueva propuesta era más concreta y ambiciosa. En primer lugar, había una debilidad evidente relacionada con la disponibilidad de las series y, por ende, de su utilidad para efectos de análisis oportuno; así como también era muy precario su tratamiento, el cual se limitaba a comparaciones del crecimiento de los datos brutos. Persons propuso una clara división para esas dos tareas. En el primer caso, buscó darle la mayor importancia al acopio de los datos y a su rápida recolección. Para la segunda tarea propuso como principio básico la separación de las series en cuatro componentes: una tendencia secular, un movimiento cíclico, un movimiento estacional y un residuo. Solo de esa forma era posible realizar comparaciones intertemporales entre las series. ${ }^{5}$

En su libro de 1922, Persons hace una cuidadosa descripción del método de construcción del barómetro de Harvard. Vale la pena aclarar, en primer lugar, que el nuevo indicador era mensual, aspecto que representa un gran avance en relación con los barómetros disponibles en ese momento. También hay que tener en cuenta que series seleccionadas en una primera versión del indicador (1903-14) fueron descartadas en la segunda versión, construida para el periodo (1918-23). La razón para esto obedece a que algunas de las series originales sufrieron influencias de diverso orden (v. gr., la Primera Guerra Mundial) que afectaron su calidad y alteraron la información que contenían (Persons, 1922, p. 39).

En la primera versión del indicador se consideraron 50 series de precios y cantidades que después del proceso de tratamiento estadístico de descomposición de sus componentes se redujeron a 22. La principal razón para escoger cualquiera de ellas era que presentara fluctuaciones cíclicas bien definidas y con sentido económico.

Un examen gráfico y de correlación permitió agrupar las series en tres categorías construyendo para ello indicadores sintéticos. ${ }^{6}$ Según Persons (1922, pp. 23-24) el criterio era el siguiente: las series se organizaban de acuerdo con una secuencia de fluctuaciones. Las que fluctuaban primero, ya fuera hacia arriba o hacia abajo, eran todas series que dependían de la inversión y/o de la especulación. Se trataba de indicadores como los precios promedio de los bonos de ferrocarriles, el precio promedio de las acciones industriales, el volumen de ventas y compensaciones de la Bolsa de Nueva York. A este grupo se le denominaba especulativo o grupo A. La segunda categoría correspondía al grupo de negocios o grupo B, el cual seguía con rezago al anterior. Este contenía estadísticas que tenían relación con la actividad industrial como, por ejemplo, la producción de arrabio, las compensaciones bancarias fuera de Nueva York y el índice de precios de productos básicos del Bureau of Labor Statistics. El último grupo también seguía al de negocios con rezago y se llamó bancario (o grupo C), por la información sobre el negocio bancario y el mercado de dinero que incorporaba. Las series de este grupo eran del tipo de los títulos comerciales, y los créditos y depósitos en Nueva York.

La estructura del barómetro de Harvard y de sus componentes permitía hacer previsiones sobre el comportamiento futuro de la economía. Sin embargo, su interpretación fue variando en el tiempo como lo recuerda Favero (2007). En un primer momento, se pensaba que la aso-

5 La tendencia se calculaba por medio de un ajuste lineal (algunas veces exponencial o parabólico). La estacionalidad se calculaba a su vez por el método llamado de las tendencias relativas. Posteriormente, los datos se reducían a una sola unidad de dispersión dividiendo por la desviación estándar. 
ciación de las curvas con un tipo de actividad económica y la relación secuencial entre ellas brindaba una base sólida para hacer pronósticos. Hacia 1920, sin embargo, se comienza a pronosticar la curva B con las curvas A y C. Si la curva A aumentaba (caía) y la C caía (aumentaba) era una señal de un mejoramiento (empeoramiento) de la economía. Desde ese momento, desapareció la impresión errónea de un papel menor del indicador bancario y monetario. Más adelante, en el análisis, la secuencia se va a invertir completamente y la curva $C$ va a preceder a la $A$ y esta a la B (Persons, 1930). En todo caso, va a perdurar en el análisis económico la idea del adelanto de algunos indicadores a los movimientos más importantes de la actividad económica, mientras que otros los siguen.

\section{Gráfico 4. El barómetro de Harvard}

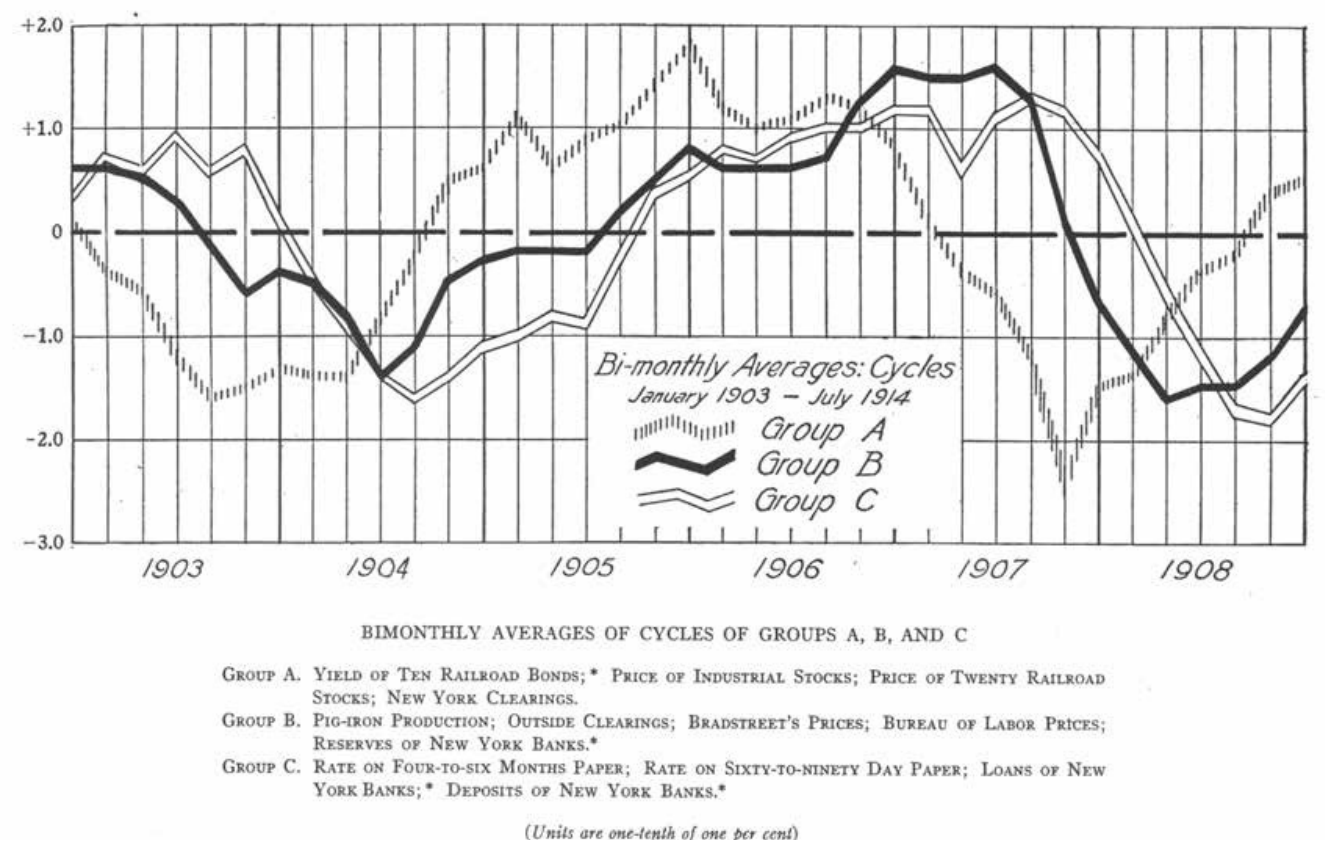

Nota: Como se afirma en el texto, el indicador A recogía la evolución de las acciones, el B de la actividad económica y el C la actividad bancaria. El A es adelantado y pronostica a B mientras que este último a su vez pronostica a C. El gráfico recoge valores históricos entre 1903 y 1908 y corresponde a la primera versión del barómetro.

Fuente: Persons (1919b, p. 112).

\section{Auge y ocaso de los barómetros}

El éxito inicial del barómetro de Harvard estuvo en que logró pronosticar la crisis de la economía de E.E. U.U. en 1920 y también, aunque en menor grado, la posterior recuperación de 1922. Para esto utilizó la nueva secuencia de indicadores descrita antes. La técnica se difundió en muchos ámbitos y pronto se empezaron a calcular barómetros en empresas privadas y entidades públicas de todo el mundo; con esto el indicador había alcanzado la aprobación de la comunidad científica. 
En la década de 1920, en muchos países las autoridades encargaron la construcción de barómetros. En el Reino Unido se fundó en 1921 el London and Cambridge Economic Service, bajo la dirección de William Beveridge, cuyo primer boletín se publicó en enero de 1923. En Francia, el Instituto de Estadística de la Universidad de París encargó a Lucien March la construcción del indicador, y con similar propósito se crearon institutos en Austria (dirigido por Hayek y después por Morgenstern), Rusia (Kondratieff), Alemania (Wagemann) y Bélgica (Dupriez), entre otros. Fue tal la creación de entidades con el mismo propósito que la Liga de las Naciones impulsó la creación de un comité internacional de expertos en el área (Favero, 2007).

En el ámbito privado, también se difundió el uso de los barómetros para la toma de decisiones y muchas empresas construyeron sus propios indicadores. De otro lado, las técnicas de tratamiento de las series estadísticas (desestacionalización y correlación) se comenzaron a utilizar para depurar las series propias (v. gr., las ventas de General Motors). Las intervenciones de los bancos centrales también fueron guiadas por las señales que daban esas herramientas.

Una visión alternativa fue la de Irving Fisher, quien, por la misma época en que se comenzó a difundir el barómetro de Harvard, empezó a publicar una columna pagada (Fisher's Business Page) en diferentes periódicos de Estados Unidos. En la columna difundía sus índices de precios de los bienes básicos y de poder de compra. Unos años después ofreció un nuevo servicio: un índice bursátil. En el primer caso se trataba de un índice ideal (de Fisher), que en realidad es un promedio ponderado de los índices de Paasche y de Laspeyres. ${ }^{7}$ El índice de poder de compra del dólar es simplemente el inverso del índice anterior. El índice de valores era un ponderado de las acciones más transadas. Se construía con base en el valor promedio de las quince acciones más vendidas en la semana anterior.

Fisher pretendía dar una educación económica al público en general, con el propósito de evitar la llamada ilusión monetaria; para ello divulgaba sus investigaciones en la prensa y no solo daba información a abonados especialistas. No era esta la única diferencia con el enfoque de los barómetros; para Fisher, faltaba teoría económica en esos instrumentos, ya que los estudios sobre los ciclos eran básicamente empíricos.

en lugar de seguir los actuales ciclos "históricos" que son el resultado de innumerables fuerzas, se deberían examinar las fuerzas principales. Yo sospecho que la fuerza principal que afecta los ciclos es la tasa real de interés, la suma de la tasa monetaria y de la apreciación (positiva o negativa) del poder de compra del dólar. (Fisher, 1923, p. 1024)

De otro lado, según Fischer, en esos trabajos perdían importancia las variaciones de los precios en los movimientos de la economía. Si estos últimos aumentaban, llevaban a una mayor producción por parte de los empresarios. El comportamiento era simétrico en el caso de un descenso en el dinero. En el artículo de 1923 concluía que era "la rapidez de los movimientos de los precios durante el periodo 1914-22 lo que parecía explicar, casi completamente, los aumentos y caídas de los negocios, las excepciones se debían a otros factores" (Fisher, 1923, p. 1027)".

7 En el índice de Paasche varían los precios y las cantidades para los periodos considerados; en el de Laspeyres las cantidades son las del año base y los precios El índice ideal corrige esos problemas. 
En términos generales se podría decir que el enfoque de Fisher sobre los ciclos era una aplicación del paradigma clásico y, muy específicamente, de la explicación de la inflación como un fenómeno monetario. En ese sentido había más teoría en su análisis que en el enfoque de Harvard que era claramente chartista. Por ejemplo, afirmaba que un dólar depreciado y un aumento de los precios de los bienes básicos era una demostración de un aumento del volumen de moneda y crédito superior al de la producción y el intercambio de bienes y servicios. En sus palabras, si la moneda y el crédito se aplican a la misma (y pequeña) cantidad de bienes y servicios, el resultado es una creciente competencia por estos últimos. El aumento en los precios podía llevar a un descenso en la tasa de interés real, a un aumento en la producción industrial y de los inventarios debido al incremento en el valor de los bienes.

El enfoque de los barómetros también fue cuestionado por otras razones. Gini y Morgenstern coincidieron en señalar que los barómetros podrían ser procíclicos y, de esa forma, influenciar el comportamiento de los empresarios en la medida en que alteraba sus puntos de referencia. ${ }^{8}$ De acuerdo con Morgenstern, esta característica de los barómetros llevaba a que fuese necesario mejorar sus aspectos técnicos y a separar el análisis científico de la divulgación comercial de los indicadores (Favero, 2007, p. 13).

Los comentarios reseñados antes fueron hechos en el seno de la reunión internacional de expertos que se llevó a cabo a finales de 1926, en el Instituto Internacional de Estadística. En 1929, ese mismo grupo se reunió a evaluar las señales que estaban arrojando los barómetros y concluyó que no había motivo de alarma. Tampoco Fisher observó nada alarmante con sus propios indicadores. La incapacidad para pronosticar la gran depresión que estalló dos meses después minó profundamente la credibilidad de los barómetros y por supuesto la reputación del mismo Fisher.

La falencia de esos indicadores es motivo de debate aún hoy en día. De hecho, Domínguez et ál. (1988), retomaron el tema y utilizaron técnicas modernas para preguntarse si era posible prever la crisis con esos instrumentos. En el caso de Domínguez et ál. (1988) se utilizaron las series originales del barómetro de Harvard y de Fisher y se construyeron con ellas diferentes modelos vectoriales autoregresivos (VAR). El trabajo de Domínguez y sus colegas fue muy cuidadoso y evaluó por separado los dos sistemas de información. También utilizó variables históricas construidas por diferentes investigadores con técnicas modernas de recolección y tratamiento, ${ }^{9}$ la idea en este caso es indagar si, eventualmente, habría sido posible prever la crisis con datos diferentes a los utilizados por el barómetro y Fisher. Para el VAR del barómetro, Domínguez et al utilizaron, en un primer ejercicio, la información de los índices A, B y C desde enero de 1919 y, posteriormente, llevaron las series hacia atrás, incluyendo los índices del barómetro, con el fin de incluir datos de periodos de recesiones severas. En el caso de Fisher, la información de este autor solo estaba disponible desde 1925 y también se hizo un ejercicio con los datos originales y otro, extendiéndolos hacia atrás.

Escañuela (2009), por su parte, se hace la misma pregunta, pero se concentra en el barómetro de Harvard. En su análisis aplicó una técnica que era conocida para la época, el llamado análisis armónico, también utilizó las pruebas estadísticas disponibles en ese momento. El

8 Para algunos agudos lectores este podía ser un antecedente de la denominada crítica de Lucas (Clements y Hendry, 1998).

9 Las variables corresponden a la producción industrial, los precios al productor, los precios de las acciones, las tasas de interés de los créditos y un agregado monetario. Para las fuentes ver Domínguez et ál. (1988).

tiempo\&economía

Vol. 6 N. ${ }^{\circ} 1$ - Enero - Junio del 2019

p. 91

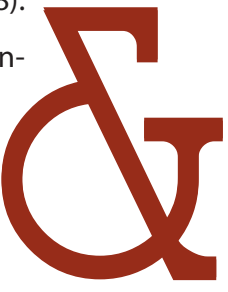


análisis armónico es en esencia una representación de las funciones o señales como una superposición de ondas; incorpora, así mismo, las nociones de series transformadas de Fourier. Los distintos indicadores ( $\mathrm{A}$, B y C) del barómetro de Harvard fueron descompuestos en curvas sinusoidales con la idea de probar su capacidad predictiva.

Los resultados de los ejercicios no son contundentes. Para Domínguez et ál. (1988), la gran crisis no podía preverse ya fuera que se usaran técnicas modernas o las disponibles en ese momento. La conclusión de Escañuela (2009) es la siguiente: con una técnica conocida era posible prever una profunda caída de la curva A (la especulación), mientras las otras dos que representaban los negocios y las variables monetarias caían ligeramente. En esa medida la conclusión del autor es que hubo una lectura incorrecta de la composición de las curvas o, en otras palabras, de sus interrelaciones, cuya interpretación se hubiera podido mejorar.

En todo caso, el juicio público en ese momento señaló la incapacidad del barómetro para predecir la caída de la bolsa: ese fue el comienzo de su fin. El enfoque de los barómetros como instrumento analítico para seguir el curso de la economía fue ampliamente cuestionado, así como su capacidad de predicción para eventos futuros. En consecuencia, en 1935 la Sociedad Económica de Harvard puso fin al trabajo del Comité, al tiempo que el Departamento de Economía suspendió transitoriamente la publicación de su revista, la reformó radicalmente y amplió su campo de estudio. Había llegado el momento de que el enfoque de los indicadores del NBER creciera y dominara la escena en el análisis de los ciclos de negocios.

\section{El enfoque de los indicadores}

\section{El NBER, cronología de los ciclos y el enfoque de los indicadores}

La crisis de 1929 produjo cambios metodológicos y teóricos en el estudio de la economía y sus movimientos. La gran depresión dio a Keynes (1936) el ímpetu necesario para escribir la Teoría General, el libro que impulsó la macroeconomía. De acuerdo con Skidelsky,

la Teoría General no hubiera podido escribirse diez años antes. Esa acusación particular sobre la economía clásica y, de hecho, sobre la forma como la economía se comportaba necesitaban de una gran caída para que cristalizase la redacción de ese texto. (Skidelsky, 1996)

También se dio el importante desarrollo de modelos matemáticos completos de los ciclos económicos, con una forma de agregación muy abstracta, en los trabajos de Frisch (1933), Kalecky (1935) y Samuelson (1939), entre otros. Para la misma época surgió la econometría con los modelos construidos por Tinbergen para la economía holandesa, la economía estadounidense y posteriormente para el Reino Unido durante la época del patrón oro en el siglo XIX (Klein, 2004).

Asimismo, una idea muy influyente en el análisis económico del ciclo fue el enfoque denominado impulso-propagación, presente en el trabajo de Slutzky (1937). Según ese autor, las fluctuaciones (ciclos) surgen como resultado de pequeños choques tipo "ruido blanco" tam- 
bién conocidos como impulsos. ${ }^{10}$ Estos últimos se propagan con el tiempo a todo el sistema económico.

Los anteriores desarrollos, con su énfasis en el análisis de los agregados macroeconómicos, así como los requerimientos más urgentes y prácticos de los actores económicos que exigían mejores indicadores, condujeron a una profunda transformación en la producción de información económica. Los dos aportes más importantes se dieron en el seno del National Bureau of Economic Research (NBER), la entidad de investigación privada sin ánimo de lucro que había sido creada en 1920 con el propósito de hacer análisis cuantitativo de la economía estadounidense y cuyo primer director de investigación fue Wesley Mitchell (Fabricant, 1984).

Los trabajos sobre el ingreso nacional elaborados por Kuznets $(1933,1934,1941)$ por encargo de Mitchell, fueron parte fundamental de los esfuerzos pioneros en esta nueva rama del conocimiento. El trabajo consistió en hacer estimativos detallados de esa variable, acompañados de los conceptos y los métodos estadísticos que utilizaron para construir el sistema de cuentas.

El otro gran desarrollo, también en el seno del NBER, fue la investigación sobre la naturaleza y las causas de los ciclos de negocios y, más adelante, sobre sus indicadores y pronósticos. Esta investigación, a diferencia de la relacionada con el ingreso nacional, comenzó casi desde la creación de esa institución (Zarnowitz, 1992). En la consolidación de esta línea de trabajo fue determinante la influencia de Mitchell y de su primer trabajo de 1913, en el cual hacía un estudio de los trabajos sobre ese tema y una revisión sistemática de datos. En ese trabajo, Mitchell planteaba su insatisfacción por las teorías de la época, en la medida en que todas apuntaban a la existencia de una condición normal o estática de los negocios y a la cual la economía retorna después de una "aberración" (¿choque?). Para él, por el contrario, hay dinámica en los negocios que pasa ininterrumpidamente de una fase a otra (Mitchell, 1913, p. 86). El objetivo del libro era mostrar sistemáticamente, y apoyado en los datos, cómo las economías pasan de una fase a otra a medida que se van acumulando diferentes tensiones. En ese momento Mitchell enunció un rasgo esencial de su trabajo: los ciclos son un fenómeno complejo con una gran diversidad de causas, ellas mismas una síntesis de diferentes teorías, fuesen antiguas o nuevas.

El objetivo de estudio del NBER era la periodización del ciclo económico. Este último era entendido de la siguiente manera, en una de las definiciones más populares en la literatura económica (Mitchell, 1927, p. 468):

Los ciclos de negocios hacen parte de un tipo de fluctuaciones que se encuentra en la actividad económica agregada de las naciones que organizan su trabajo principalmente en empresas de negocios: un ciclo consiste en expansiones que ocurren al mismo tiempo en muchas actividades, a estas le siguen generalmente recesiones, contracciones, y también reactivaciones en las cuales se condensa la fase de expansión del ciclo siguiente; esta secuencia de cambios es recurrente pero no periódica. La duración de los ciclos de negocios varía de un año hasta diez o doce años; no es posible dividirlos en ciclos más cortos de carácter similar con amplitudes que se le aproximan. (Traducción propia)

10 En términos sencillos el ruido blanco es un proceso aleatorio, o dependiente del azar, con valores para distintos momentos del tiempo que no guardan correlación entre ellos. 
En este enunciado se limitaba el alcance de lo que se pretendía hacer y se tomaba distancia frente a algunas teorías vigentes en la época. La permanencia y pertinencia de la definición se explica porque condensa varios aspectos esenciales de lo que es realmente un ciclo de negocios: 1) los ciclos de negocios son fluctuaciones de la actividad económica agregada, 2) un ciclo consiste en expansiones de muchas actividades económicas seguidas de recesiones generalizadas similares, 3 ) esa secuencia de cambios es recurrente pero no es periódica, y 4) no puede descomponerse en ciclos más cortos de magnitud y carácter similar. En el ciclo, la economía se mueve de un pico (el punto más alto) hasta un valle (el punto más bajo). Cada pico marca el fin de una expansión y el comienzo de una contracción o recesión.

\section{Cronología de los ciclos económicos}

La definición del NBER sigue en uso para la identificación y determinación de las fechas del ciclo de la economía estadounidense y fue la base de las cronologías para Inglaterra, Francia y Alemania, antes de la Segunda Guerra Mundial. Con un ajuste que permite que la actividad económica pueda medirse a lo largo de su tendencia de largo plazo, la definición también se utiliza para determinar las cronologías de los ciclos de crecimiento de muchas economías (Moore y Zarnowitz, 1986). El primer caso se conoce como la visión clásica del ciclo, mientras que el segundo concepto corresponde al ciclo de crecimiento.

El fuerte crecimiento económico de la postguerra en Estados Unidos y Europa, así como la difusión del enfoque del NBER hacia países menos desarrollados y con altas tasas de crecimiento, llevó a que se revisara el concepto clásico del ciclo. La cuestión era que las recesiones y los indicadores que la representaban eran fenómenos más escasos y de vida más corta y esto no se reflejaba en la visión clásica. De esa forma, en la cronología clásica del ciclo la identificación de las expansiones y recesiones se hace en relación con los niveles absolutos de las variables utilizadas en el análisis, sin removerles su componente secular, en otras palabras, no se condiciona al filtrado de sus componentes de baja frecuencia (tendencia).

En la gráfica 5 se presentan a manera de ilustración las dos versiones del ciclo calculadas para los datos colombianos. La gráfica en el panel superior (5a) corresponde al ciclo clásico. De otro lado, en forma simplista, se puede aproximar el ciclo de crecimiento partiendo del clásico y dibujando una línea de tendencia de largo plazo calculada a partir de un filtro. Las desviaciones respecto a esta tendencia representan los ciclos de crecimiento (ver gráfica 5b). Hay que tener en cuenta que en los ciclos clásicos se entiende que hay una fase de expansión cuando la dirección de la actividad económica va en aumento a partir del punto mínimo de la recesión anterior y las fases de recesión son aquellas en los que la dirección de la actividad económica va disminuyendo a partir del pico (punto máximo) de la expansión anterior. En contraste, los ciclos de crecimiento registran las variaciones positivas y negativas en relación con la tendencia de crecimiento de largo plazo que típicamente abarca varios ciclos de negocios. El pico del ciclo de crecimiento ocurre cuando éste se encuentra en su punto más alto por encima de su tendencia de largo plazo, mientras que el valle o punto mínimo se da cuando está lo más apartado por debajo de su tendencia de largo plazo (Mintz, 1969).

Desde un punto de vista conceptual, hay que señalar el significado de la nueva definición del Ilamado ciclo de crecimiento. En un ciclo clásico à la Burns-Mitchell una recesión es aso- 
ciada con crecimiento negativo o, en otras palabras, con una reducción absoluta en el nivel de la actividad económica agregada. De igual forma, una expansión se caracteriza por periodos de crecimiento positivo de la actividad. En el ciclo de crecimiento se puede decir que una economía está en recesión aun cuando esté presentando periodos de crecimiento positivo, pero la actividad económica esté por debajo de una tendencia subyacente de crecimiento; esto se conoce como una recesión de crecimiento.

Gráfica 5a. El ciclo clásico en Colombia y su tendencia polinómica

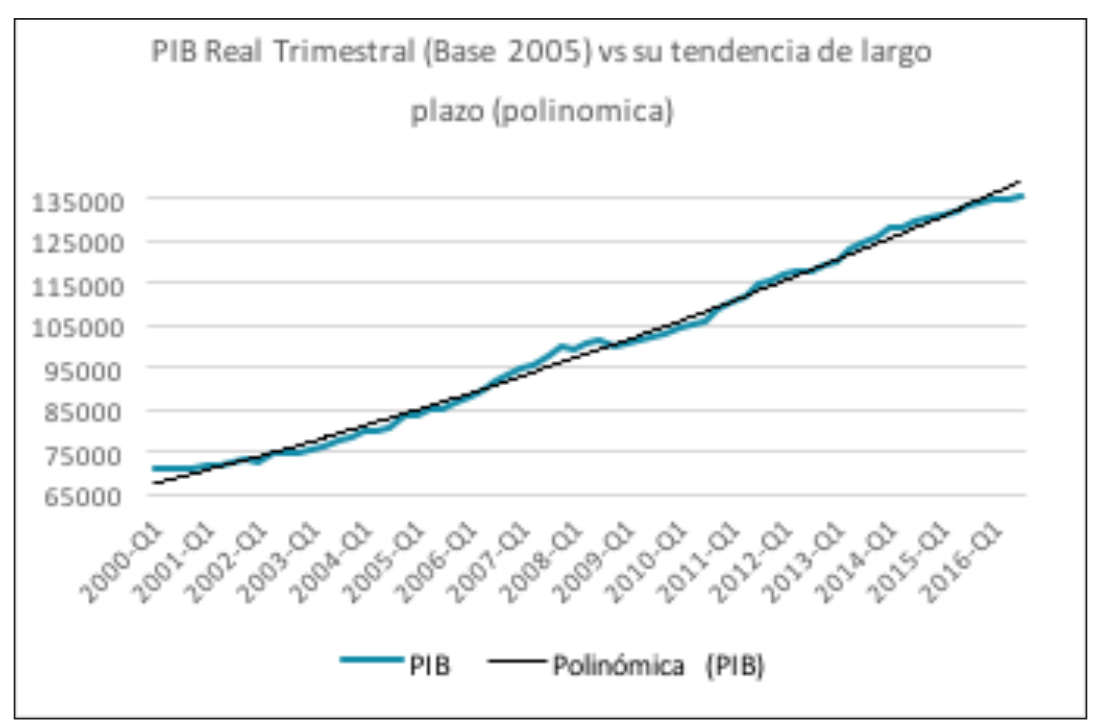

Fuente:DANE, elaboración propia. La serie desestacionalizada correspondeal PIB a precios constantes base 2005, en millones de pesos.

Gráfica 5b. El ciclo de crecimiento de Colombia

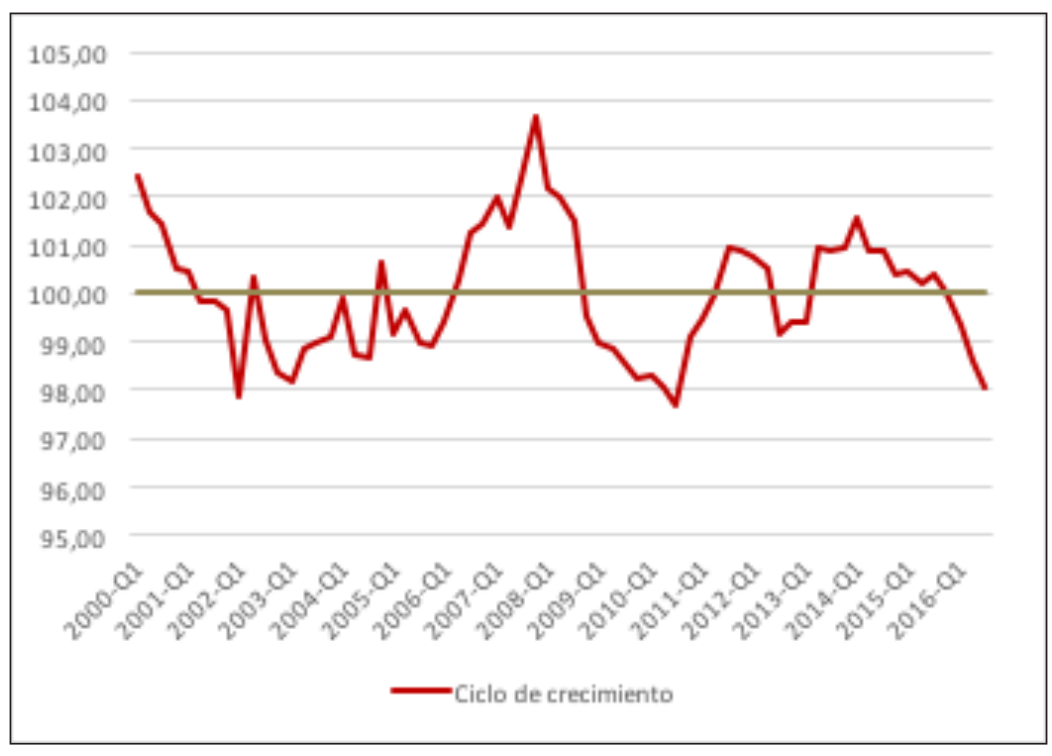

Fuente: DANE. Elaboración propia. Filtro H-P factor $\lambda=1600$.

tiempo\&economía

Vol. 6 N. ${ }^{\circ} 1$ - Enero - Junio del 2019

p. 95 
La visión clásica del ciclo se enunció por primera vez en un momento (1927) en el cual todavía no se contaba con las cuentas nacionales y, por ende, con mediciones del producto agregado. En esas condiciones, la cronología de los ciclos tempranos del capitalismo era una tarea difícil e imprecisa debido a que se enfrentaba a grandes limitaciones de datos. Sin embargo, para ese entonces, el NBER había recopilado dos grandes tipos de información complementaria que le permitieron producir su primera cronología de los ciclos: i) los llamados "anales de los ciclos", y ii) las series estadísticas.

Los anales de los ciclos eran estudios detallados de la actividad económica de 17 países construidos por Thorp (1926) a partir de documentos públicos, periódicos, análisis de historiadores y reportes contemporáneos. Thorp (1926) definió su narrativa clasificando la información que tenía en cuatro categorías: (i) industria, comercio y trabajo; (ii) dinero, seguridad y mercado cambiario; (iii) producción y precios agrícolas; y (iv) fenómenos no económicos como eventos políticos, guerras y catástrofes. Una vez definida la clasificación Thorp planteaba la existencia de una de las cuatro fases del ciclo que mejor se ajustaba al estado de la economía en ese año: depresión, reactivación, prosperidad y recesión. Las series estadísticas, por su parte, eran, en su gran mayoría, anuales, aunque ya existía una buena cantidad de información mensual. Para Estados Unidos y Gran Bretaña se pudo obtener información mensual y trimestral desde 1854, mientras que las series anuales se consiguieron desde 1790.

Para su artículo de 1927, Mitchell se tomó el trabajo de contrastar los años de inflexión señalados por Thorp como fechas de recesiones y reactivación con ciclos bien establecidos y aceptados. Esa fue la base para su propuesta de cronología de ciclos para el periodo 17901920 (Mitchell, 1927, p. 387).

El NBER refinó gradualmente su cronología de los ciclos. Dentro del desarrollo de la producción y calidad de la información económica de la década de 1940, uno de los mayores esfuerzos fue el cálculo de un mayor número de series de frecuencia mensual. Con esto, la identificación de los picos y valles de la actividad económica que definen la duración de las recesiones y las expansiones se fue haciendo más precisa. El cálculo de los agregados macroeconómicos a partir de las cuentas nacionales también permitió cualificar la discusión. Así mismo, la creación del sistema de indicadores, también en el seno del NBER, contribuyó en esa dirección.

Son dos los principios que definen la aproximación del ciclo según el NBER. En primer lugar, de la definición citada antes se desprende que la complejidad del ciclo hace que no pueda ser entendido si se le examina desde un único punto de vista, con lo cual es necesaria la consideración de diferentes tipos de enfoques y, en segundo lugar, en un plano más empírico, el otro principio consiste en que no existe un indicador único para definir un pico o un valle dentro de la cronología del ciclo.

A partir de 1961 el Departamento de Comercio comenzó a incluir la cronología del ciclo en su publicación mensual. En ese año, el NBER se convierte en el árbitro oficial de los ciclos económicos en ese país. Más adelante, a partir de 1980, los puntos de giro oficiales de los ciclos de negocios en Estados Unidos son definidos por un comité en el seno del NBER (NBER's Business Cycle Dating Committee).

Actualmente, existe una gran diferencia con el trabajo que hacía el NBER en los años veinte, en la investigación sobre la cronología de los ciclos. En ese entonces -como ya se mencionólos investigadores examinaban cientos de series y determinaban los puntos de giro de cada 
una, buscando definir la coincidencia de ellos en las diferentes series (Burns y Mitchell, 1946, p. 13 y pp. 77-80). Hoy en día se ha concluido que los puntos de giro de unas pocas series son los que permiten establecer la cronología del ciclo.

Como afirman Hall et ál. (2003) para el Comité no existe una regla fija para determinar qué otras series estadísticas contribuyen al proceso de determinación de la cronología. Es claro que esa posición expresada explícitamente no apoya la idea de que se requiere que haya dos trimestres consecutivos de crecimiento negativo del PIB para definir un punto de giro (valle) de la economía. Se puede presentar, por ejemplo, en 2001, en que una recesión en que la recesión no incluya dos trimestres consecutivos de caída en el PIB real. Así, en primer lugar, el comité no está de acuerdo con identificar la actividad económica únicamente con el PIB o con el ingreso agregado disponible y utiliza otro tipo de indicadores. En segundo lugar, pone un gran énfasis en los indicadores mensuales con el fin de llegar a una cronología mensual. En tercer lugar, considera que para definir una recesión es necesario tener en cuenta la profundidad del declive de la actividad económica. En cuarto lugar, para examinar el comportamiento de la producción doméstica se tienen en cuenta no solo los estimativos del PIB del lado de la oferta, sino también los conceptualmente equivalentes del ingreso disponible desde el lado de la demanda. Puede darse el caso, como en 2007-2009, en que los indicadores de esos dos conjuntos de estimativos presenten diferencias en la información que proveen.

Sobre el último punto, en 2003 Hall et ál., afirmaban que las recesiones corresponden a un declive significativo de la actividad en toda la economía que dura algunos meses y normalmente se observa en el PIB, el ingreso real, el empleo, la producción industrial y las ventas. Si bien el Comité considera que el PIB es la mejor medida de la actividad económica, trata de mantener una cronología mensual de los ciclos lo cual no es posible con el PIB calculado trimestralmente. Por esa razón da gran importancia a indicadores mensuales que ofrecen un buen panorama de la economía como un todo: (1) el ingreso personal real sin transferencias y (2) el empleo. Adicionalmente, el Comité examina la información de la industria y de las ventas para seguir el mercado de bienes. También estudia los estimativos mensuales del PIB producidos por diferentes entidades.

En la tabla 1 se observa la cronología del ciclo de Estados Unidos definida con la metodología del NBER. Si se hace una comparación de la frecuencia y duración de las recesiones y expansiones que muestra la cronología se obtiene evidencia acerca de la moderación del ciclo de la economía estadounidense. En efecto, las expansiones (contracciones) después de la Segunda Guerra Mundial son dos veces más largas (cortas) que las observadas antes de la Primera Guerra. Esta característica del ciclo había sido advertida por Diebold y Rudebusch (1992), utilizando para ello un procedimiento estadístico riguroso. 
Tabla 1. Cronología del NBER para la economía de Estados Unidos

\begin{tabular}{|c|c|c|c|c|c|c|c|}
\hline Mes pico & Mes valle & $\begin{array}{c}\text { Número } \\
\text { del mes } \\
\text { pico }\end{array}$ & $\begin{array}{c}\text { Número } \\
\text { del mes } \\
\text { valle }\end{array}$ & $\begin{array}{l}\text { Duración, } \\
\text { pico-valle }\end{array}$ & $\begin{array}{l}\text { Duración, } \\
\text { valle-pico }\end{array}$ & $\begin{array}{c}\text { Duración, } \\
\text { pico-pico }\end{array}$ & $\begin{array}{c}\text { Duración, } \\
\text { valle- } \\
\text { valle }\end{array}$ \\
\hline & December 1854 & & 660 & & & & \\
\hline June 1857 & December 1858 & 690 & 708 & 18 & 30 & & 48 \\
\hline October 1860 & June 1861 & 730 & 738 & 8 & 22 & 40 & 30 \\
\hline April 1865 & December 1867 & 784 & 816 & 32 & 46 & 54 & 78 \\
\hline June 1869 & December 1870 & 834 & 852 & 18 & 18 & 50 & 36 \\
\hline October 1873 & March 1879 & 886 & 951 & 65 & 34 & 52 & 99 \\
\hline March 1882 & May 1885 & 987 & 1025 & 38 & 36 & 101 & 74 \\
\hline March 1887 & April 1888 & 1047 & 1060 & 13 & 22 & 60 & 35 \\
\hline July 1890 & May 1891 & 1087 & 1097 & 10 & 27 & 40 & 37 \\
\hline January 1893 & June 1894 & 1117 & 1134 & 17 & 20 & 30 & 37 \\
\hline December 1895 & June 1897 & 1152 & 1170 & 18 & 18 & 35 & 36 \\
\hline June 1899 & December 1900 & 1194 & 1212 & 18 & 24 & 42 & 42 \\
\hline September 1902 & August 1904 & 1233 & 1256 & 23 & 21 & 39 & 44 \\
\hline May 1907 & June 1908 & 1289 & 1302 & 13 & 33 & 56 & 46 \\
\hline January 1910 & January 1912 & 1321 & 1345 & 24 & 19 & 32 & 43 \\
\hline January 1913 & December 1914 & 1357 & 1380 & 23 & 12 & 36 & 35 \\
\hline August 1918 & March 1919 & 1424 & 1431 & 7 & 44 & 67 & 51 \\
\hline January 1920 & July 1921 & 1441 & 1459 & 18 & 10 & 17 & 28 \\
\hline May 1923 & July 1924 & 1481 & 1495 & 14 & 22 & 40 & 36 \\
\hline October 1926 & November 1927 & 1522 & 1535 & 13 & 27 & 41 & 40 \\
\hline August 1929 & March 1933 & 1556 & 1599 & 43 & 21 & 34 & 64 \\
\hline May 1937 & June 1938 & 1649 & 1662 & 13 & 50 & 93 & 63 \\
\hline February 1945 & October 1945 & 1742 & 1750 & 8 & 80 & 93 & 88 \\
\hline November 1948 & October 1949 & 1787 & 1798 & 11 & 37 & 45 & 48 \\
\hline July 1953 & May 1954 & 1843 & 1853 & 10 & 45 & 56 & 55 \\
\hline August 1957 & April 1958 & 1892 & 1900 & 8 & 39 & 49 & 47 \\
\hline April 1960 & February 1961 & 1924 & 1934 & 10 & 24 & 32 & 34 \\
\hline December 1969 & November 1970 & 2040 & 2051 & 11 & 106 & 116 & 117 \\
\hline November 1973 & March 1975 & 2087 & 2103 & 16 & 36 & 47 & 52 \\
\hline January 1980 & July 1980 & 2161 & 2167 & 6 & 58 & 74 & 64 \\
\hline July 1981 & November 1982 & 2179 & 2195 & 16 & 12 & 18 & 28 \\
\hline July 1990 & March 1991 & 2287 & 2295 & 8 & 92 & 108 & 100 \\
\hline March 2001 & November 2001 & 2415 & 2423 & 8 & 120 & 128 & 128 \\
\hline December 2007 & June 2009 & 2496 & 2514 & 18 & 73 & 81 & 91 \\
\hline \multicolumn{2}{|c|}{ 1854-2009 (33 ciclos) } & & & 17,5 & 38,7 & 56,4 & 56,2 \\
\hline \multicolumn{2}{|c|}{ 1854-1919 (16 ciclos) } & & & 21,6 & 26,6 & 48,9 & 48,2 \\
\hline \multicolumn{2}{|c|}{ 1919-1945 (6 ciclos) } & & & 18,2 & 35,0 & 53,0 & 53,2 \\
\hline \multicolumn{2}{|c|}{ 1945-2009 (11 ciclos) } & & & 11,1 & 58,4 & 68,5 & 69,5 \\
\hline
\end{tabular}

Nota: La numeración mensual comienza en enero de 1800. 


\section{Los sistemas de indicadores}

En el NBER se desarrolló originalmente el sistema de indicadores que comprendía series de indicadores líderes, coincidentes y rezagados. A partir de 1961, el gobierno estadounidense, a través del Bureau of the Census, comenzó la publicación de un reporte mensual Business Cycle Developments en colaboración con el NBER y el Consejo de Asesores Económicos del Presidente, en el cual se daba a conocer la actualización de los indicadores. En 1968, el reporte cambia de nombre a Business Conditions Digest. En 1972, se encargó de la construcción de los indicadores al Bureau of Economic Analysis (BEA). En 1990, el reporte fue incorporado al Survey of Current Business como una sección aparte. Finalmente, el BEA decide concentrarse en las Cuentas Nacionales y en 1995 transfiere el programa de investigación y producción de los indicadores de ciclo de negocios al Conference Board, una entidad privada independiente.

En su forma clásica, el sistema de indicadores cíclicos probó ser un instrumento útil para analizar las secuencias de expansiones y contracciones en diferentes sectores de la economía que constituyen un ciclo económico, de acuerdo con la definición del NBER citada arriba.

Desde su creación, una de las labores fundamentales del nBER fue la recopilación y el análisis de una gran cantidad de información. Como afirman Moore y Shiskin (1967), la primera selección de variables fue hecha en 1938 con datos hasta 1933. La lista de 21 variables elegidas se confeccionó con base en el estudio de más de 500 series mensuales y trimestrales que cubrían diferentes periodos. La lista final recogía los 21 indicadores más apropiados para capturar las reactivaciones cíclicas. Buena parte de ese trabajo de 1938 fue recogida posteriormente en el libro de Burns y Mitchell, de 1946.

Desde entonces se publicaron varias listas de variables. En 1950 y 1960 se produjeron un par de listas basadas en el trabajo de Moore sobre el ciclo de la economía estadounidense. La lista de 1950 tuvo en realidad pocos cambios frente a la de 1938. Un avance sustancial fue la incorporación de series que también eran indicadoras de recesiones; así como la clasificación de las series en tres grupos: coincidentes, adelantadas o líderes y rezagadas, de acuerdo con su comportamiento dentro del ciclo.

Los indicadores coincidentes corresponden a variables agregadas que miden la actividad económica o, en otras palabras, definen el ciclo económico. Se trataría de series como el producto, el empleo o las ventas. Los indicadores líderes son series que tienden a adelantar cambios en la dirección del ciclo económico. Un ejemplo ilustrativo es el de las mediciones que se puedan hacer de las expectativas de los consumidores. Este tipo de indicadores solo tienen sentido si se utilizan dentro de un sistema. Por último, los indicadores rezagados corresponden a variables que tienden a cambiar de dirección después de los indicadores coincidentes. Su utilidad se basa en que pueden ayudar a determinar desbalances estructurales que pueden surgir en la economía como consecuencia de una recesión. Un ejemplo clásico de un indicador de este tipo es la serie de desempleo.

El mayor cambio en 1960 fue la adición de las series de cambios en los inventarios y de beneficios corporativos; también en este caso se dejaron por fuera algunas de las variables de la lista de 1950. El resultado final fue la selección de 26 series claves, de las cuales 12 eran adelantadas, 9 coincidentes y 5 rezagadas. 
En el boletín mensual que se comenzó a divulgar en 1961 por parte del Bureau of the Census, se publicaron esas mismas 26 series, pero se agregaron 54, para un total de 80 . De esas últimas, 30 fueron clasificadas como indicadores adelantados, 15 como coincidentes y 8 como rezagados. Con respecto a las restantes, se consideró que tenían importancia dentro del ciclo, pero no fueron agrupadas dentro de las categorías usuales. Muchas consideraciones se hicieron para llegar a esta larga lista. Un argumento fue la posibilidad de llegar a una clasificación que tuviera en cuenta el proceso económico (empleo, producción, ingreso, precios), también se supuso que con las nuevas series era posible obtener más información y de forma más oportuna. Se tuvo en cuenta también que una lista más larga, divulgada por una agencia estatal, proyectaría también la imagen de un gobierno más acucioso y cuidadoso en sus análisis del comportamiento de la economía.

Moore y Shiskin (1967) produjeron una nueva revisión de la lista de 1938, en este caso la novedad fue un sistema de elección de series (scoring indicators), todavía en uso. En esa ocasión se evaluaron 100 series y se eligieron 88. El criterio principal fue la calidad de las series como indicadoras de las expansiones y contracciones de la economía, así como su posibilidad para un uso efectivo. Con la asignación de un puntaje entre 1 y 100 para cada serie, se buscaba tener un criterio objetivo de elección. Los puntos se otorgaban teniendo en cuenta una lista de propiedades que permitía establecer el valor de una serie para su utilización en el análisis de los ciclos económicos: significancia económica, idoneidad estadística, relación histórica con los ciclos económicos, registros de temporalidad cíclica, estabilidad y oportunidad de publicación.

La nueva lista se clasificó de acuerdo con dos criterios (i) la temporalidad y (ii) el tipo de proceso económico. En el primer caso incluía 36 series adelantadas, 25 coincidentes, 11 rezagadas y 16 no clasificadas. Del total de series, 72 eran mensuales y 16 trimestrales. Desde el segundo punto de vista las series se clasificaron en los siguientes grupos: (i) empleo y desempleo: 14 series, (ii) producción, ingreso, consumo y comercio: 8 series, (iii) inversión en capital fijo: 14 series, (iv) inventarios e inversión en inventarios: 9 series, (v) precios, costos y beneficios: 11 series, (vi) moneda y crédito: 17 series, (vii) comercio exterior y pagos: 6 series, (viii) actividad del gobierno federal: 9 series, (ix) actividad en otros países.

La quinta revisión la realizó el departamento de comercio en 1975. Asimismo, se cambiaron muchas de las series de 1966. Unos años más adelante en 1989 se llevó a cabo una nueva revisión; en este caso entraron dos series nuevas y salieron dos indicadores avanzados. De ahí en adelante se efectuaron pequeños cambios al sistema, hasta llegar a la lista vigente que fue elaborada en 1996.

De lo dicho hasta ahora queda claro que el punto de partida del análisis del NBER es la identificación del ciclo de referencia. En palabras de Burns y Mitchell (1946), se buscaba establecer los puntos de giro de los movimientos cíclicos de la actividad económica. Esos puntos de giro, cuya secuencia hace parte de la cronología del ciclo, son adoptados como una referencia contra la cual son examinadas todas las variables tenidas en cuenta en el análisis de este último y en la construcción de los indicadores líderes, coincidentes y rezagados. De otro lado, en Estados Unidos el ciclo de referencia fue establecido de manera independiente al de las otras etapas del análisis del ciclo. La determinación de los puntos de giro se hizo primero con un gran número de indicadores y posteriormente, a partir de la construcción de las cuentas nacionales, a través de un grupo pequeño de variables que capturan la evolución de todas las 
actividades económicas. En ese grupo aparecen sistemáticamente el producto, el empleo y las variables asociadas al ingreso.

\section{De los indicadores de difusión a los indicadores compuestos}

En 1937 una agencia pública hizo un requerimiento al NBER acerca de la situación de la economía estadounidense; como resultado la entidad publicó un breve estudio sobre el tema, basado en los indicadores que tenía a mano. Del banco de información de cerca de 500 variables mensuales o trimestrales, se seleccionaron 71 para comenzar, para finalmente llegar a 21, las series más útiles en el análisis de los ciclos. Para llegar a esa conclusión se examinó el desempeño de las series, comparándolo con la cronología del ciclo establecida.

Era necesario presentar la información de manera comprehensiva, con el fin de poder ofrecer un mensaje claro y contundente sobre la situación de la economía. La definición de ciclo del NBER, reseñada antes, precisa cuál debe ser el interés de un analista del fenómeno: se trata de mostrar cómo un movimiento cíclico se esparce de una industria a otra, de una actividad a otra. La definición se refiere no únicamente a la actividad agregada, sino a la difusión de los movimientos cíclicos por toda la economía. Al fin de cuentas según Mitchell (1927), "el ciclo comprende expansiones que ocurren al mismo tiempo en muchas actividades económicas, seguidas de recesiones generalizadas, contracciones y reactivaciones que contienen la fase de expansión del nuevo ciclo".

Al respecto, la primera propuesta del NBER fue la construcción de los llamados índices de difusión. Estos índices miden los indicadores de actividad, ya sea en el total de la economía o dentro de un grupo, que están experimentando expansiones (o contracciones) en un periodo determinado. Lo anterior significa que es posible construir índices de difusión para aquellos grupos de actividades que cambian tempranamente en el proceso cíclico (adelantadas), para aquellas que coinciden (coincidentes) y para las que reaccionan tardíamente (rezagadas). Con los índices de difusión es posible presentar indicadores sintéticos de cada uno de esos grupos.

Las medidas de difusión eran muy simples. Ellas registraban en términos porcentuales cuántos sectores industriales, por ejemplo, estaban experimentando un incremento de su producción en un determinado momento, así como cuántos estaban experimentando una expansión (Moore, 1961b). Sin embargo, los índices de difusión no tenían en cuenta la magnitud del cambio sino únicamente su dirección. Adicionalmente, aunque se habían realizado algunos ejercicios de ponderación con el fin de tener en cuenta la importancia de alguna(s) serie(s) particulares dentro de los índices agregados, estos se presentaban únicamente sin ponderar. Por esa razón, no reflejaban ni la profundidad de una contracción de la economía ni el vigor de su recuperación; era indispensable encontrar un método que combinara los movimientos de un grupo heterogéneo de series de tiempo que no podían combinarse por cantidad, precio u otra forma de ponderación, como es habitual en la construcción de números índices.

A mediados del siglo pasado, Moore y sus colegas desarrollaron el primer índice compuesto, como respuesta a los problemas que presentaba el de difusión. El inconveniente era que una vez se tenían en cuenta las magnitudes, al lado del conteo de cambios, se presentaban movimientos amplios del índice sintético, como consecuencia de la influencia relativa que por construcción adquirían dentro de éste los indicadores más volátiles. La respuesta fue 
encontrar un denominador común de varios indicadores basado en su sensibilidad al ciclo económico. Esta idea permitía ajustar las amplitudes de cada uno de los componentes del índice compuesto por medio de la relación entre su propia volatilidad histórica y aquella de la serie objetivo. Tomando los indicadores en términos de su sensibilidad relativa al ciclo, se tenía una dimensión común que permitía que se combinaran en un solo índice. Más adelante, Shiskin generalizó ese procedimiento estandarizando cada componente de acuerdo con su propia volatilidad, sin tener en cuenta otras series (Shiskin, 1961). Este último es el llamado índice ajustado por amplitud. Una versión posterior fue publicada en 1967 por Moore y Shiskin.

La preocupación por la estandarización no es solamente el elemento técnico que diferencia a los índices de difusión con los índices compuestos; es, al mismo tiempo, un factor que permite distinguir entre diferentes tipos de estos últimos. En el método de Shiskin los cambios mensuales de cada uno de los componentes se dividen por un factor de estandarización propio a cada componente, este último se define como el promedio de los cambios mensuales en un periodo específico. Los cambios estandarizados pueden ponderarse explícitamente y agregarse, la suma de cambios resultante puede acumularse para construir el índice compuesto. La Oficina Estadística de Canadá propuso una solución alternativa que difiere en dos aspectos de la propuesta de Shiskin: i) el factor de estandarización es la desviación estándar de los cambios mes a mes en lugar del promedio absoluto, y ii) el índice compuesto es suavizado por medio de filtros con el fin de eliminar señales falsas.

Como afirman Boschan y Banerji (1990), esos dos métodos de estandarización generan una posible dominancia de la tendencia o de los movimientos irregulares sobre los movimientos cíclicos. Esto se debe a que la forma de estandarización utilizada por medio de los cambios mensuales incluye el ciclo, la tendencia y los componentes irregulares. Esto hace que, de dos series con amplitudes cíclicas idénticas, la que tenga una tendencia más grande (o componente irregular) sea la que tenga un factor de estandarización más grande y menores movimientos cíclicos.

La Oficina Británica de Estadística propone como solución la utilización de un promedio absoluto de la desviación a la tendencia; mientras que la OECD propone el uso de las desviaciones promedio absolutas de las series sin tendencia en relación con su media. Sin embargo, estas soluciones acarrean nuevos problemas. El principal de ellos está asociado con el hecho de que la tendencia es una variable no observada, que debe reestimarse con la nueva información, con lo cual las series obtenidas van a cambiar en cada ocasión. De otro lado, si se extrae la tendencia de las series individuales se pueden desplazar sus puntos de giro. La remoción de la tendencia destruye la integridad de los ciclos clásicos que estudiaron Burns y MitcheII. Esta problemática va a ser uno de los desafíos importantes que va a enfrentar el sistema de indicadores.

\section{Modernización del sistema de indicadores}

Como debe haber quedado claro a esta altura, el programa de investigación original del NBER fue moldeado por su definición del ciclo ya descrita. El enfoque era básicamente empírico y estaba concentrado en el examen sistemático de un amplio conjunto de variables; el punto de partida era la identificación del ciclo de referencia o, en otras palabras, la determinación 
de los puntos de giro de los movimientos cíclicos de la actividad económica. La secuencia de esos puntos constituye la llamada cronología del ciclo. En la tradición del NBER la determinación del ciclo de referencia es independiente de las otras etapas del análisis cíclico, pero es una condición necesaria para este. El grupo de variables es comparado y medido contra ese ciclo de referencia con el fin de determinar su comportamiento en el tiempo y establecer si se trata de indicadores líderes, coincidentes o rezagados. El desarrollo del sistema de indicadores se completó con la construcción de los indicadores compuestos para cada grupo de variables.

Para entender la evolución posterior es conveniente señalar que la concepción del ciclo de referencia y de la cronología del ciclo del NBER estaba basada en la concepción clásica del ciclo, condensada en su definición. En particular, se hacía referencia a las expansiones y las recesiones identificadas en relación con los niveles absolutos de las variables utilizadas en el análisis, sin removerles su componente tendencial o, en otras palabras, sin filtrar de las series el componente de baja frecuencia. Este último es un procedimiento estándar en el cálculo de los ciclos de crecimiento.

El procedimiento específico para las cronologías de los ciclos de crecimiento se inició en el NBER en 1973 y puede resumirse en los siguientes pasos, según Moore y Zarnowitz (1984): 1) Las medidas de la actividad económica agregada tales como la producción industrial, el producto nacional bruto, el ingreso personal, el empleo, el desempleo, y las ventas de bienes y servicios son expresadas en unidades físicas o en precios constantes, desestacionalizadas y se les extrae la tendencia de largo plazo. El método de extracción de la tendencia se conoce como phase-average trend. Este método provee una tendencia que está libre de los movimientos de corto plazo. 2) Para cada una de las series mencionadas se derivan picos y valles calculados a partir de las desviaciones de las series desestacionalizadas en relación con la tendencia de crecimiento estimada; se utiliza un programa de computador construido por Bry y Boschan (1971). 3) Los puntos de giro son revisados visualmente y si se considera necesario son corregidos. 4) Se computan las fechas medianas de las agrupaciones de picos y valles de todas las series examinadas. 5) Se construye un índice compuesto basado en las series estudiadas antes de removerles la tendencia. La tendencia se remueve del índice y los puntos de giro se seleccionan de las desviaciones en relación con la tendencia. 6) Las agrupaciones de fechas, la mediana de las fechas y las fechas del índice compuesto son examinadas y se define qué fecha mensual es la mejor. Esas fechas corresponden a los picos y valles.

\section{La modernización de la metodología}

El recuento realizado hasta ahora señala que una determinada percepción de los ciclos económicos ha persistido durante un siglo, si se tiene en cuenta que el primer trabajo de Mitchell se publicó en 1913. Este hecho es una consecuencia de una muy sólida concepción técnica y metodológica. No ha sido un camino fácil. La visión de los ciclos económicos del NBER ha tenido, para comenzar, una tensa relación con la teoría. Su renuencia a abrazar una determinada elaboración teórica trajo sus costos. En 1947, Koopmans señaló el punto al afirmar que la metodología del NBER carecía de cualquier teoría.

Lo destacable es que la utilización de la cronología del ciclo y de los indicadores cíclicos se mantuvo durante el periodo de desarrollo del enfoque de la econometría estructural de los 
grandes modelos keynesianos y aún después, cuando esta fue abandonada en beneficio de la econometría no estructural. Recientemente, el avance de las técnicas sofisticadas de las series de tiempo ha permitido la modernización de la metodología, incluso dentro del enfoque de la medición sin teoría.

Ya se reseñaron los primeros cambios en la metodología. La cronología del ciclo, en primer lugar, pasó a hacerse con unas pocas variables, cuando anteriormente se utilizaba una amplia base de datos. Así mismo, en la búsqueda de los puntos de giro de las variables se empezó a utilizar una técnica no paramétrica que mejoraba el procedimiento manual utilizado hasta ese momento (Bry y Boschan, 1971). La construcción de los indicadores sintéticos permitió un examen más expedito de la situación de la economía en el ciclo y aportó información muy importante a la llamada cronología del ciclo.

La incorporación de la discusión sobre el ciclo de crecimiento en contraposición a la visión clásica del NBER sobre el análisis del ciclo fue una respuesta al creciente interés de la entidad en el crecimiento económico per se o en la forma como este afecta el ciclo. En su enfoque tradicional para el NBER cada serie estadística fuera mensual o trimestral era tratada como un producto (o al menos como una suma) de tres componentes: estacional (S), irregular (I) y ciclo tendencia (CT). Después de la eliminación de la estacionalidad (S) de las series, se les aplicaba una serie de métodos de suavización con el fin de reducir los efectos sobre la tendencia-ciclo de la gran cantidad de movimientos cortos irregulares distribuidos aleatoriamente y así poder identificar los puntos de giro de la economía, el elemento central de la cronología del ciclo. No se hacía ningún esfuerzo para eliminar los efectos de los movimientos de largo plazo de episodios de perturbaciones mayores asociadas a guerras, huelgas, malas cosechas, innovaciones tecnológicas, entre otras (Zarnowitz y Ozyldirim, 2002).

Un trabajo de síntesis elaborado por Zarnowitz en 1985, citado por Ng y Wright (2013), menciona que la visión dominante en ese momento era que el ciclo económico reflejaba las desviaciones estacionarias alrededor de una tendencia determinística, atribuida a un crecimiento exógeno y que todos los ciclos eran parecidos, en el sentido que compartían unos rasgos comunes. Desde entonces se han dado cambios en el análisis del ciclo económico originados en los mismos hechos macroeconómicos que reflejan modificaciones profundas en las economías modernas, así como en los avances de la estadística, la econometría y en la teoría macroeconómica.

\section{Hechos estilizados acerca de los ciclos}

Los choques macroeconómicos asociados al precio internacional del petróleo que se dieron en la década de 1970 llevaron a desplazamientos en el nivel y la tendencia de muchas variables. Esto hizo que los economistas reflexionaran acerca de la caracterización de los datos macroeconómicos en el paradigma tendencia-estacionariedad.

De otro lado, un examen de los ciclos económicos definidos por el NBER para Estados Unidos (tabla 1), muestra que desde 1980 hasta la última recesión con inicio en 2007, el crecimiento económico, con dos recesiones suaves y más cortas, era más estable que el observado anteriormente. Si el análisis se hace desde la segunda guerra mundial y se compara con la historia anterior, se observan relativamente menos recesiones y de más corta duración; al tiempo 
que se ven expansiones más largas. De otro lado, para la misma época la inflación fue baja y relativamente estable; por ese desempeño, el periodo ha sido conocido como la Gran Moderación, en parte por el contraste con la etapa anterior de gran volatilidad y elevada inflación (Bernanke, 2004; Bean, 2009). Este fenómeno, la tendencia de los datos a comportarse de manera diferente en las expansiones y en las recesiones, no está circunscrito a Estados Unidos, si no que ocurrió también en otras economías avanzadas.

\section{Efectos de los avances en la estadística y la econometría sobre el análisis del ciclo}

El cambio en el comportamiento de los datos llevó a qué hoy en día, en la econometría, se acepte mayoritariamente que las series de tiempo son estacionarias en diferencia. Se acepta también que ocasionalmente hay cambios en la media, inestabilidad en los parámetros, volatilidad estocástica y tendencias comunes, todos rasgos que deben tenerse en cuenta en el análisis. Las herramientas estadísticas actuales son capaces de aprovechar la información cada vez más numerosa y de un amplio espectro de la economía. Los datos pueden provenir de muy diversas fuentes y tener frecuencias diferentes. Esos desarrollos han tenido un gran impacto en el análisis del ciclo económico y, en particular, de su datación y cronología.

De acuerdo con el recuento de Boldin (1994), dentro de los métodos de datación más conocidos se encontraban: i) NBER, ii) regla del PIB, iii) picos y valles de los indicadores cíclicos y iv) indicadores cíclicos à la Stock y Watson. Ante la constatación de la tendencia de los datos a comportarse de manera disímil en las expansiones y en las recesiones, varios autores desarrollaron pruebas de asimetría. En particular, Hamilton (1989) dio un paso más adelante y argumentó que los datos no pueden ser caracterizados por modelos lineales si los ciclos son asimétricos. El trabajo de Hamilton (1989) se sumó a los desarrollos estadísticos y econométricos en la cronología del ciclo y, en especial, a la datación de los puntos de giro. Como se sabe, un punto de giro es una fecha que separa dos fases del ciclo de negocios. Cuando se habla de los métodos de datación se hace referencia a las técnicas utilizadas para encontrar las fechas y detectar los cambios en la evolución de una determinada variable.

i. NBER

La cronología del ciclo propuesta por el NBER parte de la búsqueda de los puntos de giro de la actividad económica. El enfoque original puede definirse como no paramétrico y se basa en el análisis de diferentes series de tiempo. Cuando se institucionalizó el comité de datación de los ciclos de negocios, el enfoque se volvió muy pragmático, en la medida en que sus integrantes comenzaron a utilizar diversos métodos para analizar las condiciones macroeconómicas y la tendencia de la economía.

En general, se mantuvo la idea de Mitchell de no limitar el análisis a un solo indicador, pero se redujo sustancialmente el número de series examinadas. Stock y Watson (2010) recuerdan que para definir el pico de 2007 el Comité utilizó cuatro series mensuales (ingreso personal menos transferencias, ventas al por menor, producción industrial y empleo no agrícola), cuando, en contraste, el NBER examinaba inicialmente cientos de series y definía los puntos de giro detectando en qué fecha se agrupaban los cambios en las series evaluadas.

tiempo\&economía

Vol. 6 N. 1 - Enero - Junio del 2019

p. 105

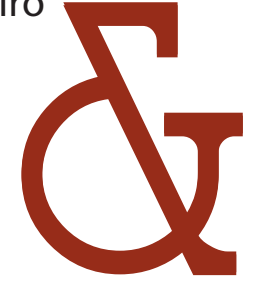


El algoritmo de Bry y Boschan (1971), ya mencionado, replica el proceso de decisión del Comité y permite eludir algunas de las críticas dirigidas a éste como su posible falta de transparencia y su potencial de inconsistencia cuando se presentan cambios en sus miembros. El éxito del algoritmo se encuentra en su capacidad de replicar la cronología del nBer. Hay que resaltar que este procedimiento puede ser utilizado para las series individuales o para indicadores agregados.

ii. Regla de crecimiento del PIB

Existe otro método no paramétrico muy popular: si se presenta un crecimiento negativo del PIB durante dos trimestres consecutivos estaría comenzando oficialmente una recesión en la economía. Esta definición de recesión se expresó formalmente por primera vez en un artículo de prensa de Shiskin (1974). En el artículo se proponían varias reglas de aproximación (rules of thumb), pero la que hizo carrera fue esa.

Varios autores han demostrado que la afirmación no es muy exacta y puede llevar a conclusiones erróneas. Boldin (1994) encuentra en su análisis que varios de los puntos de giro definidos por el NBER, ampliamente aceptados y reconocidos, no coinciden con los que se podrían determinar con la regla de los dos trimestres del PIB. En igual sentido se pronuncia Heath (2012) quien muestra que la regla ha fallado en numerosas ocasiones para comenzar. Dice que: "por ejemplo, entre el 2001 y 2002 hubo un solo trimestre de crecimiento negativo, lo cual llevó a muchos funcionarios públicos a declarar que no había recesión. Sin embargo, en julio del 2002 hubo una revisión a los datos y resultó que hubo tres trimestres consecutivos a la baja. Tiempo después, ya con datos más concretos, se supo que hubo varios trimestres negativos, pero no en forma consecutiva. No obstante, la NBER declaró oficialmente la existencia de una recesión de 10 meses entre marzo y diciembre del 2001" (Heath, 2012, p. 39).

Otros autores insisten sobre las limitaciones que tiene el PIB para definir una recesión o, en general, un punto de giro de la actividad económica. Para definir adecuadamente si se presenta una recesión sería necesario considerar variables del mercado laboral como la pérdida de empleos, los ingresos de los hogares y las ventas (Achuthan y Banerji, 2008). Estas últimas, son las variables que utiliza actualmente el comité de datación del ciclo del NBER.

iii. Picos y valles en los indicadores cíclicos

En este enfoque existe una versión clásica y varias variantes modernas. En la versión clásica que heredó el BEA (Commerce Department's Bureau of Economic Analysis), se construyeron los indicadores adelantados, coincidentes y rezagados con la idea de tener índices únicos en cada caso. El cambio porcentual mensual de cada indicador sintético es la suma ponderada del crecimiento de cada componente individual. En este caso existían algunas reglas generales para elegir los puntos de giro, pero se puede afirmar que al final había poca claridad. En las versiones modernas se utilizan tanto técnicas no paramétricas asociadas al procedimiento Bry-Boschan como también paramétricas.

Una primera versión moderna consiste en una mezcla de procedimientos no paramétricos; el Bry-Boschan se utiliza para encontrar los puntos de giro de las series individuales, el conjunto de dichos puntos se agrega con la aproximación no paramétrica desarrollada por Harding y Pagan (2006). La segunda detecta los puntos de giro suavizando las series con un filtro bandpass y aplica el Bry-Boschan para obtener las fechas de los puntos de giro. 


\section{iv. Indicadores cíclicos à la Stock y Watson}

El trabajo de Stock y Watson de 1989 fue una respuesta directa a las críticas a los indicadores clásicos por su falta de rigor científico. Se trata de un enfoque totalmente paramétrico que tiene como objetivo utilizar el análisis de series de tiempo para derivar un nuevo sistema de indicadores para los Estados Unidos. ${ }^{11}$ Como punto de partida, los autores definieron el índice compuesto de indicadores coincidentes como una única variable no observada: el estado de la economía. El índice se calcula por medio del análisis factorial dinámico, con el fin de extraer los movimientos comunes entre varias series agregadas de tiempo; los parámetros del índice se determinan por una estimación de máxima verosimilitud utilizando para esto un filtro de Kalman. Para el cálculo del indicador adelantado se construye un pronóstico del indicador coincidente con modelo de vectores auto regresivos (VAR).

Formalmente, Stock y Watson (1989) definen el siguiente modelo:

$$
\begin{gathered}
\Delta X_{t}=\beta+\gamma(L) \Delta C_{t}+\mu_{t} \\
D(L) \mu_{t}=\varepsilon_{t} \\
\varphi(L) \Delta C_{t}=\delta+\eta_{t}
\end{gathered}
$$

En este caso $X_{t}$ corresponde a un vector $n x 1$ de los logaritmos de las variables macroeconómicas que supuestamente se mueven contemporáneamente con las condiciones económicas. Esa variable está conformada por dos componentes estocásticos: i) $C_{t}$ que representa el estado de la economía y es una variable no observada, ii) un componente $n$-dimensional $\mu \mathrm{t}$, que representa los movimientos idiosincráticos en las series y el error de medida. $L$ es un operador de rezagos que permite varias situaciones según se trate de un escalar, vector o matriz (respectivamente ). $\varphi(L), \gamma(L), D(L))$.

El sistema de ecuaciones (1)-(3) conforma una representación estado-espacio que puede resolverse con el filtro de Kalman para obtener los parámetros y el estado no observado de la economía.

v. Análisis de factores y modelo de factores dinámicos

Entre los distintos tipos de análisis de factores existentes, tal vez los más empleados son los basados en los métodos de componentes principales y de factores dinámicos. Ambos obtienen un componente inobservable que resume la información del conjunto de variables empleado. El primer método es utilizado cuando no se cuenta con un modelo causal explícito y simplemente se quiere reducir la dimensionalidad de un conjunto de datos. El método de factores dinámicos también se emplea para reducir la dimensionalidad de un conjunto de datos y cuenta con un mayor respaldo teórico que el de componentes principales.

La idea de la técnica de componentes principales es la siguiente: al reducir la dimensionalidad los nuevos componentes principales o factores serán una combinación lineal de las va-

11 Se hace referencia al enfoque paramétrico de la estadística el cual comprende los procedimientos estadísticos y de decisión que están basados en las distribuciones de los datos reales. Estas son determinadas usando un número finito de parámetros. 
riables originales, y además serán independientes entre sí. El método realiza el cálculo de la descomposición en valores propios de la matriz de covarianza, normalmente tras centrar los datos en la media de cada atributo.

De otro lado, el modelo de factores dinámicos permite capturar los co-movimientos de las diferentes series que surgen de una única fuente $\Delta C_{t}$. El modelo de factores dinámicos es, en este caso, un instrumento óptimo en tanto parte de la premisa según la cual unos pocos factores dinámicos latentes dominan los co-movimientos de un vector de variables de tiempo de gran dimensión, que de todas formas es afectado también por perturbaciones idiosincráticas de media cero.

Esta idea de los co-movimientos en un amplio rango de series para hacer análisis del ciclo juega un papel importante en la tradición de Burns y Mitchell (1946). Un desarrollo metodológico al respecto se encuentra en la idea de representar esos co-movimientos utilizando el análisis de factores (Zarnowitz, 1985).

Un modelo de factores estático para las series $x_{i t}$ tendría la siguiente representación:

$$
x_{i t}=\lambda_{i}^{\prime} F_{t}+e_{i t}
$$

Donde $F_{t}=\left(F_{1 t}, \ldots, F_{r t}\right)^{\prime}$ es un vector de $r$ factores comunes, $\lambda_{i}$ es el vector de las ponderaciones ae Ios ractores y $e_{i t}$ son los errores idiosincráticos. El análisis factorial descompone las variaciones en aquellas que son omnipresentes y aquellas que son idiosincráticas. Los choques con efectos omnipresentes son la fuente de los co-movimientos.

El modelo de factores dinámicos fue desarrollado en sus orígenes por Geweke (1977), Sargent y Sims (1977), Stock y Watson (1988) y Watson y Engle (1983). En esencia este modelo parte también de la idea de descomponer grandes paneles de datos en un pequeño número de factores comunes. Con esa técnica puede superarse el problema de los escasos grados de libertad que se daría en un análisis de regresión ante una gran cantidad de información. Adicionalmente, en ese caso se incorpora la dinámica completa del sistema. En particular se plantea una dinámica de cada serie que puede descomponerse en dos componentes ortogonales: el componente común y el componente idiosincrático. ${ }^{12}$

Una presentación general del modelo de factores dinámicos sería la siguiente: ${ }^{13}$

$$
x_{t}=\Lambda_{0} f_{t}+\Lambda_{1} f_{t-1}+\cdots+\Lambda_{m} f_{t-m}+\mu_{t}
$$

En este caso $\Lambda_{0} \ldots \Lambda_{\mathrm{m}}$ son matrices $N x r y$ f $f_{t}$ es un vector de $q$ factores estacionarios. Los componentes idiosincráticos se suponen procesos estacionarios independientes (o débilmente independientes).

12 En matemáticas, el término ortogonalidad (del griego 'orthos' -recto- y 'gonía' -ángulo-) es una generalización de la noción geométrica de perpendicularidad. Formalmente, en un espacio vectorial con producto interior $V$, dos vectores $x$ e $y$ son ortogonales si su producto escalar es cero. En el texto esta propiedad significa que un componente no afecta al otro.

13 Una buena revisión de la literatura sobre factores dinámicos se encuentra en Breitung y Eickmeier (2005). 
Los modelos de factores dinámicos son una rama muy vigorosa de la econometría. Se han dado avances importantes en la determinación del número de factores y en las técnicas de estimación. Se han combinado con las técnicas estándares de un VAR para identificar los efectos de la política monetaria en un gran número de variables, para el examen de los ciclos internacionales y para analizar los choques externos que afectan a las economías modernas.

En general, uno de los más fecundos campos de aplicación de los modelos de factores ha sido la construcción de indicadores económicos. Dos de los ejemplos más destacables son los indicadores coincidentes mensuales de la Reserva Federal de Chicago para Estados Unidos (Chicago Fed National Activity Index conocido también como CFNAI) y del área del euro (EUROcoin). El primer indicador corresponde al primer componente principal estático de un gran número de variables macroeconómicas y es el sucesor del modelo original de Stock y Watson (1989) que se mantuvo hasta 2003. Para el caso del EUROcoin se trata del componente principal dinámico (Breitung y Eickmeier, 2005).

En el análisis económico de corto plazo uno de los problemas más sensibles continúa siendo el rezago en la disponibilidad de información importante. Al respecto, es ilustrativa la necesidad que tienen las autoridades monetarias para contar con la información del PIB, el cual en la mayoría de los países que cuentan con sistemas de Cuentas Nacionales es producido con frecuencia trimestral y, además, es revisado posteriormente en la medida que llega información nueva.

El problema de pronosticar en tiempo real se ha denominado nowcasting (Banbura et ál., 2010). Este término corresponde también a un método que permite, en general, obtener estimativos de indicadores esenciales por medio de datos relacionados con la variable objetivo pero que son recolectados con una frecuencia mayor, mensual normalmente, y dados a conocer de manera oportuna, aunque no necesariamente sincronizada. Para el caso del crecimiento del PIB trimestral es posible contar con estimativos de producción y encuestas cualitativas divulgados mensualmente. Asimismo, existen otros datos de frecuencia similar que también pueden ser informativos sobre el estado de la economía.

La disponibilidad de nueva información lleva a revisar los pronósticos del PIB; sin embargo, el interés no es solamente revisar, sino entender qué causa la revisión de esos últimos. Para ese tipo de análisis es necesario modelar la dinámica conjunta de los datos mensuales y de la variable trimestral objetivo. Al respecto, los trabajos seminales son los de Evans (2005) y Giannone et ál. (2008) quienes, además de trabajar en un marco unificado los dos tipos de variables, proponen soluciones para estimar cuándo hay observaciones faltantes al final de la muestra como consecuencia de los rezagos en la publicación de la información. El marco estadístico general más utilizado es un modelo factorial à la Forni at al. (2000), aunque el método de estimación puede variar.

vi. El modelo Markov-Switching y su utilización en la cronología del ciclo

Una forma de encontrar los puntos de giro para un sistema de indicadores a la Stock y Watson es la utilización del algoritmo de Bry y Boschan (1971), constituyéndose de esa forma un sistema mixto con un bloque paramétrico y otro no paramétrico. Sin embargo, con el modelo no lineal Markov-Switiching también es posible tener un enfoque totalmente paramétrico con un sistema de indicadores à la Stock y Watson y, al tiempo, detectar los puntos de giro de la serie examinada. 
Es claro que, con la asimetría, la dependencia o la volatilidad características del ciclo económico un modelo no lineal como el M-S tiene ventajas en el análisis, frente a modelos lineales como los autoregresivos (AR), de media móvil (MA) o incluso los mixtos (ARMA). Dentro de la familia de modelos no lineales que se ha desarrollado hace relativamente poco tiempo, el M-S tiene sus fortalezas. La principal ventaja del modelo M-S frente a otros modelos no lineales se encuentra en que, además de capturar no linealidades asociadas con la asimetría característica del ciclo, permite reconstruir la cronología de los estados de la economía en cada instante, a través de la inferencia basada en la información de la muestra.

La versión sencilla de Hamilton (2005) plantea que el modelo M-S es especialmente apropiado en el estudio de eventos que lleven a cambios abruptos en el comportamiento de una variable $x_{t}$. En ese caso, se puede modelar de la siguiente forma:

$$
x_{t}=c_{s_{t}}+\phi x_{t-1}+\varepsilon_{t}
$$

Con $\varepsilon_{t} \sim N\left(0, \sigma^{2}\right)$. De otro lado, $s_{t}$ es una variable aleatoria que, como resultado de los cambios institucionales, puede tener dos valores $s_{t}=1$ para $t=1,2, \ldots t_{0}$ y $s_{t}=2$ para $t=t_{0}+1+t_{0}+2$, ... Una descripción completa de la ley de probabilidad que gobierna los datos observados requeriría de un modelo probabilístico para explicar la razón del paso de $s_{t}=1 a s_{t}=2$. La especificación más simple sería que $s_{t}$ es la realización de una cadena de Markov de dos estados de la naturaleza:

$$
\operatorname{Pr}\left(s_{t}=j \mid s_{t-1}=i, s_{t-2}=k, \ldots, x_{t-1}, x_{t-2}, \ldots\right)=\operatorname{Pr}\left(s_{t}=j \mid s_{t-1}=i\right)=p_{i j}
$$

Con el supuesto según el cual $s_{t}$ no se observa directamente y solo se puede inferir a través del comportamiento de $x_{t^{\prime}}$ los parámetros necesarios para describir completamente la ley de probabilidad que gobierna a esta última variable son: la varianza de la innovación gaussiana $\delta^{2}$, el coeficiente autorregresivo $\varnothing$, los dos interceptos $C_{1}$ y $C_{2}$ y y las dos probabilidades de transición y $p_{1}$ y $p_{2}$.

Este sistema (6)-(7) es la formulación básica pero es un buen punto de partida. En (6) puede darse la presencia de un orden autoregresivo superior o también la ausencia de elementos autorregresivos $(\varnothing=0)$. También pueden darse especificaciones probabilísticas más generales que la presentada en (7). Igualmente, es posible definir la permanencia o no del cambio de régimen definiendo el valor de $p_{22}$.

En el área de los ciclos económicos, además del trabajo de Hamilton (1989), se han dado desarrollos muy importantes en los trabajos de Krolzig (1997), quien trabaja con modelos M-S con vectores autorregresivos que examinan el tema de sincronización de ciclos de varios países. A su vez, el trabajo de Hamilton y Pérez-Quiros (1996) introduce la problemática de los indicadores líderes en el mundo no lineal de los modelos M-S.

Hamilton produce de manera periódica un indicador de recesión para los EE. UU., el cual se puede observar en la gráfica 6. ${ }^{14} \mathrm{El}$ indicador se basa en un trabajo anterior (Chauvet y Hamilton, 2006), en el cual los autores proponen la utilización de la metodología M-S para obtener la probabilidad de que ese país entre en una recesión. Esto se logra a partir del cálculo de la

14 El blog se puede consultar en el enlace: http://econbrowser.com/recession-index 
ley de probabilidad que gobierna el crecimiento del PIB (GDP, en este caso), sin condicionarlo a las fechas definidas por el NBER. De esa forma, es posible inferir los parámetros asociados a la extensión y a la magnitud de las recesiones. Para las estimaciones se utiliza el principio de máxima verosimilitud.

Hay un aspecto importante que Chauvet y Hamilton (2006) tienen en cuenta en su ejercicio; esto se refiere a las revisiones periódicas, muchas veces sustanciales, que se hacen al cálculo del GDP. Por esa razón, el indicador se construye con la información original revelada en un primer momento y que es la utilizada en el comité del NBER. Esta es la base de datos conocida como información en tiempo real del GDP recopilada por la Reserva Federal. Por esa razón, el resultado que se obtiene se refiere a la probabilidad de recesión para el próximo trimestre.

Gráfica 6. Indicador de recesión basado en el GDP de Estados Unidos

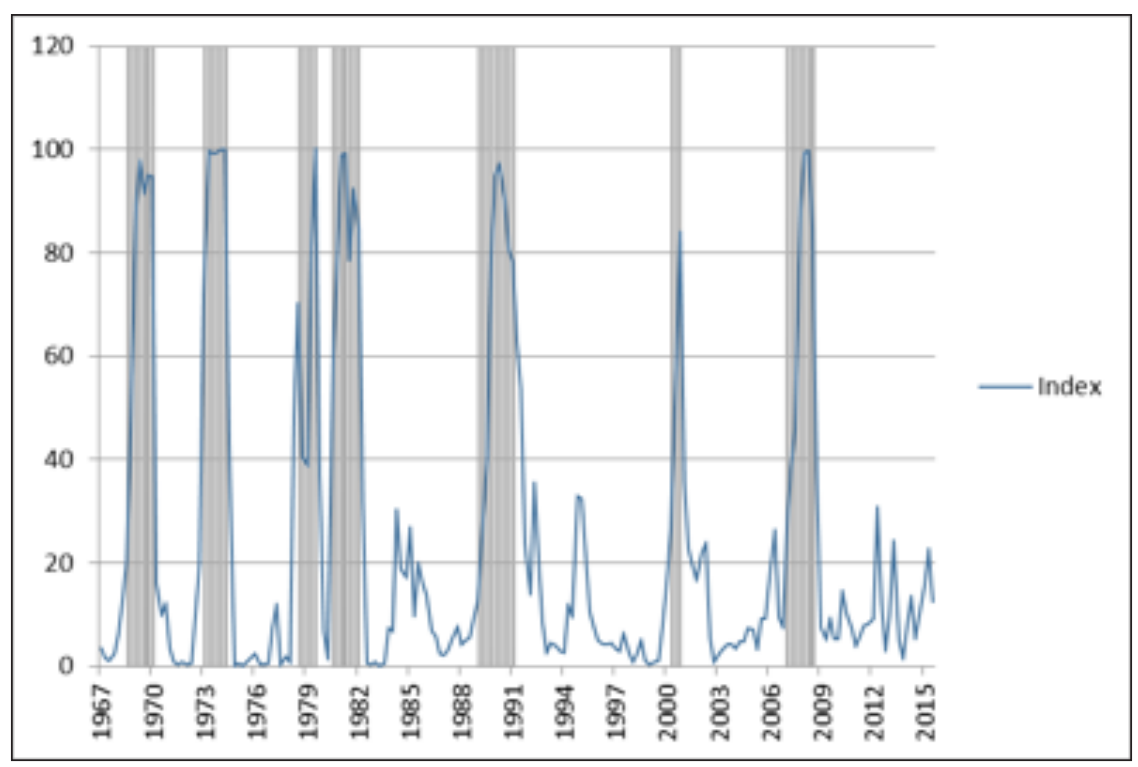

Fuente: Econbrowser.

Las áreas sombreadas en la gráfica corresponden a recesiones determinadas por el NBER, construidas con información en tiempo real y nunca revisadas posteriormente. En el trabajo original los autores definen una regla a partir de sus resultados: si el índice alcanza un valor superior al $67 \%$ puede declararse que la economía entró en una recesión en el trimestre anterior y se utiliza la muestra total para asignar una fecha probable para el inicio de ésta, definida para el valor más alto de $j$ para el cual Prob $(S t-j=1 \mid Y t)>1 / 2$ donde $S t=1$ indica una recesión. $Y$ una vez se declara la recesión su duración se extiende hasta que el índice cae por debajo de un valor de $33 \%$. En ese punto se define el fin de la recesión basado en el valor reciente más alto de $j$ para el cual Prob $(S t-j=1 \mid Y t)<1 / 2$. El ejercicio con el indicador se repite cada vez que se conoce el valor del GDP trimestral y se publica en el blog mencionado. El cálculo está disponible desde 1967 con datos simulados desde antes de 2005, cuando se realizó el primer ejercicio. 
vii. Nuevos indicadores: el internet como fuente de información para el análisis del ciclo

La utilización creciente del internet en los negocios y por parte de los hogares, ha traído consigo la posibilidad de que los registros electrónicos generados en esas operaciones puedan constituirse en una valiosa fuente de información, en la medida en que está disponible rápidamente y tiene un margen de error reducido.

Existen dos tipos de datos provenientes de la red que han mostrado ser útiles para el análisis del ciclo. Una primera posibilidad se encuentra en la innovación en los pagos que representa el uso cada vez más extendido de las tarjetas débito y crédito. La frecuencia de esos datos es diaria y puede servir para seguir el comportamiento del consumo de los hogares, prácticamente, en tiempo real. De otro lado, de un tiempo para acá, los analistas del ciclo han mostrado un gran interés en las búsquedas de los usuarios de Google. Esa empresa pone a disposición de los investigadores, por medio del instrumento Google Trends creado en 2006, las tendencias de las búsquedas que hacen sus usuarios. Las categorías propuestas por el instrumento reagrupan las pesquisas por tema y también por áreas geográficas.

Este último tipo de datos ha sido el más utilizado para examinar la coyuntura económica, en virtud de la facilidad para trabajar con el instrumento provisto por Google. En la medida en que el monitoreo oportuno de la actividad económica es un aspecto importante de la ejecución de la política económica, el potencial del instrumento es muy grande. Hay que tener en cuenta en todo caso que las series son cortas pues los datos están disponibles solamente desde 2004; a pesar de esto, hoy en día se cuenta con una buena cantidad de trabajos que exploran el potencial de las variables obtenidas con Google Trends.

Esa línea de investigación se inició con un trabajo de Choi y Varian (2009a), en el cual se ilustra el uso de Google Trends para hacer pronósticos sobre las ventas al por menor, ventas de automóviles, casas y tendencias de viaje en Estados Unidos. De acuerdo con el estudio, los pronósticos para esas variables podrían mejorarse introduciendo ese tipo de series en los modelos simples que utilizan la dinámica de la serie a ser pronosticada (modelos autoregresivos). Desde entonces se ha dado una amplia difusión de la información ofrecida por Google Trends para varios temas y se ha integrado también en modelos econométricos complejos (Bortoli y Combes, 2015).

En las gráficas 7 y 8 se presentan dos ejemplos de extracción de información con Google Trends que tendrían la posibilidad de utilizarse en el análisis del ciclo, en este caso de la economía canadiense. Los términos política monetaria y política fiscal parecieran generar un interés esporádico en el periodo estudiado. No parece haberse producido una tendencia cíclica desde la recesión de 2008 señalada en el área sombreada. Este es un resultado que difiere del encontrado por Tkacz (2003) quien realizó un ejercicio similar. Faltaría precisar, en todo caso, si los aumentos detectados corresponden a algún anuncio de las autoridades económicas canadienses.

\section{Cambios en la economía}

Además de los cambios en la volatilidad de la economía, también su estructura ha cambiado y esto ha llevado a reflexiones y ejercicios empíricos diferentes a los que desarrolló y 
Gráfica 7. Término de búsqueda "monetary policy", Canadá - Todas las categorías, enero de 2004 a diciembre de 2016, mensual

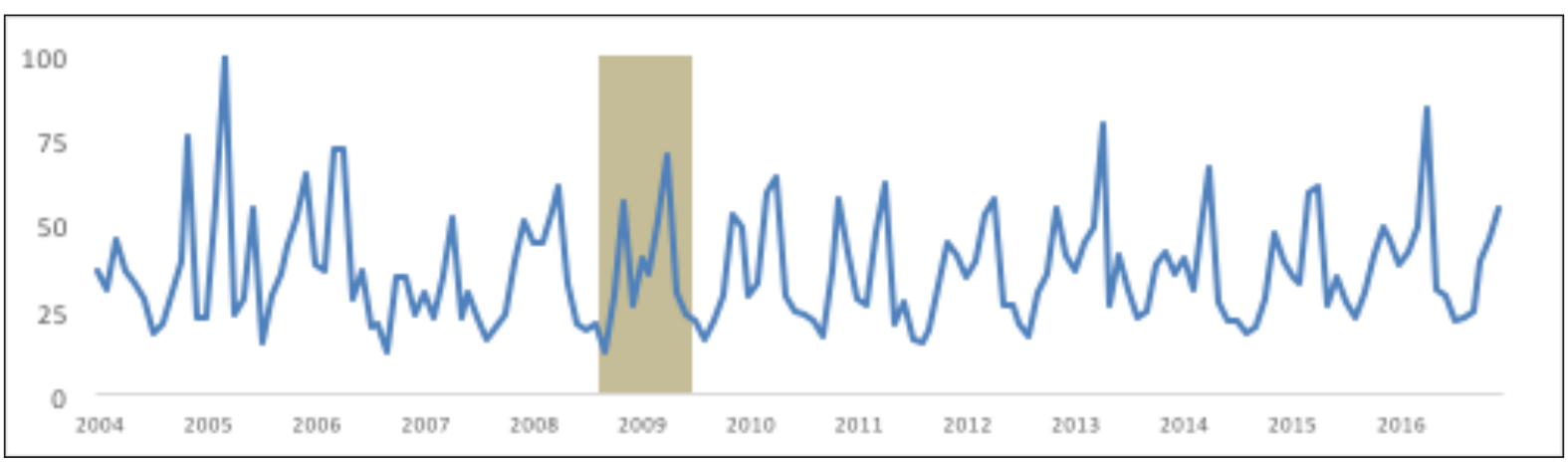

Fuente: elaboración propia a partir de datos de Google Trends.

Gráfica 8. Término de búsqueda "fiscal policy", Canadá - Todas las categorías, enero de 2004 a diciembre de 2016, mensual

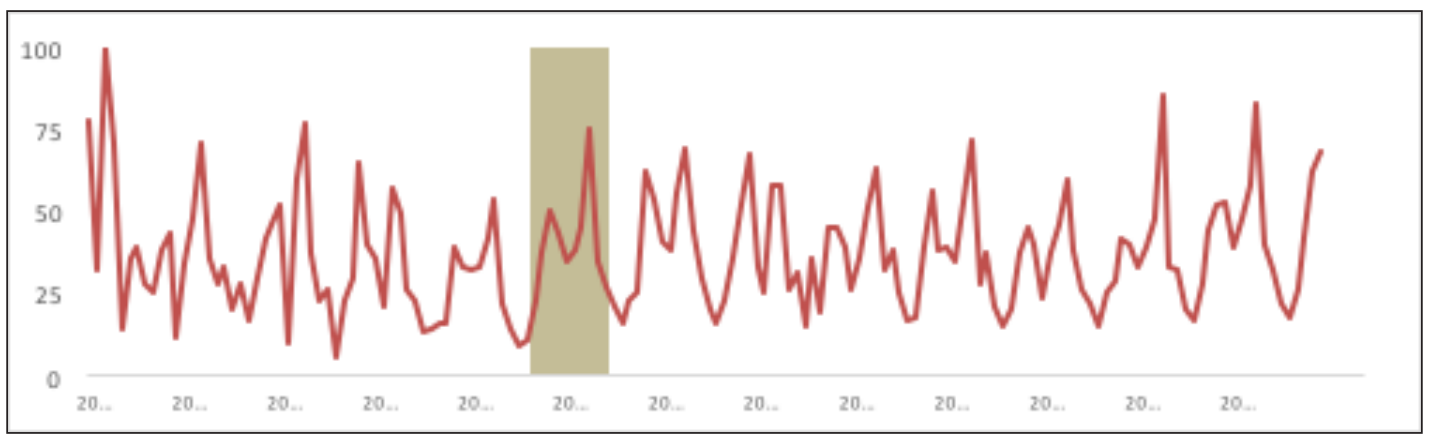

Fuente: elaboración propia a partir de datos de Google Trends.

difundió el NBER. Sinai (2010) propone una lista de hechos novedosos en los ciclos económicos modernos que deberían llevar a un replanteamiento del enfoque dominante sobre este fenómeno: i) la creciente importancia del llamado "factor financiero" en los ciclos de negocios, que se observa desde la segunda guerra mundial. Si bien esa característica siempre ha estado presente en los ciclos, los factores financieros tuvieron una gran importancia en la recesión de 2008, y se podría decir que los elementos financieros fueron determinantes en su evolución y duración. Se hace referencia a la burbuja de precios de activos que se observó con anterioridad al estallido de la crisis, así como al efecto riqueza que se generó al estallar la burbuja y a los efectos que el elevado endeudamiento de los hogares tuvo sobre su consumo; ii) las economías modernas, incluso aquellas en desarrollo, son cada vez más economías de servicios y menos de bienes. En los estudios del NBER eran predominantes los indicadores asociados a la producción de bienes, tales como el producto industrial y el empleo no agrícola. Según los datos de Sinai (2010) los empleos en el sector de servicios participaban en 2010 con un 86\% del empleo no agrícola en EE. UU. En la década de 1950, los servicios aportaban un $70 \%$ del 
empleo. El problema con la decreciente importancia del empleo del sector real es que continúa siendo una variable esencial de la cronología del ciclo en EE. UU. y que, adicionalmente, es muy volátil; iii) el tercer elemento está muy vinculado con el anterior y corresponde al mercado laboral y sus modificaciones contemporáneas; en efecto, en EE. UU. el enganche de trabajadores no agrícolas después de las crisis recientes ha sido muy lento. Este hecho ofrece una gran enseñanza. El indicador de trabajo no agrícola era hasta hace un tiempo coincidente pero actualmente debería ser considerado rezagado. Esta circunstancia afecta directamente las decisiones de cronología del ciclo que debe tomar el Comité respectivo.

El último aspecto hace referencia a los cambios en marcha que se observan en la economía global y que están alterando las características de los ciclos locales. Estos cambios son recurrentes en la historia, en la medida en que por diferentes razones las economías entran en declive y su papel dentro de las fuerzas que moldean los equilibrios internacionales es remplazado por economías en ascenso. Tal vez el caso reciente más ilustrativo es China, país cuya economía ha pasado a ser la segunda en tamaño dentro del contexto mundial, en términos del producto interno bruto.

\section{Cambios en la teoría}

La tensión entre la teoría de los ciclos y su análisis empírico persiste, aunque esos dos enfoques se han sofisticado cada uno por su lado. Sin embargo, desde el punto de vista de la teoría de los ciclos económicos, para muchos autores la mayoría de las principales preguntas aún están sin resolver.

En cuanto a lo que se refiere a la pregunta sobre el origen de los ciclos, se mantiene una dicotomía entre aquellos que postulan que en cada fase del ciclo está la semilla de la siguiente y quienes afirman, más recientemente, que la razón que explica las fluctuaciones está en los choques de distinto origen que sufren las economías. Al respecto, el principal problema se encuentra en que, aunque el impulso inicial pueda ser el mismo, los mecanismos de propagación pueden ser muy diferentes en cada caso. Esto finalmente se traduce en un serio problema de identificación. A pesar de ello, la teoría de los ciclos cambió radicalmente con el desarrollo de los modelos RBC y DSGE, caracterizados por tener unos sólidos fundamentos microeconómicos. En ese último tipo de modelos, los choques fiscales, de preferencias, monetarios y de oferta se propagan y amplifican de acuerdo con las decisiones intertemporales de los agentes, tomadas en un entorno de percepciones erróneas, información incompleta y rigideces reales y nominales.

Aunque los desarrollos de la econometría, la computación y de los métodos numéricos han permitido llevar esos modelos a los datos y validar algunas de sus hipótesis, lo cierto es que el inconformismo persiste en varios aspectos como discute Blanchard (2017). En cuanto al problema de identificación de los choques se refiere, se mantiene la crítica acerca del reflejo en las respuestas dinámicas a estos, así como de los supuestos impuestos a los modelos como una respuesta a la complejidad de la economía real. La correcta especificación de los modelos es un desafío muchas veces imposible de superar (Ng y Wright, 2013). 
De otro lado, la crisis del subprime en Estados Unidos y sus secuelas en las economías desarrolladas y emergentes dio pie a un intenso debate acerca de la relación entre la macroeconomía y las finanzas, y de las interacciones entre los ciclos de negocios y los ciclos financieros (Claessens et ál., 2012). El mundo académico recordó la historia de las recesiones que en el pasado estuvieron acompañadas de perturbaciones financieras y se hicieron varias propuestas para abordar el tema.

En esas condiciones revivió la discusión que estaba presente en los trabajos de los economistas que estudiaron la Gran Depresión de 1929, escribieron sobre ella y enfatizaron la importancia de las fricciones financieras y la inestabilidad inherente del sistema financiero. Fue así como se examinaron los aportes de Fisher (1933), Keynes (1936), Gurley y Shaw (1955), Minsky (1982) y Kindleberger (1978). ${ }^{15}$ Los avances se dieron de manera dispersa en diferentes ramas de la economía: macroeconomía, finanzas y teoría del equilibrio general.

Brunnermeier et ál. (2013) hacen una detallada revisión de la literatura moderna en la que conecta los desarrollos mencionados. La literatura relacionada deriva las restricciones financieras endógenamente de un contrato financiero óptimo y de una variedad de problemas de información en las finanzas corporativas. Los empresarios financian su inversión usando fondos propios y externos. Debido a las fricciones financieras endógenas, los empresarios enfrentan restricciones para obtener fondos externos. Asimismo, las restricciones financieras pueden variar a lo largo del ciclo. Para esos autores, si las fricciones financieras existen son importantes las consideraciones de liquidez y la distribución de la riqueza, a diferencia de si estas no están presentes. En ese mundo, el financiamiento externo para una empresa es más costoso que el interno con utilidades retenidas. Los problemas de incentivos hacen que los agentes más productivos emitan deuda, la limitación en ese caso es que choques adversos pueden afectar la riqueza de la firma endeudada, limitando con esto su capacidad futura para tomar riesgos.

De esa forma, en una economía con esas características podrían darse tres efectos macroeconómicos adversos. En primer lugar, un choque negativo transitorio puede ser muy persistente y durar hasta que los agentes reconstruyan su riqueza por medio de la retención de utilidades. De otro lado, una segunda implicación de la existencia de fricciones financieras es la amplificación del choque inicial debido a que los agentes tienen que vender su capital a precios de "quema", con la consecuencia de deprimir el precio del capital, afectándose su riqueza neta. Por último, la amplificación de los choques puede llevar a que las interacciones dentro de la economía aumenten el riesgo endógeno. Los riesgos de crédito pueden verse desplazados por los de liquidez. Todos esos mecanismos tienen profundos efectos en los agregados macroeconómicos y en sus dinámicas. Las fricciones financieras pueden crear ciclos de negocios endógenos, en el sentido de producir fluctuaciones económicas aún sin la presencia de choques exógenos.

La propuesta de Borio (2014), es más radical. Para ese autor, las fricciones financieras no son suficientes para entender la problemática del ciclo financiero. Su enfoque se aleja del paradigma Frisch-Slutzky según el cual los choques exógenos por medio de mecanismos de propagación generan el ciclo de negocios. Su punto de vista estaría más cerca de los análisis de ciclos anteriores a la Segunda Guerra Mundial con fuerzas endógenas que perpetúan los

15 Así como los de Patinkin (1956) y Tobin (1969), quienes enfatizaron la trascendencia de la estabilidad financiera en las economías monetarias. 
ciclos irregulares. En ese sentido, cada fase del ciclo genera la siguiente. En su enfoque es necesario también evitar la incorporación de expectativas racionales en las teorías porque su presencia oscurece el análisis pues lleva a resultados artificiales. Debe permitirse, de otro lado, que el riesgo sea estado-dependiente. En otras palabras, el riesgo debe variar de acuerdo con el estado de la economía, la riqueza y las hojas de balance. Por último, según Borio (2014) es indispensable tener en cuenta el carácter monetario de las economías modernas, algo que no está presente en los modelos RBC y DSGE. Para mejorar el cálculo o medición del ciclo es fundamental incluir variables financieras, partiendo de que el ciclo financiero es más largo que el ciclo de negocios.

Otro tema muy discutido se refiere a la naturaleza sincronizada que tiene el patrón del ciclo en los diferentes sectores de una economía y que es punto resaltado en la definición del NBER. Al respecto, Christiano y Fitzgerald (1998), explican que los macroeconomistas se concentran en entender la persistencia de los aumentos y descensos de la actividad agregada. La omisión del examen de la sincronización entre sectores es un reflejo de la dificultad conceptual que existe de pensar una economía con diferentes sectores. Los esfuerzos revisados no son satisfactorios en su mayoría, lo cual lleva a Christiano y Fitzgerald (1998) a concluir que todavía no existe una teoría aceptada de los co-movimientos y que, tratándose de un elemento central de los ciclos económicos, la teoría de los ciclos continúa siendo un rompecabezas.

En Colombia, el desarrollo de indicadores de coyuntura se dio al tiempo del del sistema estadístico. En la construcción de este último fueron muy importantes las escuelas de ingeniería en Medellín y Bogotá, las cuales instauraron las primeras cátedras de estadística, a principios del siglo XX. El principio para impartir esa disciplina era muy claro: la recolección de estadísticas, su tratamiento y análisis eran esencial para los negocios. Además de divulgar los principios de la disciplina, los catedráticos fueron también muy críticos de los primeros intentos para organizar la producción de estadísticas en Colombia (Ley 63 de 1914), al tiempo que publicaron importantes trabajos que con rigurosidad científica diseccionaron la situación económica de su región. ${ }^{16}$

Las ideas de estos autores, así como la escuela que instauraron con sus cátedras, fueron determinantes en la organización de los departamentos estadísticos de las instituciones creadas por recomendación de Kemmerer en 1923: la Contraloría General y el Banco de la República. ${ }^{17}$ La labor de estas entidades fue la base del sistema estadístico colombiano moderno y en su desarrollo se encuentra su impronta. De hecho, el Departamento Administrativo Nacional de Estadística (DANE) fue creado en 1953 a partir de la Dirección Nacional de Estadística, que a su vez tenía en su origen a la Oficina Nacional de Estadística de la Contraloría General de la República.

Alejandro López, tal vez el más importante de los autores involucrados, emprendió en 1936 la construcción de un índice de la actividad económica colombiana. Este índice no es otra cosa que un barómetro a la usanza de los construidos en la década de los años veinte en Estados Unidos y Europa. De esa forma, se trata del primer indicador de la actividad económica agregada que se construyó en el país.

16 Ver, entre otros, López y Rodríguez (1914) y López (1915).

17 De acuerdo con la tesis de Mayor (2002). 
El índice de López está compuesto por trece indicadores recopilados por la Contraloría General, todos ellos se llevan a índices con el año base en 1934 e información anual para 19271936. Los índices son los siguientes: ferrocarriles (pasajeros, carga y valor total de la producción), comercio (valor de los exportaciones y de las importaciones), café (valor exportado y cantidad), producción de oro, recaudos tributarios, consumo de ganado mayor, valor del numerario emitido, valor de la compensación de cheques e índice de los valores bursátiles. Una vez calculados los respectivos índices se construyó un indicador agregado con el promedio aritmético de todos ellos (ver la gráfica 9).

Gráfica 9. Colombia - Índice de actividad económica

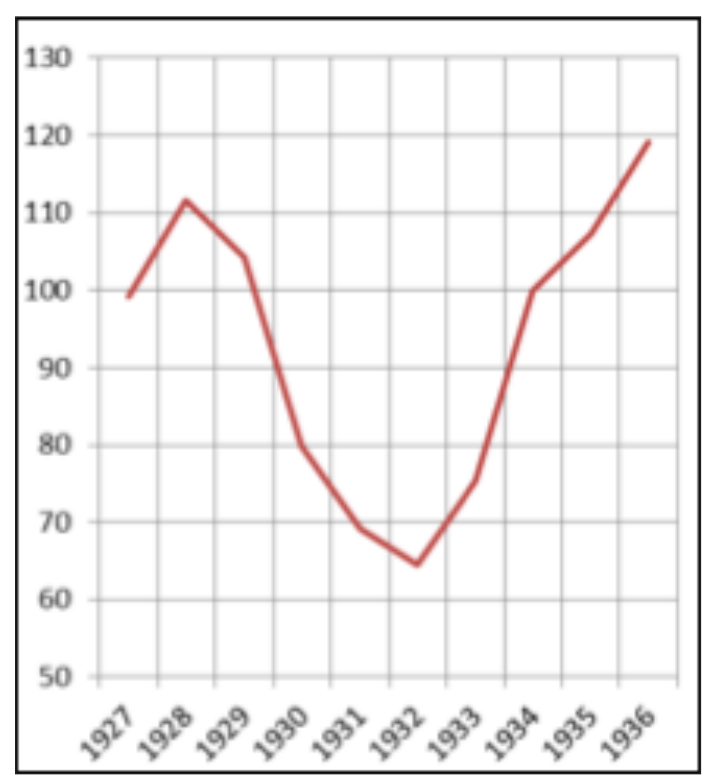

Fuente: López (1937) y cálculos propios.

El índice agregado captura ex post el efecto de la gran crisis mundial en la economía colombiana. De acuerdo con el indicador, se observa como la economía alcanzó una sima en 1932 y posteriormente se recupera con gran rapidez. Para 1935 la economía había alcanzado prácticamente el pico precrisis de 1928 y había seguido de largo, lo que llevo al autor a hacer un rudimentario pronóstico según el cual el índice avanzaría todavía unos diez puntos en 1937 (López, 1937).

Es claro que el barómetro colombiano estaba fuera de su tiempo. El esfuerzo de López fue mayúsculo y culminaba una tesonera labor para introducir ideas modernizantes a Colombia, dentro de las cuales se encontraba la construcción y el uso de las estadísticas. En este caso, sin embargo, los barómetros habían sido ya expulsados de los principales centros académicos por su incapacidad para adelantarse a la gran crisis. Habían sido reemplazados por las novedosas propuestas del NBER para las cuales Colombia, como muchos países en desarrollo, no estaba preparada debido a la debilidad de su sistema estadístico.

En 1947 se publica otro índice general de actividad elaborado por Torres (1947) y publicado por el Banco de la República. Si el trabajo de López era tardío, el de Torres resultaba obsoleto. 
Su enfoque metodológico también se apoyó en los barómetros y por eso fue duramente criticado en una reseña a su trabajo (Meyer, 1950). Textualmente la comentarista afirma:

Desde hace por lo menos un decenio, economistas y estadísticos han reconocido unánimemente las ventajas que tienen los cálculos de ingreso, producto y gasto nacionales sobre cualquier índice sintético de la actividad económica. En efecto, mientras estas series proporcionan una medida integral de la actividad económica de acuerdo con los factores que la determinan $y$, consecuentemente, de las fluctuaciones que presenta a lo largo del tiempo, los índices permiten, a los sumo, obtener una indicación del sentido y magnitud de dichas variaciones a través de los cambios registrados por series estadísticas relativas a ciertos fenómenos importantes, pero aislados. La misma estructura de los índices sintéticos puede dar lugar a que presenten indicaciones falsas; así ocurre cuando las actividades no captadas por el índice presentan movimientos contrarios a la tendencia de las series incluidas en el mismo. (Meyer, 1950, p. 319)

La dureza del comentario apuntaba a destacar los avances que ya se empezaban a tener en los cálculos de cuentas nacionales para América Latina (Domínguez, 1947) e incluso internamente en el Banco de la República y que eran ignorados por Torres. La única referencia de este autor hacia esos trabajos estaba en la utilidad que podrían tener para ponderar adecuadamente los índices que conformaban el barómetro (Torres, 1947, p. 175).

Para matizar la crítica hay que reconocer que es cierto que los barómetros ya habían sido abandonados para la época por la academia internacional, pero los indicadores estilo NBER convivían (y siguen conviviendo) con los sistemas de cuentas nacionales. De otro lado, hay que rescatar el esfuerzo de recolección de datos mensuales de Torres. Aunque también hay que tener en cuenta que la selección de series que llevó a cabo tiene grandes vacíos, como por ejemplo haber dejado por fuera la producción agrícola con el argumento de que podía estar siendo capturada por otros indicadores presentes en el índice, como los de transporte. Así mismo, el tratamiento de las series y su incorporación al índice adolece de serios problemas conceptuales. Tal vez esa sea la explicación del comportamiento espasmódico que presenta el índice de actividad general en algunos periodos (ver la tabla 2 y la gráfica 10).

Torres utilizó para el cálculo del índice general el promedio geométrico de 6 series de indicadores compuestos, construidos con información desde enero de 1934 hasta diciembre de 1946. Las series compuestas corresponden a la producción, las finanzas, el comercio, el transporte, el consumo y la hacienda pública.

\section{La experiencia colombiana con los sistemas de indicadores}

Los indicadores à la NBER llegaron tardíamente a Colombia. El primer esfuerzo conocido lo realizó el Ministerio de Hacienda, apenas hacia 1988, mientras que en el panorama internacional para entonces ya eran un instrumento establecido en muchos países desarrollados y algunos en desarrollo.

Cuando comienza a difundirse en el mundo la visión del NBER sobre los ciclos, la realidad era que en Colombia el sistema estadístico era muy precario (McGreevey, 1975). Como se mostró anteriormente, los requisitos de información para poder llegar a tener un buen análisis eran 
Tabla 2. Índice general de la actividad económica colombiana

\begin{tabular}{|c|c|c|c|c|c|c|c|c|c|c|c|c|c|}
\hline \multicolumn{14}{|c|}{ Indice General de la Actividad Económica Colombiana } \\
\hline \multicolumn{14}{|c|}{ Base para todos los indices: $1934=100.0$} \\
\hline Meses & 1934 & 1935 & 1936 & 1937 & 1938 & 1939 & 1940 & 1941 & 1942 & 1943 & 1944 & 1945 & 1946 \\
\hline Enero & 90,6 & 109,5 & 115 & 139,4 & 137,3 & 151,1 & 163,3 & 156,1 & 191,5 & $5 \quad 233,5$ & 233,3 & 307,4 & 372,9 \\
\hline Febrero & 94 & 108,1 & 112,5 & 129,8 & 134,9 & 148,9 & 158,6 & 160,1 & 174,3 & 231,2 & 263,9 & 293,9 & 369,2 \\
\hline Marzo & 95,8 & 104,9 & 111,7 & 136,6 & 140,2 & 160,6 & 154,8 & 171,9 & 184,4 & 243,6 & 261,9 & 284,6 & 380,8 \\
\hline Abril & 98,1 & 102,7 & 112,3 & 130,8 & 130 & 152,1 & 163,3 & 175,2 & 188,1 & 231,4 & 267,3 & 306,3 & 371,7 \\
\hline Mayo & 101,7 & 103,6 & 111,1 & 26,3 & 135,4 & 159,9 & 164 & 190,4 & 193,9 & 256 & 263,2 & 309,4 & 413,4 \\
\hline Junio & 98,5 & 99,6 & 114,3 & 36,7 & 144,9 & 158,6 & 160,1 & 179,9 & 213,1 & 252,3 & 260,6 & 320,5 & 396,5 \\
\hline Julio & 2,7 & 7,4 & & & 9,2 & & 172 & 80,1 & 208,8 & 260 & 269 & 335,6 & 432,6 \\
\hline Agosto & 106 & 105,2 & 116,9 & 136,6 & 145,8 & 106,2 & 158,2 & 157,2 & 198 & 249,5 & 275,8 & 337,1 & 423,2 \\
\hline Septiembı & 100,2 & 102,2 & 115,4 & 131,5 & 144,2 & 153,5 & 153,4 & 177,8 & 216,8 & 260,6 & 285,9 & 309,7 & 398,4 \\
\hline Octubre & 100,6 & 104,9 & 114,5 & 132 & 145,1 & 156,7 & 161,7 & 184,9 & 202,5 & 243,3 & 308 & 330,8 & 429,2 \\
\hline Noviembr & 100,8 & 99,7 & 120,8 & 134,7 & 147,5 & 159,7 & 166,9 & 187,3 & 204,2 & 249,1 & 280,2 & 320 & 414,4 \\
\hline Diciembre & 100,9 & 100,4 & 124,5 & 132,7 & 132,8 & 153,8 & 179,4 & 182,2 & 210,5 & 250,7 & 281,8 & 331 & 425,7 \\
\hline Total & 100 & 105,2 & 116,5 & 134,3 & 141,6 & 156,7 & 164,1 & 177,4 & 201,6 & 248,1 & 274,6 & 318,2 & 404,4 \\
\hline & & & & & & & & & & & & & \\
\hline
\end{tabular}

Fuente: Torres (1947).

Gráfica 10. Índice general de la actividad económica colombiana

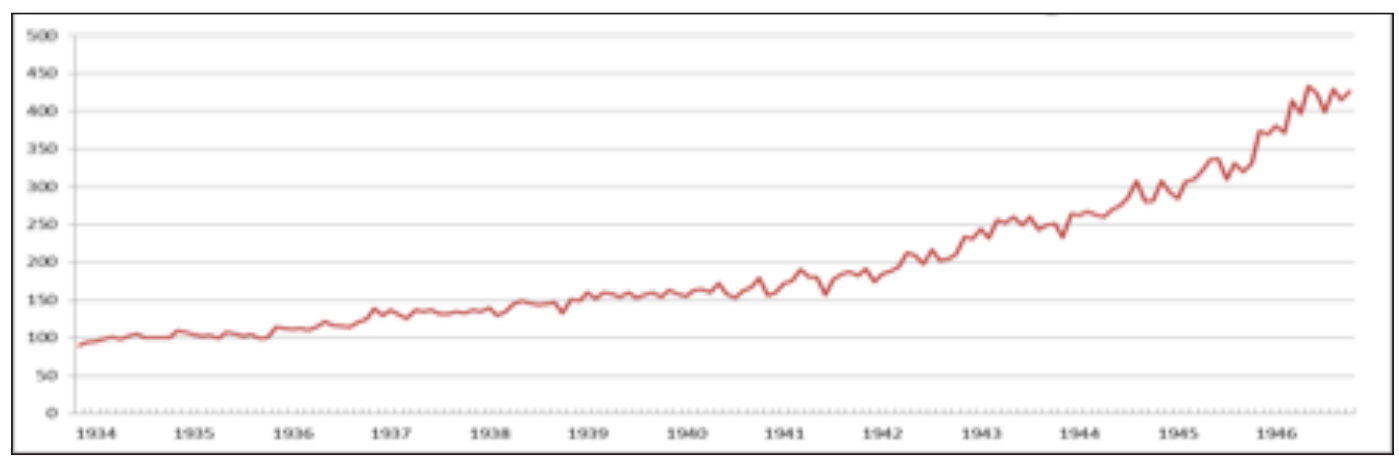

Fuente: Torres (1947).

inmensos y adicionalmente necesitaban variables de más alta frecuencia que la anual, la dominante en el país. Esa es la razón por la cual ese tipo de enfoque no pudo arraigar. De hecho, la preocupación más importante que se tenía en la década de 1930 era la construcción de un sistema estadístico moderno para lo cual se contaba con las instituciones creadas en 1923, la Contraloría y el Banco de la República.

Esas instituciones cumplieron juiciosamente su labor y comenzaron a generar información muy valiosa. Como en otras muchas latitudes, el país optó -siguiendo recomendaciones internacionales- por la construcción de un sistema de cuentas nacionales anuales en el Banco de la República y el desarrollo de información mensual para alimentar el primero y poder seguir la evolución de la actividad económica en el corto plazo, tanto en el Banco como en la Contraloría. El punto más alto de ese desarrollo se alcanzó en la década 1950 con la creación del DANE, entidad que empezó a elaborar el índice de precios al consumidor, las estadísticas laborales y del sector real. Posteriormente, las Cuentas Nacionales pasaron al DANE y el Banco de la República se concentró en la producción de las estadísticas de la balanza de pagos y las variables monetarias, conservando para sí también la producción de las cuentas financieras y del índice de precios al productor. 
Un problema sentido en los primeros años de funcionamiento del sistema estadístico, y que perduró un buen tiempo, era la demora en la entrega de cifras. La necesidad de contar con información oportuna para el diagnóstico coyuntural llevó a que en 1979 una entidad privada (Fedesarrollo), comenzara a producir una encuesta mensual de opinión a los empresarios colombianos, siguiendo una tradición en ese tipo de sondeos que se inició en Alemania después de la Segunda Guerra Mundial. De hecho, la denominada Encuesta de Opinión Empresarial fue puesta en funcionamiento gracias a la asesoría de la Fundación Ebert de ese país (Caballero, 1995). Este enfoque -que ampliaré más adelante- fue seguido por otros sondeos y, poco a poco, se consolidó como una herramienta indispensable para el seguimiento de la actividad económica.

Por la misma época y también urgido por sus necesidades de análisis coyuntural, el Departamento Nacional de Planeación hizo varios estudios internos para el cálculo del piB trimestral (Cardozo, 1982 y Silva y Ramirez, 1979). Finalmente, el DNP terminó contratando un estudio externo que con técnicas econométricas generaba esa misma serie (Carrizosa y Botero, 1984). Este cálculo se realizó periódicamente hasta que en agosto de 1997 el DANE produjo un PIB trimestral, utilizando para esto la metodología de las cuentas nacionales. ${ }^{18}$

A pesar del avance en la construcción de estadísticas en Colombia, nunca existió una entidad equivalente al NBER que produjera y mantuviera un sistema de indicadores, ni un Comité encargado de determinar una cronología del ciclo. El primer intento (en 1988) no respondió en realidad a un propósito explícito por oficializar esa última, sino más bien a una necesidad de seguimiento de la coyuntura y, de la misma manera, fue esta la motivación de los trabajos que le siguieron. Las fechas tanto de recesiones como de expansiones que se definieron en los diferentes trabajos no pasaron de ser opiniones de los investigadores involucrados. Es más, en el país no existe esa preocupación y cuando ha surgido el tema hace carrera la idea de definir el comienzo de una recesión por la llamada regla de aproximación del PIB. En otras palabras, se aceptaba la existencia de un valle si el PIB trimestral crecía negativamente durante dos trimestres consecutivos. Esta, como se mencionó previamente, es una definición muy cuestionada en los países y entidades que hacen cronología del ciclo.

En la tabla 3 se resumen las principales investigaciones sobre sistemas de indicadores tipo NBER que se han realizado hasta el momento en el país, así como la técnica que utilizan y la definición de ciclo que adopta cada uno. El primer esfuerzo para construir un sistema de indicadores es el de Melo et ál. (1988), de ahí en adelante se produjeron una gran cantidad de trabajos que utilizaron muchas de las técnicas descritas antes.

Para Melo et ál. (1988), la noción de ciclo es la clásica. Para el análisis es esencial construir un ciclo de referencia, entendido como el índice o magnitud que refleja el movimiento de la actividad económica agregada y a partir del cual se pueden determinar si las series estudiada son líderes, coincidentes o rezagadas. La utilización del PIB como ciclo de referencia es rechazada por dos razones: i) se trata de una estadística anual que no es conveniente para el análisis de corto plazo, e ii) incluye sectores como la agricultura que tienen un comportamiento independiente del ciclo urbano y manufacturero, el más importante dentro de la actividad agregada.

18 La serie del DANE pudo calcularse desde el primer trimestre de 1994. 
Para la construcción del ciclo de referencia Melo et ál. (1988) utilizan la metodología del índice de difusión por fases, la cual consiste en la determinación de la expansión y contracción en todas las series seleccionadas. Se compara en cada momento el número de series que se están expandiendo con las que están en contracción; a partir de ese cálculo se definen las diferentes fases que puede tener el índice, ya sea que las series en expansión superen a las que están en contracción, se igualen, o también que las ultimas superen a las primeras. Con esa medición puede establecerse si la economía está en expansión, se está contrayendo o está en un punto máximo o mínimo. Matemáticamente, el índice de difusión está definido como la primera derivada -o la pendiente- de la curva del ciclo. En esas condiciones, para obtener el ciclo de referencia es necesario acumular el índice de difusión por fases, en tanto se trata de una variable discreta.

Para la construcción del índice de referencia descrito es necesario un trabajo previo de depuración de las 73 series mensuales preseleccionadas. ${ }^{19}$ Una vez elegidas, las series fueron deflactadas y desestacionalizadas y se determinaron las fechas de cada fase del ciclo específico para cada una de ellas. Solo una vez terminado este proceso es posible construir el índice de difusión y el correspondiente ciclo de referencia. Las fechas de expansión y contracción definidas en este trabajo se resumen en la tabla 3.

Un segundo trabajo pionero fue el de Ripoll et ál. (1995), los autores aplicaron la metodología de la OECD, una modificación de la propuesta del NBER conocida también como método de fases aplicada al concepto de ciclo de crecimiento. El método utiliza cálculos sucesivos de medias móviles para suavizar la serie original. En la investigación construyeron dos ciclos de referencia de diferente frecuencia (mensual y trimestral) con la serie del índice real de producción industrial. Una vez construidos los ciclos de referencia se utilizaron técnicas econométricas (polinomio de Almon, VAR) con el fin de determinar si dos grupos de series tienen algún tipo de relación con el ciclo de referencia. La combinación de dos enfoques: estadística descriptiva y econometría, permite construir un sistema de indicadores con series adelantadas y rezagadas en relación con el ciclo de referencia. En el caso de la frecuencia mensual la serie adelantada es la productividad mientras que las rezagadas son el IPC total y algunos componentes del IPP de acuerdo con la clasificación por destino económico (CUODE). Para el caso trimestral la variable adelantada es el consumo final y las rezagadas son los diferentes componentes de la inversión.

A mediados de la década de 1990 el DNP patrocinó la construcción de un sistema de indicadores. El resultado final de la investigación fue la construcción de un ciclo mensual de referencia y un indicador avanzado (Maurer et ál., 1996 a, b). El ciclo de referencia es un índice compuesto elaborado a partir de un promedio no ponderado de 54 variables desestacionalizadas, no todas de la misma longitud. El ciclo corresponde al periodo comprendido entre febrero de 1960 y julio de 1996, aunque en el documento únicamente se presenta desde 1970.

Aunque en este caso también se utilizó la metodología modificada de la OECD, la diferencia con Ripoll et ál. (1995) está en que para estos últimos autores el ciclo de referencia fue construido con una sola variable. Sin embargo, el fundamento conceptual sigue siendo el mismo:

19 La preselección se llevó a cabo con criterios de frecuencia, consistencia metodológica, seriedad institucional de las fuentes y calidad estadística. Una vez efectuado el proceso fueron eliminadas 23 series por "falta de comportamiento cíclico, baja calidad o duplicidad" (nota al pie del anexo 1 de Melo et ál., 1988). 
se busca obtener un ciclo de crecimiento. El cálculo de este ciclo se lleva a cabo como la diferencia entre la serie original del índice compuesto y la tendencia, esta última estimada a partir de un promedio móvil de orden cinco. Una vez se cuenta con el ciclo de referencia los autores establecen una cronología de los puntos de giro y de las expansiones y contracciones, reproducida en la tabla 3.

Para el cálculo del índice avanzado se utilizó información desde 1970. El procedimiento es similar al utilizado para el cálculo del ciclo de referencia. En primer lugar, se establecen los puntos de giro de las series y, posteriormente, cuáles de ellas son líderes del ciclo de referencia; al final, las elegidas solamente fueron diez del total de series examinadas. Un aspecto que llama la atención de este trabajo es el tono de precaución que tienen las conclusiones de los autores. Ante las grandes dificultades que enfrentaron advierten sobre los riesgos que tiene la actualización del sistema y sobre la necesidad de mejorar el cálculo del índice avanzado.

El Banco de la República llevó a cabo varios esfuerzos para construir un sistema de indicadores. Los resultados del primer grupo de trabajos se divulgaron al comienzo del nuevo milenio tanto para el índice coincidente (Nieto y Melo, 2001; Melo et ál., 2001; Nieto, 2003) como para el avanzado (Melo et ál., 2003). La metodología de cálculo para los dos indicadores fue la de Stock y Watson (1989, 1991 y 1992), modificada por los autores.

Como se explicó, la metodología de Stock y Watson incorpora las propiedades estadísticas de las series individuales, así como las propiedades conjuntas de estas. Asimismo, el método utiliza un criterio de optimización para obtener un factor común. Así, se formaliza la idea según la cual el ciclo de referencia se debe construir a partir de los co-movimientos de las series; en otras palabras, se trata de obtener una variable no observada que corresponde al estado de la economía. La modificación busca obtener el estado de equilibrio del modelo, algo que no se alcanza en el original. De esa forma,

la metodología parte de la hipótesis de que existe un grupo de $n$ variables económicas observables $X_{1 t}, \ldots . . X_{n t}$, integradas de orden uno relacionadas contemporáneamente con las condiciones generales de la economía y que además pueden tener otros movimientos que no están asociados con esta variable. Por lo cual cada serie coincidente, además de tener un componente atribuible a la variable común, tiene un componente único o idiosincrático que no está correlacionado con los componentes idiosincráticos de las otras series ni con el factor común. (Melo et ál., 2001)

Una vez definida la metodología se escogieron las variables que podrían estar asociadas al ciclo de la economía. De las 100 variables estudiadas se escogieron nueve series que cumplían los siguientes criterios: ${ }^{20}$ i) importancia económica, ii) periodicidad y iii) cumplimiento de algunos requisitos estadísticos. Para esto se realizaron pruebas de raíz unitaria y correlación cruzada entre cada una de las series y el índice de producción industrial.

Si bien el propósito del trabajo no fue específicamente construir una cronología del ciclo, el índice coincidente obtenido para el periodo enero de 1980 - agosto de 2001 captura, según

20 Las series elegidas para el indicador coincidente fueron: situación económica actual de la industria, volumen actual de pedidos, índice de producción real de la industria manufacturera sin trilla de café, índice de empleo de obreros de la industria, producción de cemento, demanda de energía más consumo de gas residencial e industrial, importaciones reales sin bienes de capital ni duraderos, cartera neta real y saldo real de efectivo. 
los autores, los hechos estilizados de la economía colombiana. Los resultados en términos de las contracciones de la economía colombiana concuerdan con los alcanzados en otros trabajos (Melo et ál., 1988; Ripoll et ál., 1995) y dan evidencia de una nueva desaceleración de la actividad económica en 1996 y una contracción pronunciada en 1998 y 1999 (ver tabla 4). De otro lado, la evolución del indicador se asemeja a la del índice de producción industrial para la frecuencia mensual y al PIB para el caso trimestral.

Por su parte, el indicador avanzado contiene 13 series que provienen de diferentes sectores de la economía. ${ }^{21}$ Se considera que las variables son líderes si las estadísticas de co-movimiento y las pruebas de poder predictivo de cada una de ellas, en relación con el indicador coincidente y el índice de producción industrial, son las apropiadas.

Unos años después (y aún dentro del marco de la investigación en el Banco de la República) se llevaron a cabo dos trabajos centrados exclusivamente en la cronología del ciclo colombiano (Arango et ál., 2008; Alfonso et ál., 2012). En el primer trabajo se aplicó el algoritmo de Bry Boschan (1971) a la serie del índice de producción industrial para el periodo de enero de 1980 y marzo de 2007 y al PIB trimestral entre los primeros trimestres de 1977 y 2007 . En el segundo, en el cual participaron algunos de los autores del primer trabajo, se examina el PIB trimestral en el periodo de marzo de 1977 y diciembre de 2011, de acuerdo con el criterio del Center for Economic Policy Research para definir una recesión, según el cual esta puede caracterizarse por un crecimiento negativo de ese agregado durante, al menos, dos trimestres consecutivos. Así mismo, se actualizó el ejercicio con el algoritmo Bry-Boschan para el índice de producción industrial incorporando desde enero de 1975 hasta junio de 2011. Finalmente, se calculó un índice de difusión para 41 series consideradas con mayor capacidad para representar la actividad económica. Se consideraron varias alternativas de cálculo y finalmente se definió que "el índice de difusión acumulado (aplicando el algoritmo de Bry-Boschan a cada serie) era la mejor herramienta para caracterizar el ciclo de negocios en Colombia" (Alfonso et ál., 2012, p. 21).

Estos últimos trabajos permitieron una caracterización bastante completa del ciclo colombiano en el periodo considerado y desde la concepción clásica del NBER. Si bien no hay coincidencia con los trabajos anteriores los principales hallazgos serían los siguientes (ver tabla 3 y gráfica 11): i) entre 1975 y 2011 se han presentado cuatro ciclos de negocios completos con duraciones promedio de 81 meses (6,8 años); ii) las expansiones duran en promedio 65 meses (5,4 años) mientras que las contracciones tardan 16 meses (1,3 años).

Vale mencionar que actualmente en Colombia no se utiliza ninguno de los sistemas de indicadores reseñados para hacer análisis de coyuntura. En algunas instituciones se publican grupos de variables que son consideradas líderes pero la conexión con los trabajos originales no está documentada. El conocimiento acerca del comportamiento de las variables en el ciclo y de sus interrelaciones se perdió y tendría que reconstruirse toda la historia para poner de nuevo los sistemas en operación y que puedan ser útiles en el examen del ciclo.

21 El conjunto final de series es el siguiente: pedidos en el fin de mes, expectativas de la situación económica en los seis meses siguientes, clima de los negocios, indicador de confianza, cuentas bancarias reales, M1, cuentas de ahorro, préstamos hipotecarios reales aprobados, préstamos hipotecarios reales otorgados, licencias de construcción, tasa de interés de los CDT 90 días, tasa de interés real de los CDT 90 días e importaciones reales de bienes de consumo.

tiempo\&economía

Vol. 6 N. 1 - Enero - Junio del 2019

p. 123

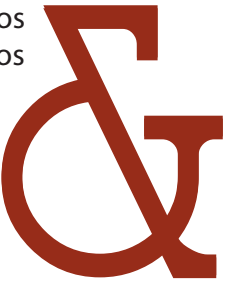




\section{Gráfica 11. Fases del ciclo económico en Colombia determinadas según el algoritmo Bry-Boschan aplicado al IPI}

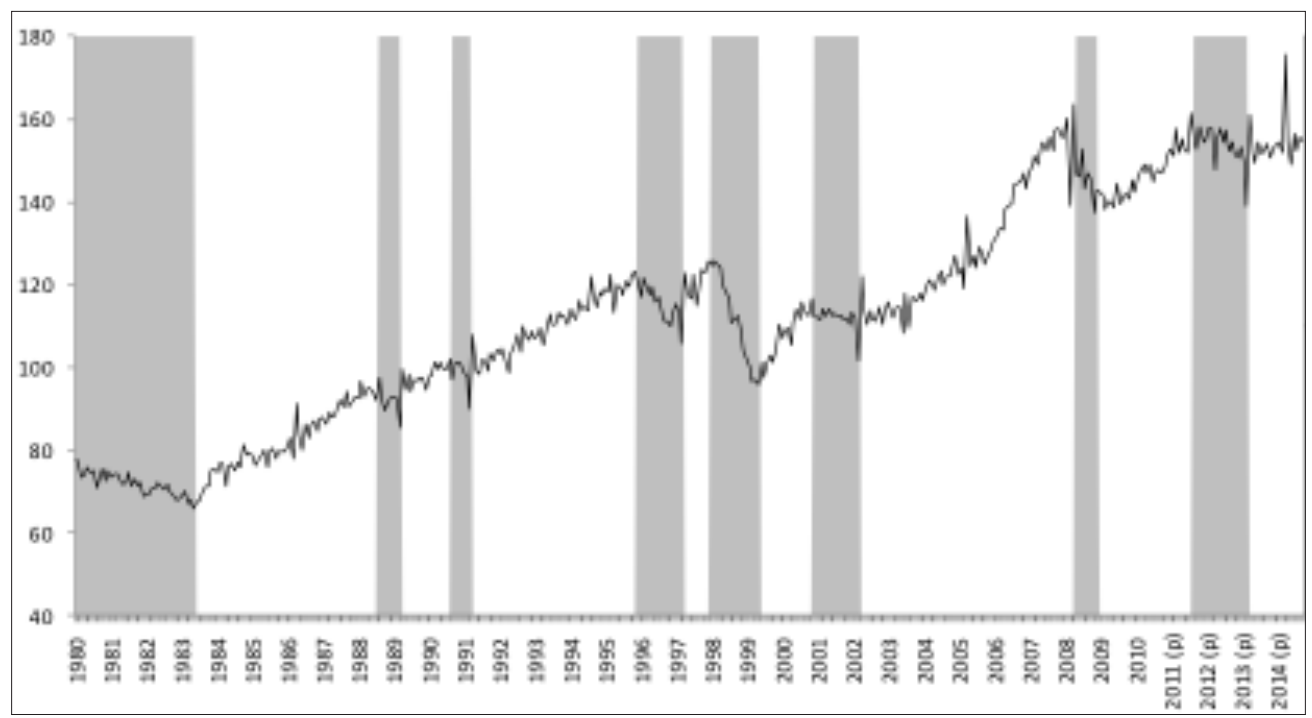

Fuente: cálculos propios. Actualizando el trabajo de Arango et ál. (2008).

\section{Desarrollos en el frente de los indicadores}

En Colombia, los trabajos recientes más importantes están en la tradición de los sistemas de indicadores, ya sea con la construcción econométrica de un agregado de variables que facilite el análisis del ciclo (Índice Mensual de Actividad Colombiana - IMACO, y nowcast) o de un sistema más cercano a la concepción del Conference Board (ALI).

En todo caso, esos ejercicios deben competir con un nuevo indicador: el de seguimiento a la economía (ISE) publicado desde abril de 2014 por el DANE. ${ }^{22}$ Se trata de un indicador mensual de desempeño de la actividad económica que tiene un rezago de alrededor de dos meses en relación con la publicación de las series originales que lo componen. El indicador sintético se construye a partir de la agregación ponderada, con la estructura de pesos de las cuentas nacionales, de nueve índices de frecuencia mensual asociados a la dinámica de los sectores que conforman el PIB. Para los meses de enero, febrero, abril, mayo, julio, agosto, octubre y noviembre se publican las variaciones mensuales, anuales y año corrido de las series originales, desestacionalizadas y la tendencia ciclo. La información del ISE para los meses marzo, junio, septiembre y diciembre, se realiza de manera simultánea con el PIB trimestral y para estos meses se incluyen los resultados del ISE desagregados y publicados por ramas de actividad económica. Por ejemplo, en el caso de la industria se usa la variación de la producción de los diferentes subsectores, obtenida de la Muestra Mensual Manufacturera. El objetivo del ISE es anticipar los "puntos de giro" de la actividad económica con horizontes de al menos dos meses.

22 Con información desde enero de 2000. 
Tabla 3. Cronología del ciclo

\begin{tabular}{|c|c|c|c|c|c|c|c|c|}
\hline \multirow[b]{2}{*}{$\begin{array}{l}\text { Mensual- } \\
\text { Trimestral }\end{array}$} & \multirow[b]{2}{*}{ Autor } & \multicolumn{3}{|c|}{ Puntos de quiebre } & \multicolumn{4}{|c|}{$\begin{array}{l}\text { Duración en meses/trimestres de los ciclos y las } \\
\text { fases }\end{array}$} \\
\hline & & Pico & Valle & Pico & $\begin{array}{c}\text { Ciclo } \\
\text { completo } \\
\text { (Pico a } \\
\text { pico) } \\
\end{array}$ & $\begin{array}{c}\text { Expansión } \\
\text { (Valle a } \\
\text { pico) }\end{array}$ & $\begin{array}{c}\text { Ciclo } \\
\text { completo } \\
\text { (Valle a } \\
\text { valle) } \\
\end{array}$ & $\begin{array}{c}\text { Contracción } \\
\text { (Pico a } \\
\text { valle) }\end{array}$ \\
\hline \multirow{4}{*}{ Mensual } & \multirow{4}{*}{$\begin{array}{c}\text { Marla Ripoll, } \\
\text { Martha Misas, } \\
\text { Enrique Lopez } \\
\text { (1995) }\end{array}$} & 1981:Ene & 1983:Ago & 1984:Dic & 48 & 17 & N.A. & 31 \\
\hline & & 1984:Dic & 1986:Ene & 1988:Ago & 45 & 32 & 29 & 13 \\
\hline & & 1988:Ago & 1989:Jun & 1990:Ene & 17 & 7 & 42 & 10 \\
\hline & & 1990: Ene & 1992:Jun & N.A. & N.A. & N.A. & 37 & 30 \\
\hline \multirow{5}{*}{ Mensual } & \multirow{5}{*}{$\begin{array}{c}\text { Fabio H. Nieto, } \\
\text { Luis Fernando } \\
\text { Melo (2001) }\end{array}$} & 1980: Ene & 1983:May & 1988:Sep & 105 & 65 & N.A. & 40 \\
\hline & & 1988:Sep & 1989:Mar & 1990:Sep & 24 & 18 & 71 & 6 \\
\hline & & 1990:Sep & 1991:Mar & 1996:Ene & 65 & 59 & 24 & 6 \\
\hline & & 1996:Ene & 1997:Mar & 1998:Ene & 24 & 10 & 73 & 14 \\
\hline & & 1998:Ene & 1999:Jun & N.A. & N.A. & N.A. & 27 & 17 \\
\hline \multirow{3}{*}{ Mensual } & \multirow{3}{*}{$\begin{array}{l}\text { Luis Fernando } \\
\text { Melo V., Fabio } \\
\text { Nieto, Mario } \\
\text { Ramos V. }{ }^{*} \\
\text { (2003) }\end{array}$} & 1993:Ene & 1996:Jun & 1997:Abr & 52 & 10 & N.A. & 42 \\
\hline & & $1997: \mathrm{Abr}$ & 1998:Oct & 1999:Ago & 28 & 10 & 28 & 18 \\
\hline & & 1999-Ago & 2000:Dic & N.A. & N.A. & N.A. & 26 & 16 \\
\hline \multirow{5}{*}{ Mensual } & \multirow{5}{*}{$\begin{array}{c}\text { Viviana } \\
\text { Alfonso, Luis } \\
\text { Eduardo } \\
\text { Arango, } \\
\text { Fernando Arias, } \\
\text { Guillermo } \\
\text { Cangrejo, Jose } \\
\text { David Pulido } \\
\text { (2012) }\end{array}$} & 1980:Dic & 1983:Jul & 1990:Ago & 116 & 85 & N.A. & 31 \\
\hline & & 1990:Ago & 1991:Mar & 1995:Oct & 62 & 55 & 92 & 7 \\
\hline & & 1995:Oct & 1996:Oct & 1997:Dic & 26 & 14 & 67 & 12 \\
\hline & & 1997:Dic & $1999: \mathrm{Abr}$ & 2008:Ene & 121 & 105 & 30 & 16 \\
\hline & & 2008:Ene & 2009:Ene & N.A. & N.A. & N.A. & 117 & 12 \\
\hline \multirow{4}{*}{ Mensual } & \multirow{4}{*}{$\begin{array}{c}\text { Alberto Melo } \\
\text { Giraldo, } \\
\text { Mercedes } \\
\text { French Collazos } \\
\text { y Nils Andrés } \\
\text { Langeback } \\
\text { Rueda(1988) }\end{array}$} & & 1966:Ene & $1974: \mathrm{Abr}$ & N.A. & 100 & N.A. & N.A. \\
\hline & & 1974:Abr & 1975:Mar & 1980:Oct & 79 & 68 & 112 & 11 \\
\hline & & 1980:Oct & 1981:Jun & 1982:Abr & 18 & 10 & 76 & 8 \\
\hline & & $1982: A b r$ & 1985:May & 1987:Dic & 69 & 31 & 48 & 38 \\
\hline
\end{tabular}




\begin{tabular}{|c|c|c|c|c|c|c|c|c|}
\hline \multirow{6}{*}{ Mensual } & \multirow{6}{*}{$\begin{array}{l}\text { Herman Kamil, José David } \\
\text { Pulido, José Luis Torres } \\
\text { (2010) }\end{array}$} & & 1983:Ago & 1987:Ene & N.A. & 42 & N.A. & N.A. \\
\hline & & 1987:Ene & 1989:May & 1990:Abr & 39 & 11 & 70 & 28 \\
\hline & & 1990:Abr & 1991:Ago & 1995:Jun & 63 & 47 & 27 & 16 \\
\hline & & 1995:Jun & 1997:Ene & 1998:Mar & 33 & 14 & 66 & 19 \\
\hline & & 1998:Mar & 1999:Jul & 2000:Oct & 31 & 15 & 30 & 16 \\
\hline & & 2000:Oct & 2002:Feb & 2007:May & 80 & 64 & 31 & 16 \\
\hline \multirow{9}{*}{ Mensual } & \multirow{9}{*}{$\begin{array}{l}\text { Martin Maurer y Maria } \\
\text { Camila Uribe (1996) }\end{array}$} & & 1961:Sep & 1961:Oct & N.A. & 1 & N.A. & N.A. \\
\hline & & 1961:Oct & 1963:Feb & 1964:Ene & 27 & 11 & 17 & 16 \\
\hline & & 1964:Ene & 1966:Nov & 1967:Ene & 36 & 2 & 46 & 34 \\
\hline & & 1967:Ene & 1968:Ago & 1974:May & 88 & 69 & 21 & 19 \\
\hline & & 1974:May & 1976:Ene & 1978:Jul & 50 & 30 & 90 & 20 \\
\hline & & 1978:Jul & 1983:Ene & 1984:May & 70 & 16 & 85 & 54 \\
\hline & & 1984:May & 1984:Jul & 1986:Sep & 28 & 26 & 18 & 2 \\
\hline & & 1986:Sep & 1989:Jul & 1991:Abr & 55 & 21 & 61 & 34 \\
\hline & & 1991:Abr & 1993:Abr & 1994:Jul & 39 & 18 & 46 & 21 \\
\hline \multirow{9}{*}{ Mensual } & \multirow{9}{*}{$\begin{array}{c}\text { Martin Maurer, Maria } \\
\text { Camila Uribe y Javier Arturo } \\
\text { Birchenall (1996) }\end{array}$} & & 1961:Jul & 1963:Ene & N.A. & 18 & N.A. & N.A. \\
\hline & & 1963:Ene & 1963:Dic & 1966:Feb & 38 & 26 & 29 & 11 \\
\hline & & 1966:Feb & 1968:Ago & 1970:Ene & 48 & 17 & 57 & 30 \\
\hline & & 1970:Ene & 1972:Feb & 1974:Ene & 49 & 23 & 43 & 25 \\
\hline & & 1974:Ene & 1975:May & 1977:Mar & 39 & 22 & 40 & 16 \\
\hline & & 1977:Mar & 1977:Oct & 1978:Sep & 18 & 11 & 29 & 7 \\
\hline & & 1978:Sep & 1980:Nov & 1982:Jul & 47 & 20 & 38 & 26 \\
\hline & & 1982:Jul & 1985:Sep & 1987:Jul & 61 & 22 & 59 & 39 \\
\hline & & 1987:Jul & 1991:Mar & 1994:Sep & 87 & 43 & 67 & 45 \\
\hline \multirow{2}{*}{ Mensual } & \multirow{2}{*}{$\begin{array}{l}\text { Sergio Clavijo, Paula García } \\
\text { y Jonathan Malagón (2005) }\end{array}$} & & 1995:Mar & 1997:Oct & N.A. & 31 & N.A. & N.A. \\
\hline & & 1997:Oct & 1999:Feb & 2004:Mar & 78 & 62 & 48 & 16 \\
\hline \multirow{9}{*}{$\begin{array}{c}\text { Trimestral* } \\
*\end{array}$} & \multirow{9}{*}{$\begin{array}{l}\text { Carlos Alberto Castro } \\
\text { Iragorri (2003) }\end{array}$} & & 1985:Sep & 1986:Sep & N.A. & 12 & N.A. & N.A. \\
\hline & & 1986:Sept & 1986:Dic & 1988:Jun & 21 & 18 & 16 & 3 \\
\hline & & 1988:Jun & 1988:Dic & 1990:Jun & 24 & 18 & 25 & 6 \\
\hline & & 1990:Jun & 1990:Dic & 1992:Mar & 21 & 15 & 25 & 6 \\
\hline & & 1992:Mar & 1992:Jun & 1993:Mar & 12 & 9 & 19 & 3 \\
\hline & & 1993:Mar & 1994:Dic & 1995:Mar & 24 & 2 & 31 & 21 \\
\hline & & 1995:Mar & 1997:Mar & 1997:Sep & 30 & 6 & 27 & 24 \\
\hline & & 1997:Sep & 1999:Sep & 2000:Jun & 33 & 9 & 31 & 24 \\
\hline & & 2000:Jun & 2002:Mar & & N.A. & N.A. & 31 & 21 \\
\hline \multirow{6}{*}{ Trimestral } & \multirow{6}{*}{$\begin{array}{c}\text { Edgar Vicente Morcillo } \\
\text { Yepez (2013) }\end{array}$} & 1984:Mar & 1985:Mar & 1989:Dic & 23 & 19 & N.A. & 4 \\
\hline & & 1989:Dic & 1991:Mar & 1997:Dic & 32 & 27 & 24 & 5 \\
\hline & & 1997:Dic & 1999:Mar & 2003:Jun & 22 & 17 & 32 & 5 \\
\hline & & 2003:Jun & 2004:Jun & 2007:Sep & 17 & 13 & 21 & 4 \\
\hline & & 2007:Sep & 2009:Jun & 2011:Jun & 15 & 8 & 50 & 7 \\
\hline & & 2011:Jun & 2012:Mar & & N.A. & N.A. & 11 & 3 \\
\hline
\end{tabular}

* Los autores no construyen un ciclo de referencia como tal, pero utilizan tres ciclos de referencia ya construidos

**El autor expresa la duración de los ciclos y fases mensualmente a pesar de calcular el ciclo de referencia trimestralmente 
Tabla 4. Indicadores coincidentes

\begin{tabular}{|c|c|c|c|c|}
\hline Autor & Metodología & Período & $\begin{array}{c}\text { Número } \\
\text { de series } \\
\text { estudiada } \\
\text { s }\end{array}$ & $\begin{array}{l}\text { Número de } \\
\text { series } \\
\text { coincidentes }\end{array}$ \\
\hline $\begin{array}{c}\text { Marla Ripoll, Martha } \\
\text { Misas, Enrique López } \\
\text { (1995) }\end{array}$ & OECD & $\begin{array}{c}\text { Enero } 1981- \\
\text { Febrero } \\
1994 \\
\end{array}$ & 17 & 3 \\
\hline $\begin{array}{l}\text { Fabio H. Nieto, Luis } \\
\text { Fernando Melo (2001) }\end{array}$ & $\begin{array}{l}\text { Stock y Watson modificada: } 1 \text {. Las variables coincidentes } \\
\text { están cointegradas } 2 \text {. Se propuso un modelo estado- } \\
\text { espacio que tenga la propiedad de estado estacionario } \\
\text { 3.Se incluyen los efectos estacionales en el modelo } 4 \text {. Se } \\
\text { desarrolla una estrategia práctica para estimar los } \\
\text { parámetros desconocidos y proveer los valores iniciales } \\
\text { necesarios para la etapa de estimación }\end{array}$ & $\begin{array}{c}\text { Enero } 1980- \\
\text { Febrero } \\
2001\end{array}$ & 9 & 9 \\
\hline $\begin{array}{l}\text { Luis Femando Melo V., } \\
\text { Fabio Nieto, Mario } \\
\text { Ramos V. (2003) }\end{array}$ & $\begin{array}{c}\text { Stock y Watson (1989, 1991,1992) modificada. Siguiendo } \\
\text { los resultados de Nieto y Melo (2001) se modifica: 1.La } \\
\text { identificabilidad del modelo } 2 \text {. El procedimiento de } \\
\text { actualización del indice }\end{array}$ & $\begin{array}{c}\text { Enero 1980- } \\
\text { Diciembre } \\
2001\end{array}$ & 83 & 9 \\
\hline $\begin{array}{l}\text { Viviana Alfonso, Luis } \\
\text { Eduardo Arango, } \\
\text { Fernando Arias, } \\
\text { Guillermo Cangrejo, Jose } \\
\text { David Pulido (2012) }\end{array}$ & NBER & $\begin{array}{c}\text { Enero } 1975- \\
\text { Diciembre } \\
2011\end{array}$ & 41 & 41 \\
\hline $\begin{array}{c}\begin{array}{c}\text { Carlos Alberto Castro } \\
\text { Iragorri (2003) }\end{array} \\
\end{array}$ & 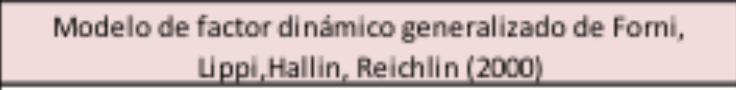 & $\begin{array}{l}\text { Enero 1984- } \\
\text { Marzo } 2003 \\
\end{array}$ & 70 & 4 \\
\hline $\begin{array}{l}\text { Alberto Melo Giraldo, } \\
\text { Mercedes French } \\
\text { Collazos y Nils Andrés } \\
\text { Langeback Rueda (1988) } \\
\end{array}$ & Índice de difusión por fases & $\begin{array}{c}\text { Enero } 1966- \\
\text { Dic } 1987\end{array}$ & 73 & 47 \\
\hline $\begin{array}{c}\text { Martin Maurer y Maria } \\
\text { Camila Uribe (1996) }\end{array}$ & OECD & \begin{tabular}{|l} 
Enero $1970-$ \\
Enero 1995
\end{tabular} & 54 & 54 \\
\hline
\end{tabular}

Fuente: elaboración propia. 
Tabla 5. Indicadores líderes

\begin{tabular}{|c|c|c|c|c|c|}
\hline Autor & Metodologia & Periodo & \begin{tabular}{|l|} 
Número \\
de series \\
estudiadas
\end{tabular} & $\begin{array}{l}\text { Número } \\
\text { de series } \\
\text { lideres } \\
\end{array}$ & Series Lideres \\
\hline \multirow{2}{*}{$\begin{array}{l}\text { Marla Ripoll, } \\
\text { Martha Msas, } \\
\text { Enrique López } \\
\text { (1995) }\end{array}$} & \multirow{2}{*}{ OECD } & \multirow{2}{*}{$\begin{array}{c}\text { Enero 1961- } \\
\text { Febrero } \\
1994\end{array}$} & \multirow{2}{*}{17} & \multirow{2}{*}{2} & Productividad \\
\hline & & & & & Consumo Final \\
\hline \multirow{13}{*}{$\begin{array}{l}\text { Luis Femando } \\
\text { Melo V., Fabio } \\
\text { Nieto, Mario } \\
\text { Ramos V. (2003) }\end{array}$} & \multirow{13}{*}{$\begin{array}{l}\text { Stock y Watson (19a9, } \\
\text { 1991,1992) madificada. } \\
\text { Siguiendo los resultados de } \\
\text { Nieto y Melo (2001) se } \\
\text { madifica: 1.La } \\
\text { identificabilidad del modelo } \\
\text { 2. El procedimiento de } \\
\text { actualización del indice }\end{array}$} & \multirow{13}{*}{\begin{tabular}{|c} 
Enero $1960-$ \\
Diciembre \\
2001 \\
\end{tabular}} & \multirow{13}{*}{83} & \multirow{13}{*}{13} & Demanda real por dinero \\
\hline & & & & & $\begin{array}{c}\text { Tasa de interés real de certificados de depósitos para los } \\
\text { bancos y las comporaciones a } 90 \text { dias }\end{array}$ \\
\hline & & & & & Area de constructión aprobada \\
\hline & & & & & Importación de bienes de consumo en términos reales. \\
\hline & & & & & Condiciones de negocios \\
\hline & & & & & Indicador de confianza \\
\hline & & & & & Numero de órdenes al final del mes \\
\hline & & & & & $\begin{array}{c}\text { Expectativas de la situación económica durante los } \\
\text { siguientes } 6 \text { meses }\end{array}$ \\
\hline & & & & & Cuentas corrientes reales \\
\hline & & & & & Cuentas de ahorros reales \\
\hline & & & & & Préstamos de construcción reales aprobadas \\
\hline & & & & & $\begin{array}{l}\text { Préstamos de construcción reales concedidas } \\
\end{array}$ \\
\hline & & & & & \begin{tabular}{|c|} 
Tasa de interés de certificados de depósitos para los bancos y \\
las corporaciones a 90 dlas \\
\end{tabular} \\
\hline \multirow{2}{*}{$\begin{array}{l}\text { Carlos Alberto } \\
\text { Castro Iragoeri } \\
\text { [2003] }\end{array}$} & \multirow{2}{*}{$\begin{array}{l}\text { Modelo de factor dinámico } \\
\text { generalizado de Fomi, } \\
\text { Lippi, Hallin, Reichlin (2000) }\end{array}$} & \multirow{2}{*}{$\begin{array}{l}\text { Enero } 1984 \\
\text { Marzo } 2003\end{array}$} & \multirow{2}{*}{70} & \multirow{2}{*}{2} & Tasa de utilización de la capacidad \\
\hline & & & & & Indice de productión industrial \\
\hline \multirow{7}{*}{$\begin{array}{c}\text { Herman Kamil, } \\
\text { José Dorvid } \\
\text { Pulido, José Luis } \\
\text { Torres }|2010|\end{array}$} & \multirow{7}{*}{$\begin{array}{c}\text { Se plantea un algocitmo de } \\
\text { búsqueda heuristico para } \\
\text { seleccionar un grupo óptimo } \\
\text { de variables lideres de tal } \\
\text { forma que su primer } \\
\text { componente principal } \\
\text { exhibiera una al ta correlación } \\
\text { adelantada con el crecimiento } \\
\text { anual acumulado doce meses } \\
\text { del pIB, que anticipará los } \\
\text { puntos de quiebre del cido } \\
\text { económico sin arrojar señales } \\
\text { falsas, y que minimizara los } \\
\text { errores de pronóstico sobre } \\
\text { dicho crecimiento. }\end{array}$} & \multirow{7}{*}{\begin{tabular}{|l|} 
\\
Enero $1990-$ \\
Marzo 2008
\end{tabular}} & \multirow{7}{*}{117} & \multirow{7}{*}{7} & Pedidos de la industria en comparación con el mes anterior \\
\hline & & & & & $\begin{array}{l}\text { Ventas del comercio en unidades en comparación con el mes } \\
\text { anterior }\end{array}$ \\
\hline & & & & & Indice de producción industrial de bienes de capital \\
\hline & & & & & Productividad por hora trabajada en la industria \\
\hline & & & & & Tasa de interés interbancaria real \\
\hline & & & & & Crecimiento de la demanda de energía \\
\hline & & & & & Crecimiento real de MB \\
\hline \multirow{14}{*}{$\begin{array}{l}\text { Edgar Vicente } \\
\text { Marcillo Yepez } \\
\text { [2013] }\end{array}$} & \multirow{14}{*}{ Modelo de factor dinámico } & \multirow{14}{*}{$\begin{array}{l}\text { Marzo } 1982 \\
\text { Junio } 2013\end{array}$} & \multirow{14}{*}{$\pi$} & \multirow{14}{*}{14} & Base monetaria \\
\hline & & & & & M1 \\
\hline & & & & & Depósitos en cuenta corriente de privados \\
\hline & & & & & $\begin{array}{c}\text { Comparación de la actividad productiva del mes actual con } \\
\text { respecto a la del mes anterior }\end{array}$ \\
\hline & & & & & Expectativa de producción en los próximos tres meses \\
\hline & & & & & Nivel de pedidos actual \\
\hline & & & & & Pedidas reobidas durante el mes \\
\hline & & & & & Situaxión económica actual \\
\hline & & & & & Indice seneral de la bolsa de Colombia \\
\hline & & & & & Capacidad unilizada de la industria \\
\hline & & & & & Indice de comercio al por menor \\
\hline & & & & & PIB de Estados Unidos \\
\hline & & & & & Tasa de desempleo de siete freas metropolitanas \\
\hline & & & & & Deoósito cuenta corriente \\
\hline
\end{tabular}


En Colombia, el ISE y el PIB trimestral son las piezas de información más importantes con que cuentan las autoridades económicas. El punto es que el ISE contiene la mejor información posible, la cual es utilizada en la elaboración del PIB trimestral, pero que es diferente metodológicamente de esa variable, en la medida en que no mide el valor agregado ni los impuestos. Adicionalmente, el DANE advierte, en su nota metodológica, que no se trata tampoco de una proyección del PIB, aunque, como se observa en la gráfica 12, sigue de cerca sus movimientos.

Gráfica 12. Colombia, PIB vs. ISE, variación \% anual

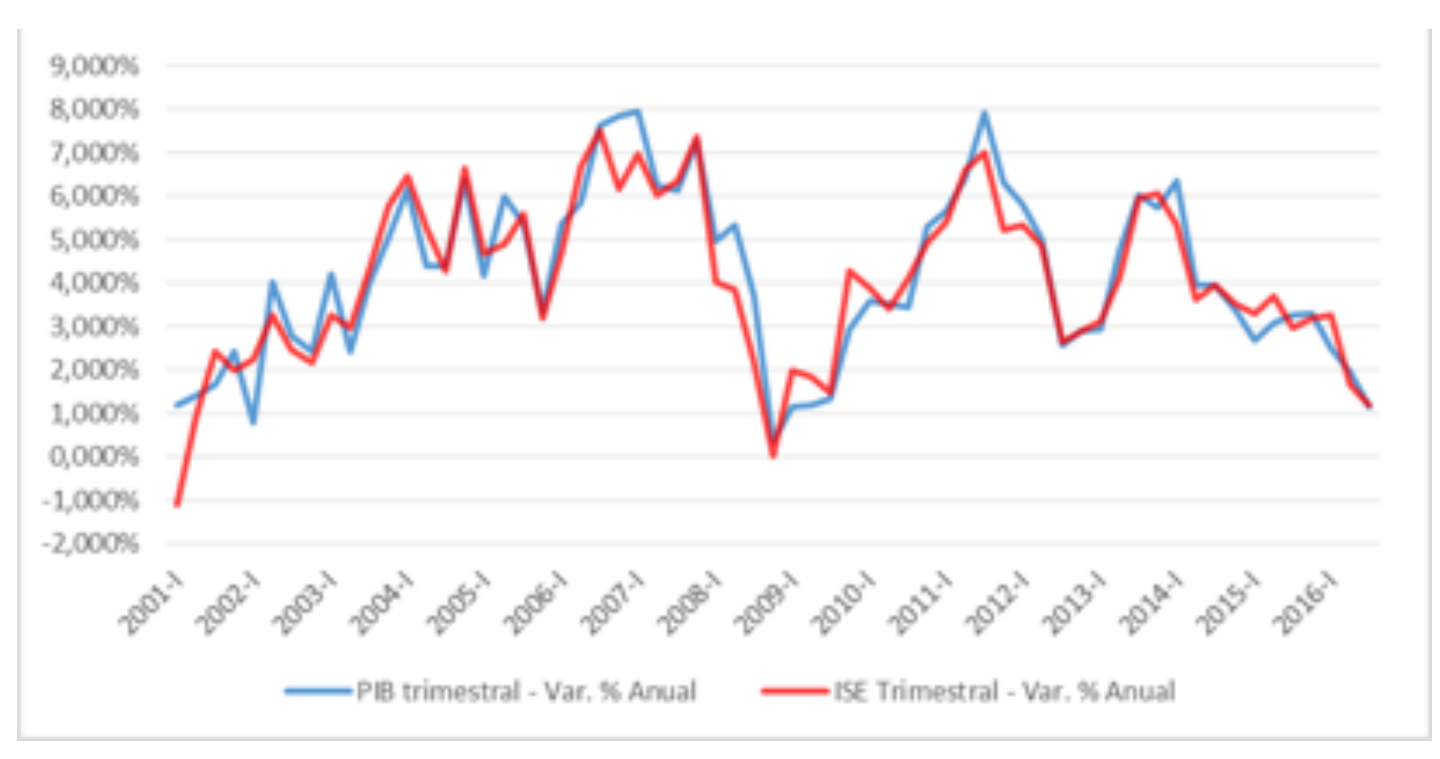

Fuente: DANE. Cálculos propios.

\section{Análisis de factores y factores comunes en Colombia}

En Colombia se ha utilizado la metodología de análisis de factores para la construcción de diferentes sistemas de indicadores. Castro (2003) es el autor del primer trabajo documentado que ha utilizado la técnica de factores comunes dinámicos, en este caso, el modelo generalizado. Este último fue propuesto por Forni et ál. $(1999,2000)$, y en esencia describe la dinámica de un conjunto de variables macroeconómicas con un grupo pequeño de factores comunes. De esa forma, cada variable puede expresarse como la suma de un componente común y un componente idiosincrático ortogonal al primero. En el estudio se utilizaron 70 series en total y la muestra utilizada cubre el periodo comprendido entre el primer trimestre de 1984 y el primer periodo de 2003. Una vez calibrado el modelo se obtienen los índices adelantados, coincidentes y rezagados para la economía colombiana. Por último, hay que destacar que el autor es muy cauteloso con sus resultados porque el número de series (70) es muy pequeño, relativamente, y no garantiza que se cumpla la consistencia de los estimativos.

La necesidad de contar con previsiones del PIB trimestral llevó al desarrollo de las dos metodologías complementarias con ese mismo propósito: i) componentes principales y ii) nowcast a partir de un modelo de factores dinámicos. 
En el primer caso, el IMACO (Índice Mensual de Actividad Colombiana) se sustenta, de acuerdo con sus autores (Kamil et ál., 2010), en un algoritmo de búsqueda heurístico que selecciona un grupo reducido de variables económicas que combinadas de manera adecuada posean tres propiedades deseables: i) una alta correlación adelantada con el ciclo económico, ii) que anticipe sus puntos de quiebre sin arrojar señales falsas, y iii) que minimice los errores de pronóstico sobre el crecimiento del PIB.

El algoritmo permitió identificar siete variables líderes de la actividad económica colombiana: los pedidos industriales, las ventas del comercio, la producción industrial de bienes de capital, la productividad por hora trabajada en la industria, la tasa de interés interbancaria real, el crecimiento real del agregado monetario M3 y la demanda de energía.

En este caso particular, de otro lado, los autores quieren construir un indicador líder sintético, pero para eso deben elegir un indicador coincidente que debe ser adelantado. La decisión que toman es construir una mensualización del PIB mediante la utilización de un algoritmo de optimización que minimiza la varianza de la serie resultante (mensual) preservando los crecimientos de la serie trimestral. El PIB mensual así construido tiene una dinámica con valles y picos, la cual fue contrastada favorablemente con la cronología del ciclo de Arango et ál. (2008).

Según sus autores, los resultados señalan que el IMACo anticipa los movimientos del PIB con cinco meses de adelanto y una correlación del 93\%, predice todos los puntos de quiebre del ciclo económico colombiano sin giros inexistentes, minimiza los errores de pronóstico sobre el crecimiento del PIB utilizado como referencia y exhibe una calidad predictiva superior a la de otros indicadores y a la de distintos modelos alternativos.

En el Banco de la República se elaboró un nowcast para Colombia siguiendo la metodología de Camacho y Pérez-Quiroz $(2009,2010)$ para construir esquemas de pronóstico de corto plazo, en este caso para el PIB trimestral. El modelo de factores dinámicos utilizado por los autores (Cristiano et ál., 2012) permite incorporar al pronóstico la información disponible en tiempo real con diferentes frecuencias de publicación. Este procedimiento posibilita que el pronóstico se actualice a medida que se produce información nueva.

Para el nowcast colombiano se tomaron inicialmente 26 series: 22 mensuales y 4 trimestrales. La depuración resultó en un grupo de 10 series de las cuales 9 tienen frecuencia mensual y tan solo una trimestral. Las variables fueron clasificadas como soft si son utilizadas para pronosticar el crecimiento anual del PIB (básicamente las series provenientes de encuestas cualitativas) o hard si pueden pronosticar el crecimiento del PIB trimestral (índice de producción industrial, ventas de comercio al por menor, demanda de energía total, horas extras trabajadas por la industria, M1+ahorros y producción de cemento). Con esas variables fue posible llegar a un único factor dinámico que explica el 53\% de la varianza del PIB.

Los pronósticos del nowcast fueron evaluados exitosamente frente a los que arrojan otras alternativas que incluyeron modelos ARX (modelo auto regresivo con variable exógena), ARMAX (auto regresivo y de media móvil con variable exógena), AR1 (auto regresivo de orden uno) y el promedio histórico del PIB. También se encontró que la incorporación del flujo de información en tiempo real proveniente de los indicadores de actividad que permite el nowcast mejora notablemente la estimación del crecimiento del PIB trimestral. 


\section{Otros indicadores}

Por su parte, en 2005 la Asociación Nacional de Instituciones Financieras (ANIF) publicó la metodología del indicador líder Au utilizado en los análisis de coyuntura de la institución. De acuerdo con Clavijo et ál. (2006), el indicador fue construido de acuerdo con la metodología del Conference Board. Lo cual significa, en este caso particular, el cálculo de un indicador compuesto, elaborado a partir de la agregación de doce variables consideradas líderes de la actividad económica; debido al adelanto de un trimestre que tienen en relación con la evolución del PIB. Las variables que conforman el ALı son ponderadas para la agregación, con base en una estructura que desde 1990, da a las variables monetarias mayor importancia y un peso similar a cada componente de los dos conjuntos de indicadores (monetarios y no monetarios). También fue utilizado un procedimiento de estandarización con el fin de "armonizar las volatilidades" de las variables y obtener una mejor agregación (Clavijo et ál., 2005, p. 12).

En Colombia también se ha explorado la información de Google Trends para la construcción de indicadores con el fin de hacer análisis coyuntural. Mejía et ál. (2013) proponen, desde el Ministerio de Hacienda, un sistema de indicadores de acuerdo con la metodología propuesta por Choi y Varian (2009a). La motivación de los autores para hacer su trabajo fue el rezago que existe en la información necesaria para hacer un análisis oportuno de la fase del ciclo que atraviesa en un determinado momento la economía.

La propuesta de Mejía et ál. (2013) se concentra en la construcción de indicadores sectoriales a partir de la metodología de Choi y Varian (2009a). Según los autores, en Colombia existe una falencia en la información secundaria sobre las ramas de actividad económica, y la escasa información existente se utiliza sobre todo como herramienta para pronosticar el producto agregado. La metodología propuesta por ellos contribuye a la creación de indicadores sectoriales para reducir la incertidumbre que genera la ausencia de datos al interior de los sectores productivos.

La utilización de la metodología permite la construcción de un grupo de indicadores que los autores denominan ISAAC -acrónimo de Indicadores Sectoriales Adelantados de Actividadcuyo propósito es anticipar las tendencias del PIB de nueve grandes ramas de la actividad de la economía colombiana en el corto plazo. Los indicadores sectoriales (agricultura, industria, comercio, construcción y transporte) construidos con Google Trends se agregan a los construidos de manera convencional con estadísticas e índices de producción para los otros sectores (minería, servicios financieros, servicios personales, electricidad, gas y agua e impuestos), para obtener un estimativo del PIB de cada sector y, finalmente, para el PIB total dentro de un ejercicio de newcast. Para el primer grupo de variables, las palabras buscadas se refieren a marcas de insumos o productos del sector, gremios y actividades relacionadas, que pueden afectar positiva o negativamente el crecimiento sectorial respectivo con las variables obtenidas con Google Trends.

Uno de los criterios de validación del instrumento fue una comparación con otros dos indicadores ya mencionados: el IMACO y el ALI. A nivel sectorial los autores destacan la capacidad del ISAAC para capturar de forma adecuada la dinámica de los sectores involucrados. En la gráfica 13 se muestra el comportamiento de estos indicadores comparado con el crecimiento del PIB, en el periodo 2009-2013. Como aclaran los autores, el IMACO se muestra en una gráfica separa- 
da, pues para este indicador la variable de referencia es el crecimiento del PIB anual (suma de los 4 trimestres), mientras que para el ALI, así como para el ISAAC+, es el crecimiento del PIB trimestral. El resultado es el esperado y cada indicador refleja el comportamiento de su variable de referencia. Tal es el caso del IMACo el cual predice la tendencia del PIB anual, mostrando un coeficiente de correlación de 0,91. Por su parte, el ALI y el ISAAC+ anticipan el comportamiento para el PIB trimestral, evidenciando una correlación de 0,84 y 0,89 respectivamente, para el periodo comprendido entre 2009 y lo corrido de 2013. Finalmente, en esta comparación el ISAAC+ muestra un buen desempeño, mostrando que es un indicador que está al mismo nivel de estos últimos.

Gráfica 13. Comparación del comportamiento de diferentes indicadores líderes

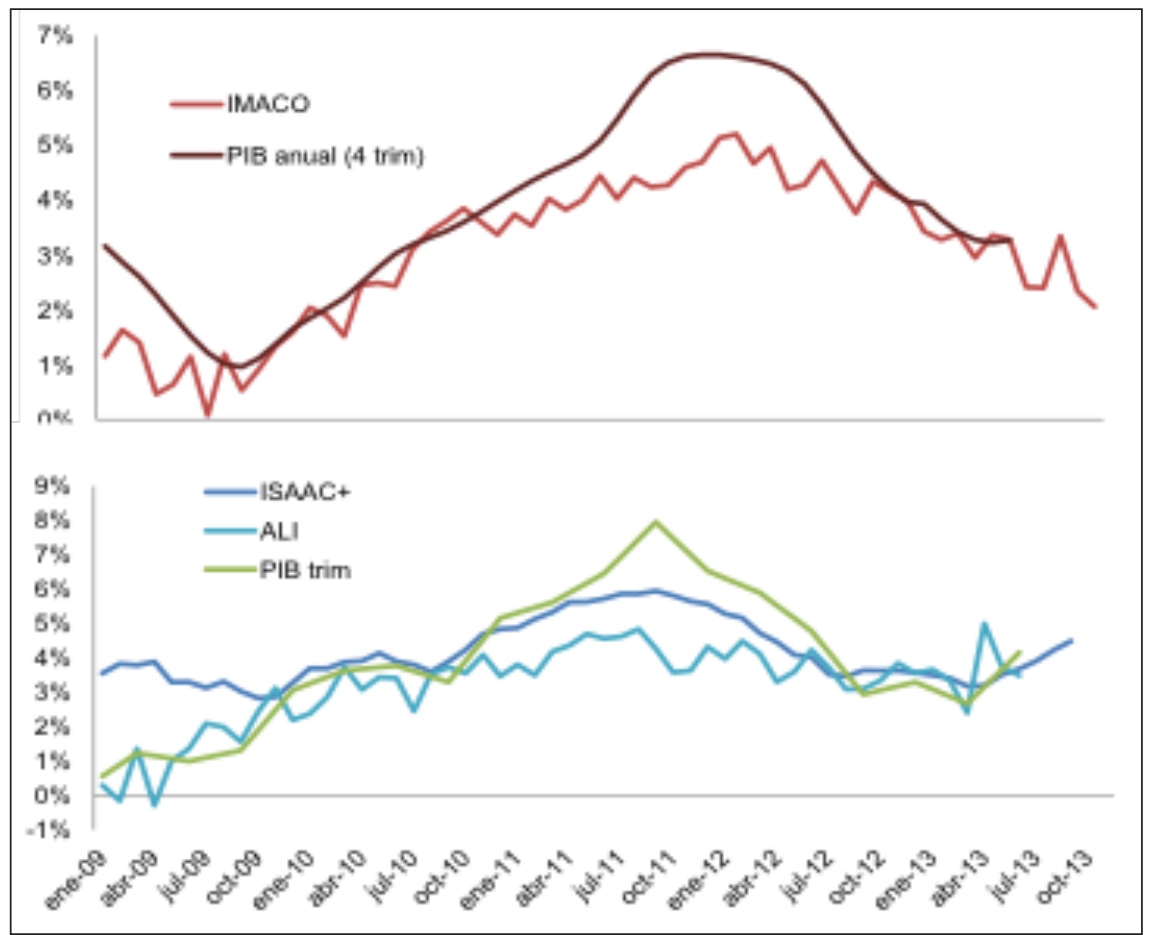

Fuente: Mejía et ál. (2013).

El triste final de esta historia es que muchos de estos indicadores, como es el caso de aquellos asociados a la tradición del NBER, ya no se utilizan en el análisis coyuntural. Sobreviven únicamente el ISE el cual no puede entenderse como un indicador avanzado; el ALI, el cual, por cierto, tiene una fecha metodológica poco trasparente; y el nowcast, cuyos resultados son poco divulgados. Todos los demás no se continuaron trabajando y al dejar de actualizarse van perdiendo su calidad y credibilidad hasta que finalmente desaparecen. En la tabla 6 se corrobora la última fecha en que se publicaron los indicadores, así como el momento en que se dieron a conocer.

¿Cuál puede ser la razón por la cual se hayan perdido esos esfuerzos valiosos? La historia contada hasta acá muestra que en el país hubo un momento en que se pudieron hacer siste- 
mas de indicadores con las técnicas más modernas, en la medida en que se pudo contar con un buen sistema de estadística y con una mano de obra especializada; sin embargo, faltó entender algo muy importante para que esos aportes no perecieran: los constructores de los instrumentos no fueron, normalmente, quienes los utilizaron. Los usuarios, por cierto, ocupan una delicada posición entre los constructores que entregan "Ilave en mano" su producto y aquellos que toman decisiones basados en ese tipo de herramientas. Los constructores, además, son reacios a participar en la utilización de la herramienta, pero son quienes conocen su detalle y sus secretos. Si el instrumento empieza a tener problemas, los usuarios no van a estar en capacidad de arreglarlo y el triste destino es que poco a poco se vayan volviendo obsoletos. Por esa razón, los trabajos pasaron a ser esfuerzos aislados porque no se apoyó su continuidad y difusión ni se cultivó el perfeccionamiento de los instrumentos ni su adecuado mantenimiento. El problema, al final, se encuentra en la concepción de un sistema estadístico donde estos instrumentos no han tenido un papel importante y no fueron articulados adecuadamente en la producción de estadísticas esenciales para el análisis del ciclo, lo cual debería cambiar con el ingreso de Colombia a la OECD, donde ese tipo de instrumentos son considerados esenciales.

Tabla 6. Indicadores líderes en Colombia

\begin{tabular}{|c|c|c|c|c|c|}
\hline INDICADOR & PERIODICIDAD & $\begin{array}{c}\text { INICIO DE } \\
\text { PUBLICACIÓN }\end{array}$ & $\begin{array}{c}\text { ÚLTIMA } \\
\text { PUBLICACIÓN }\end{array}$ & ENTIDAD & INFORME \\
\hline $\begin{array}{c}\text { IMACO - Índice } \\
\text { Mensual de Actividad } \\
\text { Económica* }\end{array}$ & Mensual & Junio de 2009 & Mayo de 2015 & $\begin{array}{c}\text { Banco de la Repú- } \\
\text { blica }\end{array}$ & Informe de inflación \\
\hline $\begin{array}{c}\text { ISAAC - Indicadores } \\
\text { Sectoriales Adelan- } \\
\text { tados de Actividad } \\
\text { Económica** }\end{array}$ & Mensual & Noviembre de 2013 & $\begin{array}{c}\text { Primer trimestre de } \\
2015\end{array}$ & $\begin{array}{c}\text { Ministerio de Hacien- } \\
\text { da y Crédito Público }\end{array}$ & $\begin{array}{c}\text { Informe Google } \\
\text { Trends ISAAC+ }\end{array}$ \\
\hline $\begin{array}{c}\text { ALI - ANIF Leading } \\
\text { Index }\end{array}$ & Mensual & $\begin{array}{c}\text { Enero de } \\
2005\end{array}$ & Diciembre de 2016 & $\begin{array}{c}\text { Asociación Nacional } \\
\text { de Instituciones Fi- } \\
\text { nancieras (ANIF) }\end{array}$ & Informe ALI \\
\hline
\end{tabular}

* Se deja de publicar debido al rediseño de la Encuesta Mensual Manufacturera (EMM) del DANE.

**El último informe mensual fue a diciembre de 2014, luego se publica el informe trimestral 2015 y no hay nuevas actualizaciones.

Fuente: elaboración propia.

\section{Conclusiones preliminares}

Este artículo se concentró en el estudio de los indicadores del ciclo en la tradición del NBER. Se mostró su origen, desarrollo y expansión en todo el mundo y en Colombia, en particular. El recuento mostró cómo se fueron perfilando dos grandes legados: la cronología del ciclo y la construcción de sistemas de indicadores compuestos de variables agrupadas de acuerdo con su papel dentro del ciclo económico según fueran avanzadas, coincidentes o rezagadas. 
En la gran mayoría de las economías desarrolladas y en muchas en desarrollo se construyeron instrumentos inspirados en los trabajos de los grandes economistas que trabajaron en el NBER. El análisis coyuntural que se hace hoy en muchos países tiene el sello de esa tradición. En el texto también se explica cómo los instrumentos se modernizaron como respuesta a los cambios estructurales de las economías, así como también a los desarrollos en el seno mismo de la estadística, la econometría y la teoría económica. Los cambios más importantes se dieron en la década de 1960 por las razones mencionadas, pero también por las modificaciones en el ciclo que llevaron a la diferenciación entre el ciclo clásico y el de crecimiento.

En Colombia se han realizado varios esfuerzos en la construcción de los indicadores, pero no ha existido realmente la tradición de la cronología del ciclo, aunque este último es un subproducto importante de la mayoría de los trabajos realizados. En otras palabras, aunque es posible obtener los periodos de auge y recesión de la economía colombiana a partir de los resultados del grupo de trabajos reseñados, esto no ha sido una preocupación en Colombia y, en consecuencia, tampoco ha habido mayor discusión acerca de las fechas de inicio y finalización de las recesiones, ni existe un encargo para que alguna entidad defina el comienzo y el fin de una recesión. En el país sigue la tradición de definir el comienzo de una recesión a partir de la regla poco científica de los dos trimestres negativos de crecimiento del PIB.

De otro lado, tampoco ha existido una política de Estado en relación con los sistemas de indicadores e, incluso, de los grupos de indicadores avanzados construidos con técnicas modernas. Los esfuerzos en esa dirección han ido pereciendo por diferentes razones, hoy la gran mayoría han dejado de funcionar y solo se mantienen algunos pocos. Sería muy importante rescatar esos esfuerzos y metodologías por su importancia para elaborar diagnósticos completos del estado de la economía colombiana.

En la actualidad, en Colombia, la medición del ciclo y el análisis de sus fases se hace, sobre todo, a partir de otra vertiente del pensamiento económico mucho más cercana a la teoría económica: las llamadas variables no observadas y sus brechas asociadas (producto, tasa de interés, tasa de cambio real y desempleo), vertiente que será analizada en la segunda parte de este trabajo. Estas mediciones se complementan con análisis detallados de las estadísticas de base que se utilizan en la construcción del producto interno bruto trimestral, ya sea por el lado de la demanda o del gasto.

\section{REFERENCIAS}

Achuthan, L., \& Banerji, A. (2008). The risk of redefining recession. CNN, http://money.cnn. com/05/05/2008/news/economy/recession/index.htm. Consultado el 09 de octubre de 2014.

Alfonso, V., Arango, L., Arias, F., Cangrejo, G., \& Pulido, J. (2012). Ciclo de negocios en Colombia, 1975-2011. Borradores de Economía, No. 651. Bogotá: Banco de la República.

Arango, L., Arias, F., Flórez, L., \& Jalil, M. (2008). Cronología de los ciclos de negocios recientes en Colombia. Lecturas de Economía, 68, enero-junio, 9-37.

Armatte, M. (1992). Conjonctions, conjoncture, et conjecture. Les baromètres économiques, 1885-1930. Histoire \& Mesure, 7(1-2), 99-149. 
Auerbach, A. (1982). The Index of Leading Indicators: Measurements without Theory. Review of Economic and Statistics.

Babson, R. (1909). Business barometers used in the accumulation of money; a text book on applied economics for merchants, bankers, and investors. Vellesley Hills, Mass.

Babson, R. (1921). Business Barometers Used in the Accumulation of Money. Wellesley Hills, Mass: Babson Institute.

Babson, R. (1950). Actions and reactions: An autobiography of Roger W. Babson, 2a ed. Revisada. New York: Harper \& Brothers Publishers.

Babson, R. (1907). Barometer Letter, started 1907.

Banbura, M., Giannone, D., \& Reichlin, L. (2010). Nowcasting. Ecares Working Paper 2010-021.

Bean, C. (2009). The Great Moderation, the Great Panic and the Great Contraction. Schumpeter Lecture at the Annual Congress of the European Economic Association. Barcelona, August 25.

Bernanke, B. (2004). The Great Moderation. Remarks at the meetings of the Eastern Economic Association. Washington DC, February 20.

Besomi, D. (2005). Clément Juglar and the transition from crises theory to business cycle theories. Paper prepared for a conference on the occasion of the centenary of the death of Clément Juglar, Paris, 2 December.

Besomi, D. (2009). Clément Juglar and his contemporaries on the causes of commercial crises. Revue européenne des sciences sociales, XLVII-143.

Blanchard, O. (2017). The need for different classes of macroeconomic models. Real Time Economic Issues Watch en PIIE.com.

Boldin, M. (1994). Dating turning points in the Business Cycle. Journal of Business Cycle, 67(1), 97-131.

Borio, C. (2014). The Financial Cycle and Macroeconomics: What Have We Learnt? Journal of Banking \& Finance, 45, 182-198.

Bortoli, C., \& Combes, S. (2015). Apports de Google Trends pour prévoir la conjoncture française : des pistes limitées. Note de Conjoncture, Insee, mars.

Boschan, Ch., \& Banerji, A. (1990). Reassessment of Composite Index. En: Ph. Klein (ed.), Analyzing Modern Business Cycle: Essays Honoring Geoffrey H. Moore. Beard Books.

Breitung, J., \& Eickmeier, S. (2005). Dynamic Factor Models. Discussion Paper Series 1: Economic Studies, 38, Deutsche Bundesbank.

Brookmire, J. H. (1913a). Methods of Business Forecasting Based on Fundamental Statistics. American Economic Review, III, 1, 43-58.

Brookmire, J. H. (1913b). The Brookmire Economic Chart Company, A Graphic Record of Fundamental, Financial and Business Conditions Since 1885. St. Louis: Brookmire.

Bry, G., \& Boschan, Ch. (1971). Cyclical Analysis of Time Series: Selected Procedures and Computer Programs. New York: Columbia University Press and NBER. 
Brunnermeier, M., Eisenbach, T., \& Sannikov, Y. (2013). Macroeconomics with financial frictions: A survey. Advances in Economics and Econometrics, Tenth World Congress of the Econometric Society. New York: Cambridge University Press.

Burns, A., \& Mitchell, W. (1946). Measuring Business Cycles. New York: National Bureau of Economic Research.

Camacho, M., \& Pérez-Quiros, G. (2009). Ñ-Sting: España Short Term Indicator of Growth. Documento de Trabajo 0912. Banco de España.

Camacho, M., \& Pérez-Quiros, G. (2010). Introducing the Euro-Sting: Short term indicator of Euro-area growth. Journal of Applied Econometrics, 25(4), 663-694.

Cardozo, O. (1982). Estimación de una serie trimestral del producto interno bruto. Revista Planeación y Desarrollo, XIV(2), 32-40.

Carrizosa, M., \& Botero. G. (1984). Trimestralización del producto interno bruto en Colombia. Coyuntura Económica, 14(4), 119-140. Bogotá: Fedesarrollo.

Castro, C. (2003). Yet another Lagging, Coincident and Leading Index for the Colombian Economy. Archivos de Economía, No. 233. Bogotá: Departamento Nacional de Planeación.

Caballero, C. (1995). Veinticinco años cerca de Fedesarrollo. En H. Gómez B. (ed.), Economía y Opinión. Tercer Mundo Editores - Colciencias.

Chauvet, M., \& Hamilton J. (2006). Dating Business Cycle Turning Points. Contributions to Economic Analysis, 276, 1-435. Nonlinear Time Series Analysis of Business Cycles Edited by Costas Milas, Philip Rothman and Dick van Dijk.

Choi, H., \& Varian, H. (2009a). Predicting the present with GoogleTrends. Google Inc., disponible en http://google.com/googleblogs/pdfs/google_predicting_the_present.pdf.

Choi, H. \& Varian, H. (2009b). Predicting initial claims for unemployment benefits. Google Inc., disponible en http://research.google.com/archive/papers/initialclaimsUS.pdf

Clavijo, S., Garcia, P. \& Malagón, J. (2006). Sistema de indicadores líderes para Colombia. Anif Leading - Index (ALI). Revista Carta Financiera, 131, ANIF.

Clements, M., \& Hendry, D. (1998). Forecasting Economic Time Series. Cambridge University Press.

Claessens, S., Kose, M., \& Terrones, S. (2012). How do Business and Financial Cycles Interact? Journal of International Economics, 87, 178-190.

Cristiano, D., Hernández, M., \& Pulido, J. (2012). Pronóstico de corto plazo en tiempo real para la economía colombiana. Borradores de Economía, No. 724, Banco de la República.

De Foville, A. (1888). Essai de météorologie économique et sociale. Journal de la Société de Statistique de Paris. July, 243-249.

Diebold, F., \& Rudebusch, G. (1992). Have Postwar Economic Fluctuations Been Stabilized? American Economic Review, 82(4), Sept, 993-1005.

Domínguez, M. (1947). National Income Estimates of Latin American Countries. Studies in Income and Wealth, v. 10, Parte III. 
Domínguez, K., Fair, R., \& Shapiro, M. (1988). Forecasting the Depression: Harvard versus Yale. American Economic Review, 78(4), Sept, 595-612.

Escañuela, I. (2009). The Harvard Barometers: Did they allow for the Prediction of the Great Depression of 1929? MPRA Paper No. 49225, posted 23. August.

Evans, M. D. (2005). Where Are We Now? Real Estimates of the Macroeconomy. International Journal of Central Banking, 1(2), 127-175.

Fabricant, S. (1984). Toward a Firmer Basis of Economic Policy: The Founding of the National Bureau of Economic Research. NBER.

Fisher, I. (1923). The Business Cycle Largely a "Dance of the Dollar". Journal of the American Statistical Association, 18(144), 1024-1028.

Fisher, I. (1933). The Debt-Deflation Theory of Great Depressions. Econometrica, 1(4), 337-357.

Favero, G. (2007). Weather forecast or rain-dance? On inter-war business barometers. Working Papers Department of Economic s, Ca' Foscari University of Venice No. 14.

Forni, M., Hallin, M., Lippi, M., \& Reichlin, L. (1999). Reference cycles: The NBER methodology revisited, 44. CEPR Discussion Papers 2400.

Forni, M., Hallin, M., Lippi, M. \& Reichlin, L. (2000). The Generalized Factor Model: Identification and Estimation. Review of Economics and Statistics, 82(4), 540-554.

Friedman, W. (2013). Fortune Tellers: The Story of America's First Economic Forecasters. Princeton University Press.

Friendly, M. (2008). The Golden Age of Statistical Graphics. Statistical Science, 23(4), 502-535.

Frish, R. (1933). Propagation Problems and Impulse Problems. In: Dynamic Economics in Economic Essays in Honor of Gustav Cassel (pp. 171-205). London: George Allen \& Unwin.

Galton, R. (1888). Correlations and their measurement, chiefly from anthropometric data. Proceedings of the Royal Society 45 (Dec. 13), pp. 135-145. Disponible en http://galton.org/ bib/JournalltemList.aspx_filterByCategory=Statistics. Consultado el 30 de mayo de 2014.

Giannone, D., Reichlin, L., \& Small, D. (2008). Nowcasting: The Real-Time Informational Content of Macroeconomic Data. Journal of Monetary Economics, 55, 665-676.

Geweke, J. (1977). The Dynamic Factor Analysis of Economic Time-Series Models. In D. Aigner and A. Goldberger (eds.), Latent Variables in Socioeconomic Models (pp. 365-383). Amsterdam: North-Holland.

Glasner, D. (2013). Business Cycles and Depressions: An Encyclopedia. Routledge. Gordon.

Gurley, J., \& Shaw, E. (1955). Financial Aspects of Economic Development. American Economic Review, 45(4), 515-538.

Hamilton, J. (1989). A New Approach to the Economic Analysis of Nonstationary Time Series and the Business Cycle. Econometrica, 57, 357-384. Reprinted in Financial Econometrics, edited by Andrew Lo, Edward Elgar Publishing Ltd., 2006.

Hamilton, J., \& Pérez-Quiros, G. (1996). What do the leading indicators lead. Journal of Business, 69, 27-49. 
Hamilton, J. (2005). Regime-Switching Models. Prepared for Palgrave Dictionary of Economics.

Harding D., \& Pagan, A. (2006). Synchronisation of Cycles. Journal of Econometrics, 132(1), 5979.

Heath, J. (2012). Lo que indican los indicadores: cómo utilizar la información estadística para entender la realidad económica de México. México DF: INEGI.

Hall, R., Feldstein, M., Frankel, J., Gordon, R., Romer, C., Romer, D., \& Zarnowitz, V. (2003). The NBER's Business-Cycle Dating Procedure. National Bureau of Economic Research.

Juglar, C. (1862). Des crises commerciales et de leur retour périodique en France, en Angleterre et aux États-Unis. Gallica: Biblioteque Numerique.

Kamil, H., Pulido, J., \& Torres, J. (2010). Un índice mensual líder de actividad económica para Colombia: IMACO. Borradores de Economía, No. 609, Bogotá: Banco de la República.

Kalecky, M. (1935). A Macrodynamic Theory of Business Cycles. Econometrica, 3, 327-344.

Keynes, J. M. (1940). How to Pay for the War. Londres: Macmillan.

Keynes, J. M. (1936). The General Theory of Employment, Interest and Money, Macmillan.

Kindleberger, C. P. (1978). Manias, Panics, and Crashes: A History of Financial Crises. New York: Basic Books, revised and enlarged, 1989, 3rd ed., 1996.

Klein, L. (2004). The contribution of Jan Tinbergen to Economic Science. De Economist, 152(2), 155-157.

Koopmans, T. (1947). Measurement Without Theory. Review of Economics and Statistics, August, 161-172.

Krolzig, H. (1997). Markov-Switching Vector Autoregressions: Modelling, Statistical Inference, and Application to Business Cycle Analysis, Berlin: Springer.

Kuznetz, S. (1941). National Income and Its Composition 1919-1938. 2 vols. New York: National Bureau of Economic Research.

Kuznetz, S. (1934). National Income 1929-1932. Senate Document No. 124. 73d Cong., 2 d Sess. Washington D.C.

Kuznets, S. (1933). The national income, 1924-31. Journal of the American Statistical Association, 28(183), 363-364.

Kuznetz, S. (1933). National Income. In Encyclopedia of the Social Sciences. New York: Macmillan $\&$ Co.

López, A., \& Rodríguez, J. (1914). Estadística de Antioquia. Medellín: Imp. De la Gaceta Antioqueña.

López, A. (1915). Antioquia. Monografía estadística de este Departamento Colombiano. Medellín: Imprenta Oficial.

López, A. (1937). Índice de la actividad económica de Colombia en 1936. Revista el mes financiero y económico. Bogotá: Contraloría General de la República. 
Marcillo Y., E. (2013). Un indicador líder para la actividad económica de Colombia. Archivos de economía, 404. Bogotá: DNP.

Maurer, M., \& Uribe, M. (1996a). El ciclo de referencia de la economía colombiana. Archivos de Macroeconomía, 45. Bogotá: DNP.

Maurer, M., \& Uribe, M. (1996b). El ciclo de negocio en Colombia. Planeación y Desarrollo, $\mathrm{XXVI}(1), I(4)$, agosto.

Mayor Mora, A. (2002). La Escuela Nacional de Minas de Medellín y los orígenes de la estadística en Colombia. Revista Colombiana de Estadística, 25(2), 73-96.

Mejía, L., Monsalve, D., Parra, Y., Pulido, S., \& Reyes, A. (2013). Indicadores ISAAC: Siguiendo la actividad sectorial a partir de Google Trends. Notas Fiscales N. 22, Ministerio de Hacienda de Colombia.

Melo, A., French, M., \& Langebaek, A. (1988). El ciclo de referencia de la economía colombiana. Hacienda, 12, Oct. 1988, 43-61, Bogotá.

Melo, L., Nieto, F., Posada, C., Betancourt, Y., \& Barón, J. (2001). Un índice coincidente para la actividad económica de Colombia. Ensayos sobre Política Económica, 40, 46-88.

Melo, L., Nieto, F., \& Ramos, M. (2003). A leading index for the Colombian economic activity, Borradores de Economía, n. 243, Banco de la República, Bogotá.

Meyer, C. (1950). Reseña de La Actividad Económica Colombiana: formación del índice general por Leonel Torres. El Trimestre Económico, 17, n. 66(2), 318-320.

McGreevey, W. (1975). La investigación cuantitativa en la historia latinoamericana de los siglos XIX y XX. En Landes et ál. (eds.). Las dimensiones del pasado: estudios de historia cuantitativa (pp. 325-354). Madrid: Alianza.

Mintz, I. (1969). Dating Postwar Business Cycles: Methods and Their Application to Western Germany, 1950-67. University of Columbia Press.

Mitchell, W. (1913). Business Cycles. University of California Press.

Mitchell, W. (1927). Business Cycles: The problem and its setting, NBER.

Mitchell, W.; Burns, A. (1938). Statistical Indicators of Cyclical Revivals. NBER, Bulletin, No. 69.

Moody, J. (1904). The Truth about The Trusts: A Description and Analysis of the American Trust Movement. New York: Moody Publishing Company.

Moore, G. (1961a). Statistical indicators of cyclical revivals and recessions. Business Cycle Indicators, vol. 1, G. Moore, (ed.) NBER.

Moore, G. (1961b). The Diffusion of Business Cycle. Business Cycle Indicators, vol. 1, G. Moore (ed.), NBER.

Moore, G., \& Shiskin, J. (1967). Indicators of Business Expansions and Contractions, NBER, Columbia University Press.

Moore, G., \& Zarnowitz, V. (1984). The Development and Role of the National Bureau's Business

Cycle Chronologies. Working Paper, No. 1394, NBER. 
Moore, G., \& Zarnowitz, V. (1986). Appendix A: The Development and Role of the National Bureau of Economic Research's Business Cycle Chronologies. R. Gordon (ed.), The American Business Cycle: Continuity and Change, NBER.

Minsky, H. (1982). Can 'it' happen again? Essays on Instability and Finance. Armonk: M E Sharpe.

Ng, S., \& Wright, J. (2013). Fact and challenges from the great recession for forecasting and macroeconomic modeling. Journal of Economic Literature, 51(4), 1120-1154.

Nieto, F. (2003). Identifiability of a coincident index model for the Colombian economy, Borradores semanales de economía. Borradores de Economía. Bogotá: Banco de la República.

Nieto, F., \& Melo, L. (2001). About a coincident index for the state of the economy. Borradores Semanales de Economía, No. 194. Bogotá: Banco de la República.

Patinkin, D. (1956). Money, Interest and Prices: An Integration of Monetary and Value Theory. Evanston, III: Row, Peterson and Company.

Persons, W. (1916). Construction of a Business Barometer Based upon Annual Data. American Economic Review, 6(4), December.

Persons, W. (1919a). Indices of Business Conditions. Review of Economics and Statistics, 1, January, 5-107.

Persons, W. (1919b). An Index of Economic Conditions. Review of Economics and Statistics, 1, April, 111-205.

Persons, W. (1922). Measuring and Forecasting General Business Conditions. Boston: American Institute of Finance.

Persons, W. (1930). The recession of 1929-1930 in the United States. Bulletin de I'Institut International de Statistique, 25/3, 479-489.

Ripoll, M., Misas, M., \& López, E. (1995). Una descripción del ciclo industrial en Colombia. Borradores Semanales de Economía, No. 33. Bogotá: Banco de la República.

Rötheli, T. (2007). Business Forecasting and the Development of Business Cycle Theory. History of Political Economy, 39(3), 481-510.

Samuelson, P. (1939). A Synthesis of the Principle of Acceleration and the Multiplier. Journal of Political Economy, 47(6), 786-797.

Sargent, T., \& Sims, C. (1977). Business cycle modeling without pretending to have too much a priori theory. In C. Sims (ed.), New Methods of Business Cycle Research. Minneapolis: Federal Reserve Bank of Minneapolis.

Schumpeter, J. (1954). Historia del Análisis Económico. Bogotá: Ediciones Aguilar.

Sigogne P., \& Riches, V. (1993). Genèse des indicateurs cycliques, et maturation aux États-Unis. Revue de I'OFCE, n. 45, 199-244.

Silva, C., \& Ramírez, J. (1979). Estimación del producto interno bruto trimestral y semestral. Revista Planeación y Desarrollo, XI(3), 175-191.

Sinai, A. (2010). The business cycle in a changing economy: Conceptualization, measurement, dating. American Economic Review, Papers \& Proceedings 100, May, pp. 25-29. 
Skidelsky, R. (1996). The influence of the Great Depression on Keynes's General Theory. History of Economics Review, Winter-Summer.

Schumpeter, J. (1954). History of economic analysis. London: Allen \& Unwin.

Shiskin, J. (1961) Signals of Recession and Recovery. National Bureau of Economic Research.

Shiskin, J. (1974). The Changing Business Cycle. New York Times, 12 de enero.

Slutzky, E. (1937). The summation of random causes as the source of cyclic process. Econometrica, 5(2), 105-146.

Stock, J. \& Watson, M. (1988). A probability model of the coincident economic indicators. NBER Working Papers, n. 2772.

Stock, J. \& Watson, M. (1989). New indexes of coincident and leading indicators. NBER Macroeconomics Annuals, 351-394.

Stock, J. \& Watson, M. (1991). A Probability Model of the Coincident Economic Indicators. In K. Lahiri \& G. Moore (eds.), Leading Economic Indicators: New Approaches and Forecasting Records (Ch. 4, pp. 63-85). New York: Cambridge University Press.

Stock, J. \& Watson, M. (1992). A procedure for Predicting Recessions with Leading Indicators: Econometric Issues and Recent Experience. NBER Working Paper, n. 4014.

Stock, J. \& Watson, M. (2010). Indicators for Dating Business Cycles: Cross-History Selection and Comparisons. American Economic Review: Papers \& Proceedings, 100, May, pp. 16-19.

The Conference Board (2001). Business Cycle Indicators Handbook. The Conference Board.

Thorp, W. (1926). Business Annals. nBeR General Series, No. 8. New York: NBER.

Tkacz, G. (2013). Predicting Recessions in Real-Time: Mining Google Trends and Electronic Payments Data for Clues. Commentary n. 387, Financial Services, C.D. Howe Institute.

Tooze, J. (2001). Statistics and the German State, 1900-1945: The making of modern economic knowledge. Cambridge Studies in Modern Economic History. Cambridge: Cambridge University Press.

Tobin, J. (1969). A General Equilibrium Approach to Monetary Theory. Journal of Money, Credit, and Banking, 1.1(1), 15-29.

Torres, L. (1947). La actividad económica colombiana: formación del índice general. Bogotá: Imprenta del Banco de la República.

Vance, R. (1925). Business and investment forecasting: Forecasting methods and their practical application, 2nd ed. New York-London: Harper \& Brothers Publishers.

von Neumann-Spallart, F. X. (1887). Mesure des variations de l'état économique et social des peuples. Bulletin de l'institut International de Statistique, n. 2, 150-159.

Watson, M., \& Engle, R. (1983). Alternative Algorithms for the Estimation of Dynamic Factor, Mimic and Varying Coefficient Regression Models. Journal of Econometrics, 23(3), 385-400.

Zarnowitz, V. y Ozyldirim, A. (2002). Time Series Decomposition and Measurement of Business Cycles, Trends and Growth Cycles, NBER Working Paper, n. 8736. 
Zarnowitz, V. (1985). Recent Work on Business Cycle in Historical Perspective: A Review of Theories and Evidence. Journal of Economic Literature, 23(2), 523-580.

Zarnowitz, V. (1992). Business Cycles: Theory, History, Indicators, and Forecasting. Chicago: University of Chicago Press. 